[Supporting Information]

\title{
Constructing Robust Covalent Organic Frameworks via Multicomponent Reactions
}

Peng-Lai Wang, San-Yuan Ding, ${ }^{*}$ Zhi-Cong Zhang, Zhi-Peng Wang, and Wei Wang*

State Key Laboratory of Applied Organic Chemistry, College of Chemistry and Chemical Engineering, Lanzhou University, Lanzhou, Gansu 730000 , China

^E-mail: wang_wei@lzu.edu.cn; dingsy@lzu.edu.cn

A. Summary of Scheme, Figures, and Tables $\quad$ S2

B. General Information $\quad$ S5

$\begin{array}{ll}\text { C. Synthesis of the Model Compound } & \text { S7 }\end{array}$

D. Synthesis, Characterization, and Structural Modeling of LZU-501 S9

E. Synthesis, Characterization, and Structural Modeling of LZU-506 S17

F. Synthesis, Characterization, and Structural Modeling of LZU-508 S25

G. Synthesis, Characterization, and Structural Modeling of LZU-512 S34

H. Stability Tests of LZU-501 and LZU-506 S42

$\begin{array}{ll}\text { I. UV/Vis Absorption Spectra } & \text { S56 }\end{array}$

$\begin{array}{ll}\text { J. Postmodification } & \text { S57 }\end{array}$

$\begin{array}{ll}\text { K. References } & \text { S61 }\end{array}$ 


\section{A. Summary of Scheme, Figures, and Tables}

$\begin{array}{lll}\text { Scheme S1 Proposed pathway for the formation of imidazole structure } & \text { S7 }\end{array}$

Fig. S1 $\quad{ }^{13} \mathrm{C} \mathrm{CP/MAS}$ and NQS MAS NMR spectra of model compound M1 $\quad$ S8

$\begin{array}{lll}\text { Fig. S2 } & \text { FT-IR spectrum of model compound M1 } & \text { S8 }\end{array}$

Fig. S3 PXRD patterns of LZU-501 synthesized with indicated conditions $\quad$ S10

Fig. S4 PXRD patterns of LZU-501 synthesized with different equiv. of $\mathrm{NH}_{4} \mathrm{OAc} \quad \mathrm{S} 10$

$\begin{array}{lll}\text { Fig. S5 } & \mathrm{N}_{2} \text { adsorption and desorption isotherms of LZU-501 S11 }\end{array}$

Fig. S6 Pore size distribution of LZU-501 S11

$\begin{array}{lll}\text { Fig. S7 } & \text { BET surface area plot for LZU-501 S12 }\end{array}$

$\begin{array}{lll}\text { Fig. S8 } & \text { FT-IR spectra of monomers and LZU-501 } & \text { S12 }\end{array}$

Fig. S9 TGA data of LZU-501 S13

$\begin{array}{lll}\text { Fig. S10 SEM images of LZU-501 S13 } & \text { S10 }\end{array}$

$\begin{array}{lll}\text { Fig. S11 TEM image of LZU-501 S13 } & \text { TEN }\end{array}$

Fig. S12 Observed and calculated PXRD patterns of LZU-501 S14

Fig. S13 PXRD patterns of monomers and LZU-501 S15

Tab. S1 Fractional atomic coordinates for the unit cell of LZU-501 S15

Fig. S14 PXRD patterns of LZU-506 synthesized with indicated conditions $\quad$ S18

Fig. S15 $\quad \mathrm{N}_{2}$ adsorption and desorption isotherms of LZU-506 $\quad$ S18

$\begin{array}{lll}\text { Fig. S16 Pore size distribution of LZU-506 } & \text { S19 }\end{array}$

$\begin{array}{lll}\text { Fig. S17 } & \text { BET surface area plot for LZU-506 } & \text { S19 }\end{array}$

$\begin{array}{lll}\text { Fig. S18 } & \text { FT-IR spectra of monomers and LZU-506 } & \text { S20 }\end{array}$

Fig. S19 $\quad{ }^{13} \mathrm{C}$ CP/MAS and NQS MAS NMR spectra of LZU-506 S20

Fig. S20 TGA data of LZU-506 $\quad$ S21

Fig. S21 SEM images of LZU-506 $\quad$ S21

Fig. S22 TEM image of LZU-506 $\quad$ S21

Fig. S23 Observed and calculated PXRD patterns of LZU-506 S22

$\begin{array}{lll}\text { Fig. S24 PXRD patterns of monomers and LZU-506 } & \text { S23 }\end{array}$

$\begin{array}{lll}\text { Tab. S2 } & \text { Fractional atomic coordinates for the unit cell of LZU-506 } & \text { S23 }\end{array}$

Fig. S25 PXRD patterns of LZU-508 synthesized with indicated conditions $\quad$ S26

$\begin{array}{lll}\text { Fig. S26 } & \mathrm{N}_{2} \text { adsorption and desorption isotherms of LZU-508 } & \text { S26 }\end{array}$

$\begin{array}{lll}\text { Fig. S27 } & \text { Pore size distribution of LZU-508 } & \text { S27 }\end{array}$ 
$\begin{array}{lll}\text { Fig. S28 } & \text { BET surface area plot for LZU-508 } & \text { S27 }\end{array}$

$\begin{array}{lll}\text { Fig. S29 } & \text { FT-IR spectra of monomers and LZU-508 } & \text { S28 }\end{array}$

$\begin{array}{lll}\text { Fig. S30 } & { }^{13} \mathrm{C} \text { CP/MAS and NQS MAS NMR spectra of LZU-508 S28 }\end{array}$

$\begin{array}{lll}\text { Fig. S31 TGA data of LZU-508 } & \text { S29 }\end{array}$

$\begin{array}{lll}\text { Fig. S32 SEM images of LZU-508 } & \text { S29 }\end{array}$

$\begin{array}{lll}\text { Fig. S33 TEM image of LZU-508 } & \text { S29 }\end{array}$

Fig. S34 Observed and calculated PXRD patterns of LZU-508 S30

$\begin{array}{lll}\text { Fig. S35 } & \text { PXRD patterns of monomers and LZU-508 } & \text { S31 }\end{array}$

Fig. S36 Observed, Pawley-refined, and predicted PXRD patterns of LZU-508 $\quad$ S32

$\begin{array}{lll}\text { Tab. S3 Fractional atomic coordinates for the unit cell of LZU-508 } & \text { S32 }\end{array}$

Fig. S37 PXRD patterns of LZU-512 synthesized with indicated conditions $\quad$ S35

$\begin{array}{lll}\text { Fig. S38 } & \mathrm{N}_{2} \text { adsorption and desorption isotherms of LZU-512 S35 }\end{array}$

$\begin{array}{lll}\text { Fig. S39 Pore size distribution of LZU-512 S36 } & \text { P12 }\end{array}$

$\begin{array}{lll}\text { Fig. S40 } & \text { BET surface area plot for LZU-512 S36 }\end{array}$

$\begin{array}{lll}\text { Fig. S41 } & \text { FT-IR spectra of monomers and LZU-512 } & \text { S37 }\end{array}$

Fig. S42 $\quad{ }^{13} \mathrm{C} \mathrm{CP/MAS}$ and NQS MAS NMR spectra of LZU-512 S37

$\begin{array}{lll}\text { Fig. S43 TGA data of LZU-512 } & \text { S38 }\end{array}$

$\begin{array}{lll}\text { Fig. S44 SEM images of LZU-512 S38 } & \text { S4 }\end{array}$

$\begin{array}{lll}\text { Fig. S45 TEM image of LZU-512 } & \text { S38 }\end{array}$

Fig. S46 Observed and calculated PXRD patterns of LZU-512 S39

$\begin{array}{lll}\text { Fig. S47 PXRD patterns of monomers and LZU-512 S40 } & \text { P42 }\end{array}$

Fig. S48 Observed, Pawley-refined, and predicted PXRD patterns of LZU-512 S40

Tab. S4 Fractional atomic coordinates for the unit cell of LZU-512 S41

Fig. S49 Residue weight percentages of LZU-501 after treatment S42

Fig. S50 SEM images of LZU-501 before and after treatment S43

Fig. S51 $\quad{ }^{13} \mathrm{C}$ CP/MAS NMR spectra of LZU-501 before and after treatment $\quad$ S44

Fig. S52 Isotherms of LZU-501 before and after treatment with $9 \mathrm{M} \mathrm{HCl} \quad$ S45

Fig. S53 BET surface area plot for LZU-501 after treatment with $9 \mathrm{M} \mathrm{HCl} \quad$ S45

Fig. S54 Isotherms of LZU-501 before and after treatment with $9 \mathrm{M} \mathrm{NaOH} \quad$ S46

Fig. S55 BET surface area plot for LZU-501 after treatment with $9 \mathrm{M} \mathrm{NaOH} \quad$ S46

Fig. S56 Isotherms of LZU-501 before and after treatment with DMF $\quad$ S47

Fig. S57 BET surface area plot for LZU-501 after treatment with DMF $\quad$ S47

Fig. S58 Isotherms of LZU-501 before and after treatment with water $\quad$ S48 
Fig. S59 BET surface area plot for LZU-501 after treatment with water

Fig. S60 Residue weight percentages of LZU-506 after treatment $\quad$ S49

Fig. S61 SEM images of LZU-506 before and after treatment $\quad$ S50

Fig. S62 $\quad{ }^{13} \mathrm{C}$ CP/MAS NMR spectra of LZU-506 before and after treatment $\quad$ S51

Fig. S63 Isotherms of LZU-506 before and after treatment with $9 \mathrm{M} \mathrm{HCl} \quad$ S52

Fig. S64 BET surface area plot for LZU-506 after treatment with $9 \mathrm{M} \mathrm{HCl} \quad$ S52

Fig. S65 Isotherms of LZU-506 before and after treatment with $9 \mathrm{M} \mathrm{NaOH} \quad$ S53

Fig. S66 BET surface area plot for LZU-506 after treatment with $9 \mathrm{M} \mathrm{NaOH} \quad$ S53

Fig. S67 Isotherms of LZU-506 before and after treatment with DMF $\quad$ S54

Fig. S68 BET surface area plot for LZU-506 after treatment with DMF $\quad$ S54

Fig. S69 Isotherms of LZU-506 before and after treatment with water $\quad$ S55

Fig. S70 BET surface area plot for LZU-506 after treatment with water $\quad$ S55

$\begin{array}{lll}\text { Fig. S71 UV/Vis Absorption Spectra } & \text { S56 }\end{array}$

Fig. S72 $\quad{ }^{13} \mathrm{C}$ CP-TOSS MAS NMR spectra of LZU-501 and LZU-501-Et $\quad$ S58

Fig. S73 $\quad{ }^{13} \mathrm{C}$ CP-TOSS MAS NMR spectra of LZU-501 and LZU-501-Bn S S58

Fig. S74 $\quad{ }^{13} \mathrm{C}$ CP-TOSS MAS NMR spectra of LZU-501 and LZU-501-Py S S9

Fig. S75 $\quad{ }^{13} \mathrm{C}$ CP-TOSS MAS NMR spectra of LZU-501 and LZU-501-EM S S59

Fig. S76 PXRD patterns of LZU-501 and LZU-501-FGs $\quad$ S60 


\section{B. General Information}

All reagents were obtained from commercial sources and used as received. Tetrahydrofuran (THF), ethanol, N,N-dimethylformamide (DMF) and $N, N$-dimethylacetamide (DMAc) were obtained from RionlonBohua (Tianjin) Pharmaceutical \& Chemical. 1,4-Dioxane were obtained from ChengDu Chron Chemicals. $N$-methyl-2-pyrrolidone (NMP) and benzaldehyde were obtained from Tianjin Kemiou Chemical Reagent. Ammonium acetate was obtained from Aladdin Industrial Corporation and ${ }^{15} \mathrm{~N}$-labeled ammonium acetate $\left(98 \%{ }^{15} \mathrm{~N}\right.$ enrichment) was obtained from Sigma-Aldrich. 1,4-Dichlorobenzene (o-DCB) and $n$-butanol $(n-\mathrm{BuOH})$ were obtained from Alfa Aesar. Mesitylene and benzyl bromide were obtained from Acros Organics. Sodium hydride (60\% dispersion in mineral oil) was obtained from Energy Chemical. 2-(Bromomethyl)-6methylpyridine and 4-(2-bromoethyl)morpholine were obtained from Innochem. 1,3,5-Tris(4-formylphenyl)benzene, 1,3,5-tris(3-fluoro-4-formylphenyl)benzene, 1,3,5-tris-(4-formylphenyl)triazine, and 1,3,5-trisforylbenzene, and tertbutylpyrene tetraone were obtained from Jilin Chinese Academy of Sciences Yanshen Technology Co., Ltd.

FT-IR spectra were recorded on a Nicolet NEXUS 670 instrument.

Powder X-ray diffraction (PXRD) data were collected on a PANalytical X'Pert Pro diffractometer operated at $40 \mathrm{kV}$ and $40 \mathrm{~mA}$ with $\mathrm{Cu} \mathrm{K} \alpha$ radiation (step size of $0.017^{\circ}$ and step time of $7.11 \mathrm{~s}$ ).

Elemental analysis was performed on an Elementar Analysensysteme $\mathrm{GmbH}$ VarioEL V3.00 elemental analyzer.

Solid-state ${ }^{13} \mathrm{C}$ NMR experiments were performed on a Bruker Avance II 400 spectrometer. Solid-state ${ }^{15} \mathrm{~N}$ NMR experiments were performed on a Bruker AvanceNEO 600 spectrometer. Solid-state ${ }^{13} \mathrm{C}$ cross-polarization magic-angle spinning (CP/MAS) NMR spectra were recorded with a 4-mm double-resonance MAS probe; a sample spinning rate of $10.0 \mathrm{kHz}$, a contact time of $3 \mathrm{~ms}$ (ramp 100 ), and a pulse delay of $3 \mathrm{~s}$ were applied. In the ${ }^{13} \mathrm{C}$ nonquaternary suppression (NQS) MAS NMR experiments, the magnetization of the nonquaternary carbons was dephased during a $60 \mu$ s pre-acquisition delay without proton decoupling. ${ }^{13} \mathrm{C}$ CP-TOSS (total suppression of sidebands) MAS NMR spectra were obtained at a spinning rate of $10 \mathrm{kHz}$ with a five-pulse total sideband suppression sequence. Solid-state ${ }^{15} \mathrm{~N}$ CP/MAS NMR spectra were recorded with a 4-mm doubleresonance MAS probe; a sample spinning rate of $15.0 \mathrm{kHz}$, a contact time of 3.5 
ms (ramp 100), and a pulse delay of $3 \mathrm{~s}$ were applied.

Field emission scanning electron microscopy (SEM) observations were performed on a Hitachi S-4800 microscope operated at an accelerating voltage of $5.0 \mathrm{kV}$.

Transmission electron microscopy (TEM) images were obtained with an FEI TF20 instrument operated at $200 \mathrm{kV}$.

The thermal properties of COF samples were evaluated using a STA PT1600 Linseis thermogravimetric analysis (TGA) instrument over the temperature range of 50 to $700{ }^{\circ} \mathrm{C}$ under nitrogen atmosphere with a heating rate of $10{ }^{\circ} \mathrm{C} / \mathrm{min}$.

Nitrogen adsorption and desorption isotherms were recorded at $77 \mathrm{~K}$ with a Micromeritics ASAP 2020M system. Prior to the measurement of the sorption isotherm, the samples were outgased for $8 \mathrm{~h}$ at $120{ }^{\circ} \mathrm{C}$. Surface areas were calculated using the Brunauer-Emmett-Teller (BET) method. The pore size distribution curves were obtained via the non-local density functional theory (NLDFT). 


\section{Synthesis of the Model Compound}

Synthesis of the model compound $\mathbf{M 1}$

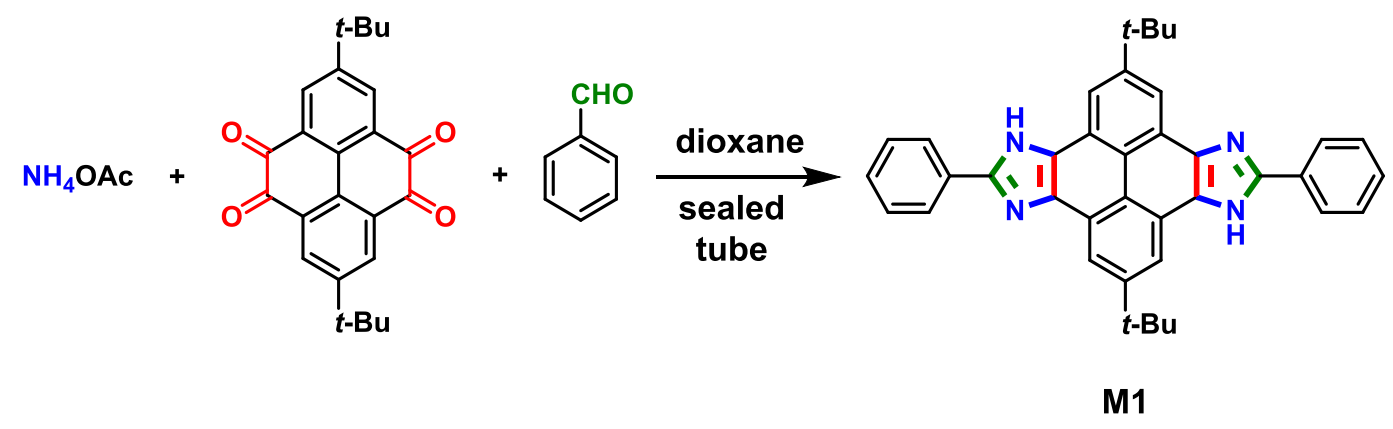

Ammonium acetate $(86 \mathrm{mg}, 1.12 \mathrm{mmol})$, tertbutylpyrene tetraone $(34 \mathrm{mg}$, $0.09 \mathrm{mmol})$, and benzaldehyde $(30 \mu \mathrm{L}, 0.30 \mathrm{mmol})$ were weighed into a glass tube (volume of $c a .20 \mathrm{~mL}$, body length of $18 \mathrm{~cm}$, and neck length of $9 \mathrm{~cm}$ ). To the mixture was added dioxane $(2.0 \mathrm{~mL})$. The tube was flash frozen in a liquid nitrogen bath, evacuated to an internal pressure of 0.5 mbar and flame sealed, reducing the total length by $c a .10 \mathrm{~cm}$. Upon warming to room temperature, the sealed tube was placed in an oven at $120{ }^{\circ} \mathrm{C}$ and left undisturbed for 3 days, yielding M1 (30 mg, 61\%). HRMS: m/z calcd for $\mathrm{C}_{38} \mathrm{H}_{34} \mathrm{~N}_{4}[\mathrm{M}+\mathrm{H}]^{+}:$547.2856, found: 547.2857. The atomic-level structure of $\mathbf{M 1}$ was confirmed by ${ }^{13} \mathrm{C}$ CP/MAS and NQS MAS NMR (Figure S1).

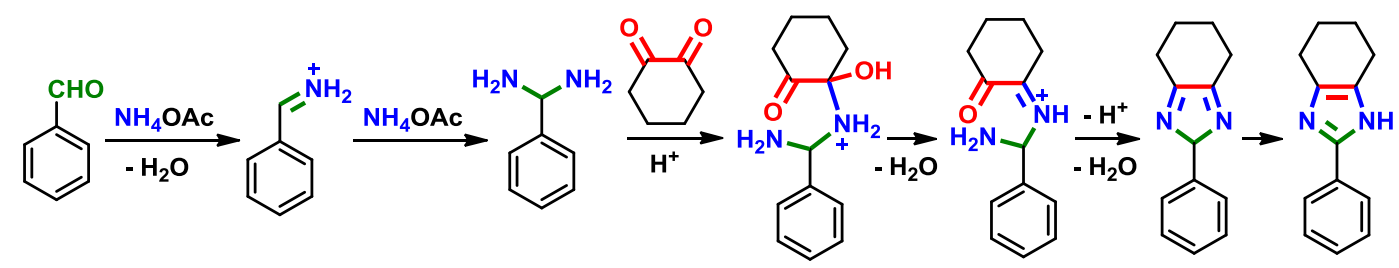

Scheme S1. Proposed pathway for the formation of imidazole structure through Debus-Radziszewski MCR. ${ }^{1}$ 


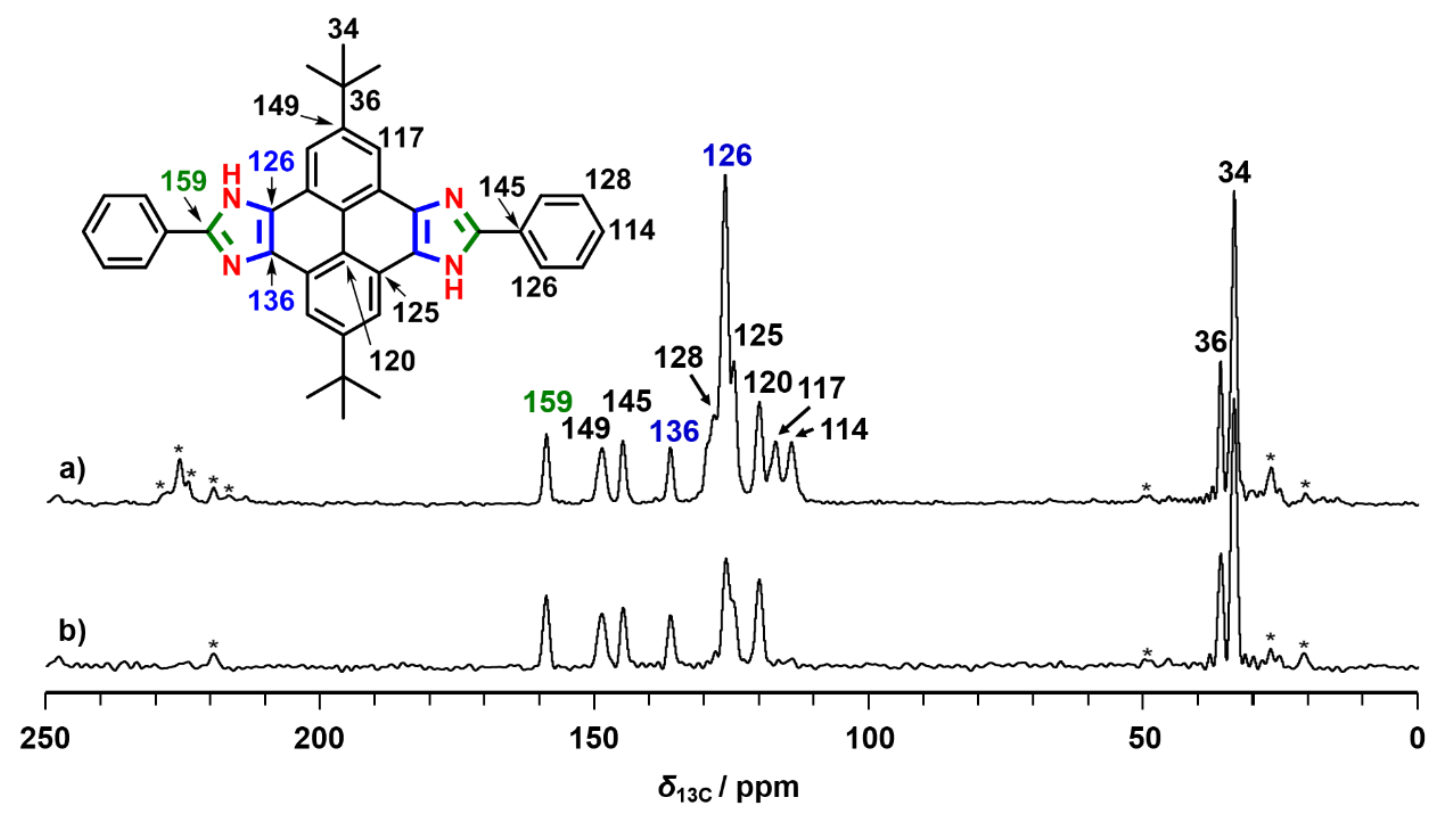

Figure S1. (a) ${ }^{13} \mathrm{C}$ CP/MAS and (b) NQS MAS NMR spectra of M1. The assignments of ${ }^{13} \mathrm{C}$ chemical shifts are shown in the chemical structure. The presence of peaks at 159,136 , and $126 \mathrm{ppm}$ indicates the formation of imidazole ring.

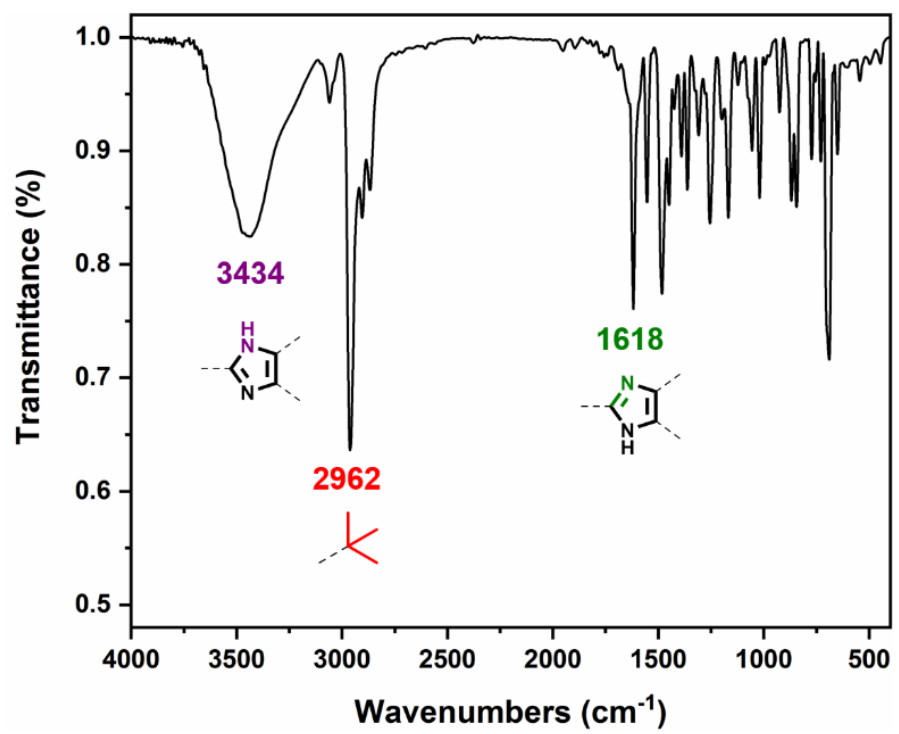

Figure S2. FT-IR spectrum of the model compound M1. The bands at $1618\left(v_{-\mathrm{N}=\mathrm{C}-}\right)$ and $3434 \mathrm{~cm}^{-1}$ are characteristic for the imidazole ring. ${ }^{2}$ 


\section{Synthesis, Characterization, and Structural Modeling of LZU-501}

Synthesis of LZU-501

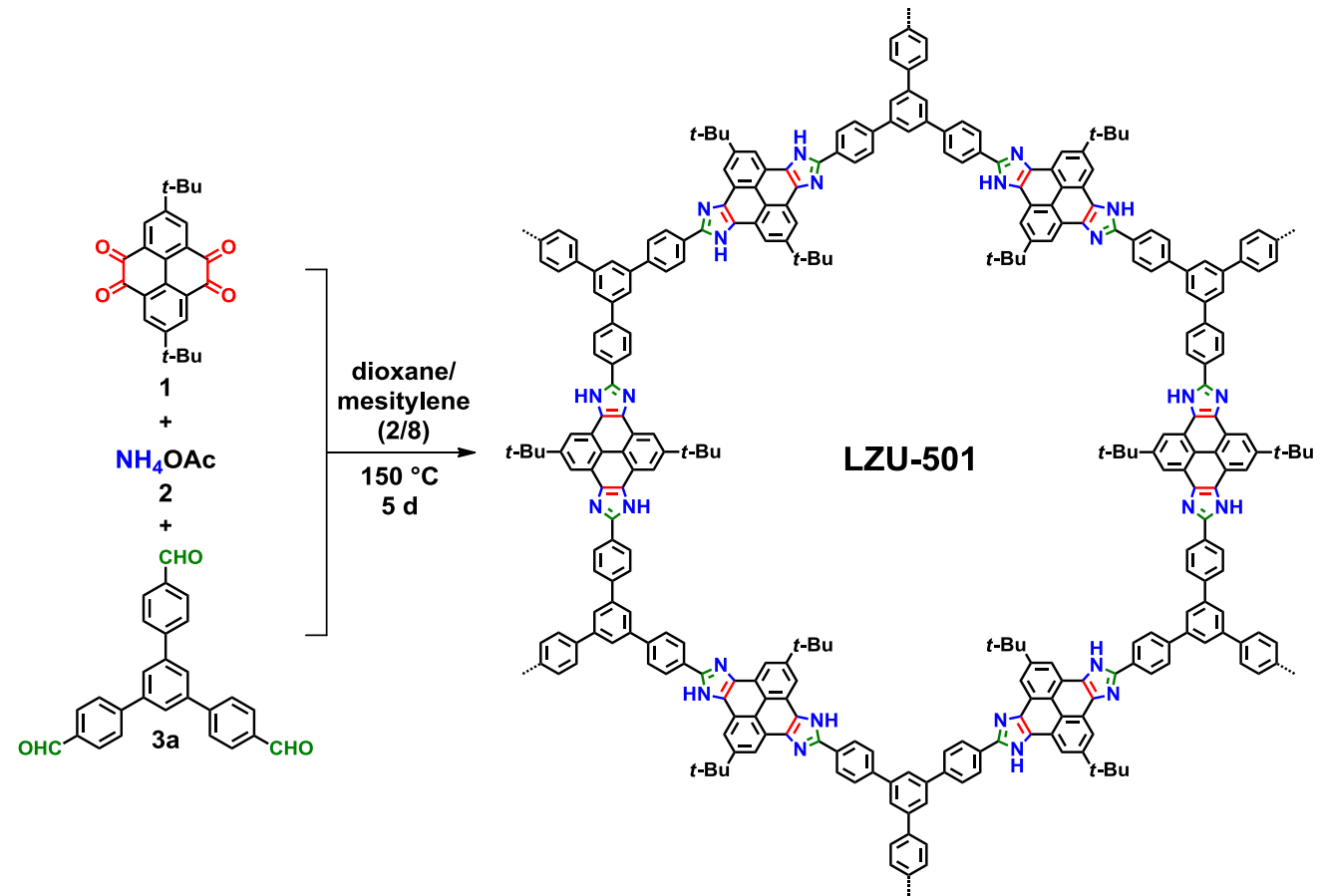

Tertbutylpyrene tetraone 1 (17 mg, $0.045 \mathrm{mmol})$, ammonium acetate 2 (21 mg, $0.270 \mathrm{mmol}$ ), and 1,3,5-tris(4-formylphenyl)benzene 3a (12 mg, $0.030 \mathrm{mmol}$ ) were weighed into a glass tube (volume of $c a .10 \mathrm{~mL}$, body length of $18 \mathrm{~cm}$, and neck length of $9 \mathrm{~cm})$. To the mixture was added dioxane $(0.2 \mathrm{~mL})$ and mesitylene $(0.8 \mathrm{~mL})$. The tube was flash frozen in a liquid nitrogen bath, evacuated to an internal pressure of 0.5 mbar and flame sealed, reducing the total length by $c a .10 \mathrm{~cm}$. Upon warming to room temperature, the sealed tube was placed in an oven at $150{ }^{\circ} \mathrm{C}$ and left undisturbed for 5 days, yielding a brown solid. The tube was broken at the neck, and the brown solid was isolated by centrifugation and washed with ethanol $(2 \times 5 \mathrm{~mL})$ and THF $(3 \times 5 \mathrm{~mL})$. The resulting solid was then purified by using Soxhlet extraction with THF as the solvent for 2 days. The powder was collected and dried at $80{ }^{\circ} \mathrm{C}$ for $12 \mathrm{~h}$ to yield LZU-501 as a brown powder (26 mg, 97\% yield). Anal. Cald for $\left(\mathrm{C}_{21} \mathrm{H}_{17} \mathrm{~N}_{2}\right)_{\mathrm{n}}$ : $\mathrm{C}$ 84.85; H 5.72; N 9.43, found: $\mathrm{C} 82.46 ; \mathrm{H} 5.68 ; \mathrm{N}$ 5.71. The deviations from the calculated values are attributed to the incomplete combustion of the material (Figure S9) and the presence of the terminal groups. ${ }^{3}$ Characterization of LZU-501 has been presented in the main text and in this SI.

The synthesis of ${ }^{15} \mathrm{~N}$-labeled LZU-501 was similar to that of LZU-501. Condensation of tertbutylpyrene tetraone 1 (17 mg, $0.045 \mathrm{mmol}),{ }^{15} \mathrm{~N}$-labeled ammonium acetate $(21 \mathrm{mg}, 0.269 \mathrm{mmol})$, and 1,3,5-tris(4-formylphenyl)benzene 3a (12 mg, $0.030 \mathrm{mmol}$ ) yielded ${ }^{15} \mathrm{~N}$-labeled LZU-501. 


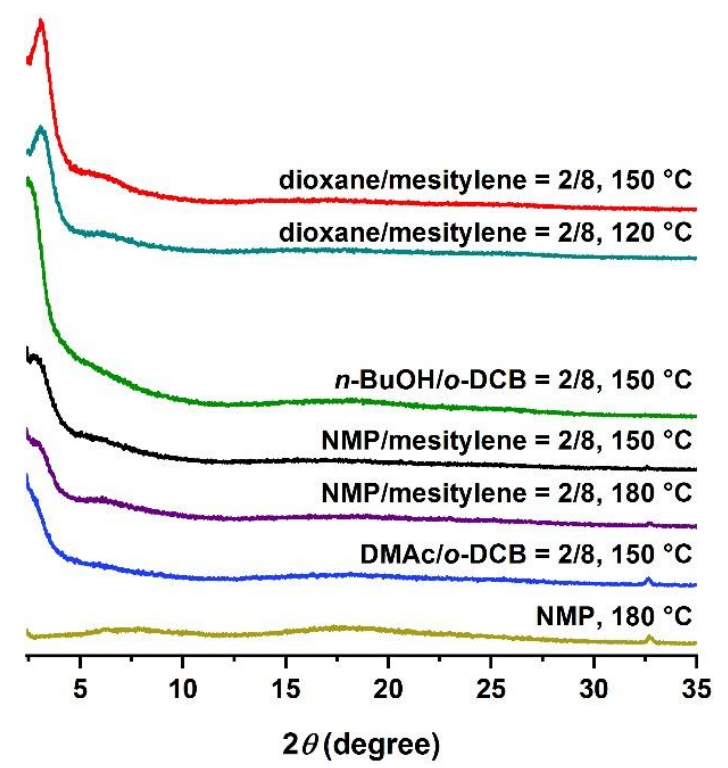

Figure S3. PXRD patterns of LZU-501 synthesized with indicated conditions. The optimized condition is using the mixed solvents of dioxane and mesitylene $\left(\mathrm{V}_{\text {dioxane }} / \mathrm{V}_{\text {mesitylene }}=2 / 8\right)$ at $150{ }^{\circ} \mathrm{C}$.

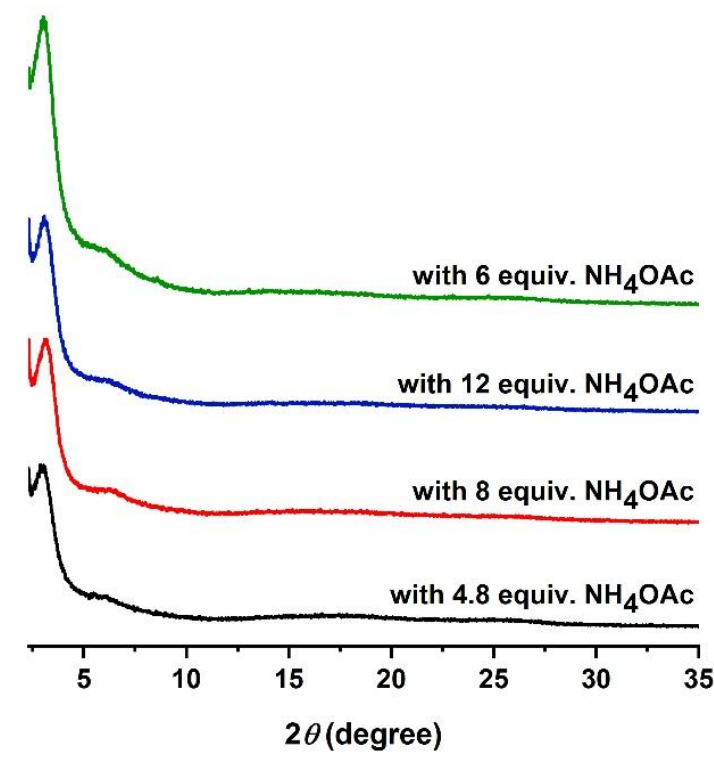

Figure S4. PXRD patterns of LZU-501 synthesized with different equivalent of $\mathrm{NH}_{4} \mathrm{OAc}$ under the optimized condition $\left(\mathrm{V}_{\text {dioxane }} / \mathrm{V}_{\text {mesitylene }}=2 / 8\right)$ at $150{ }^{\circ} \mathrm{C}$. The results indicate that adding 6 equiv. of $\mathrm{NH}_{4} \mathrm{OAc}$ gives the best result. Acting as both the reactant and the catalyst, ammonium acetate was used in excess. 


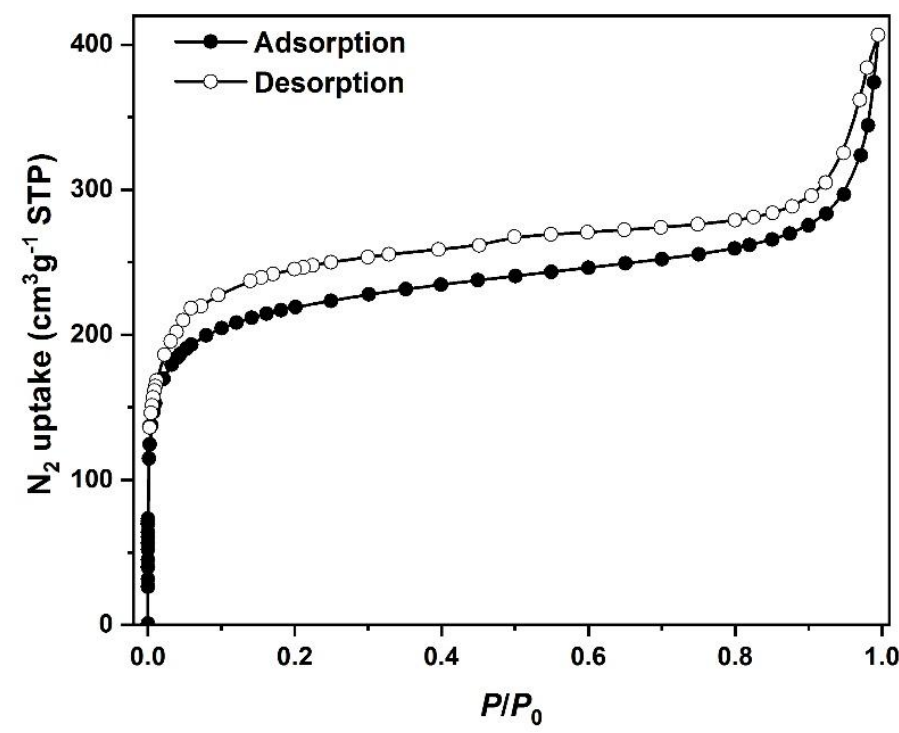

Figure S5. $\mathrm{N}_{2}$ adsorption and desorption isotherms of LZU-501.

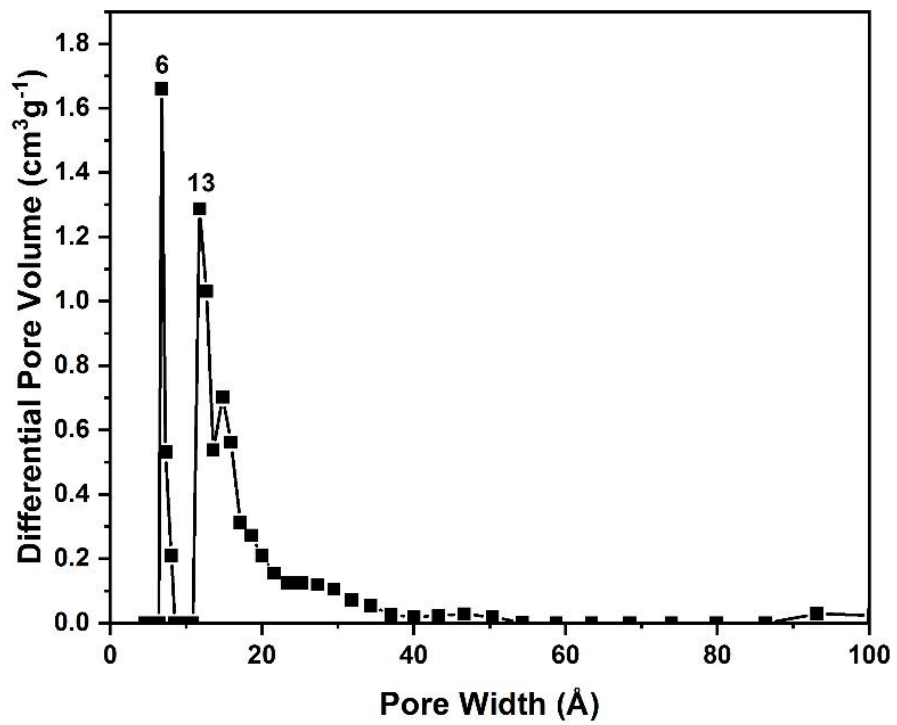

Figure S6. Pore size distribution of LZU-501 calculated by NLDFT (slit pores model). The deviation from the calculated pore size could be attributed to the presence of bulky $t$-Bu groups which makes it difficult for $\mathrm{N}_{2}$ to access the pores. ${ }^{4}$ 


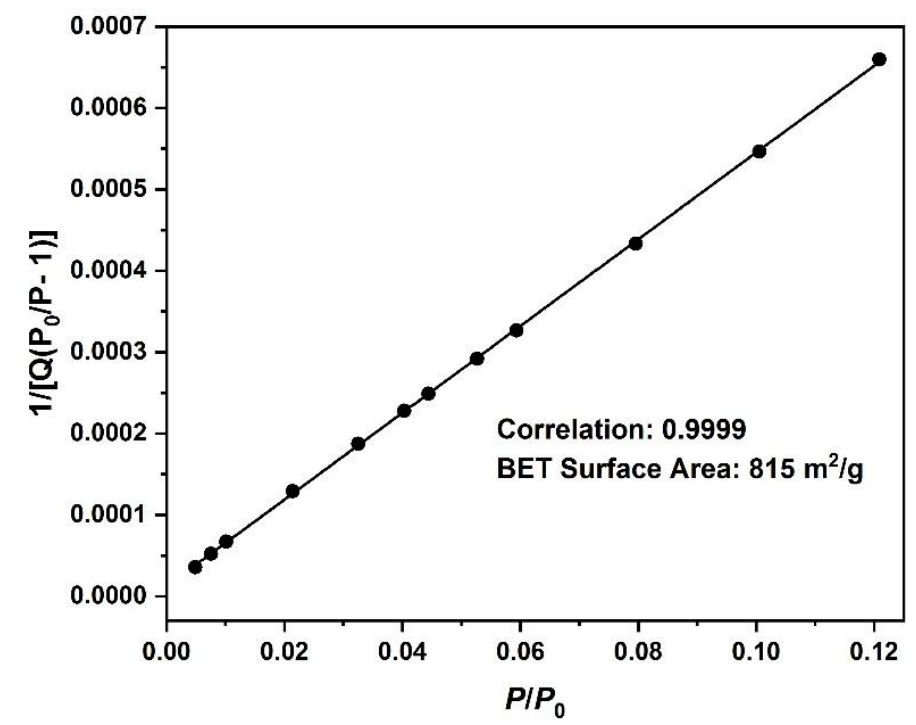

Figure S7. BET surface area plot for LZU-501 calculated from the adsorption isotherm.

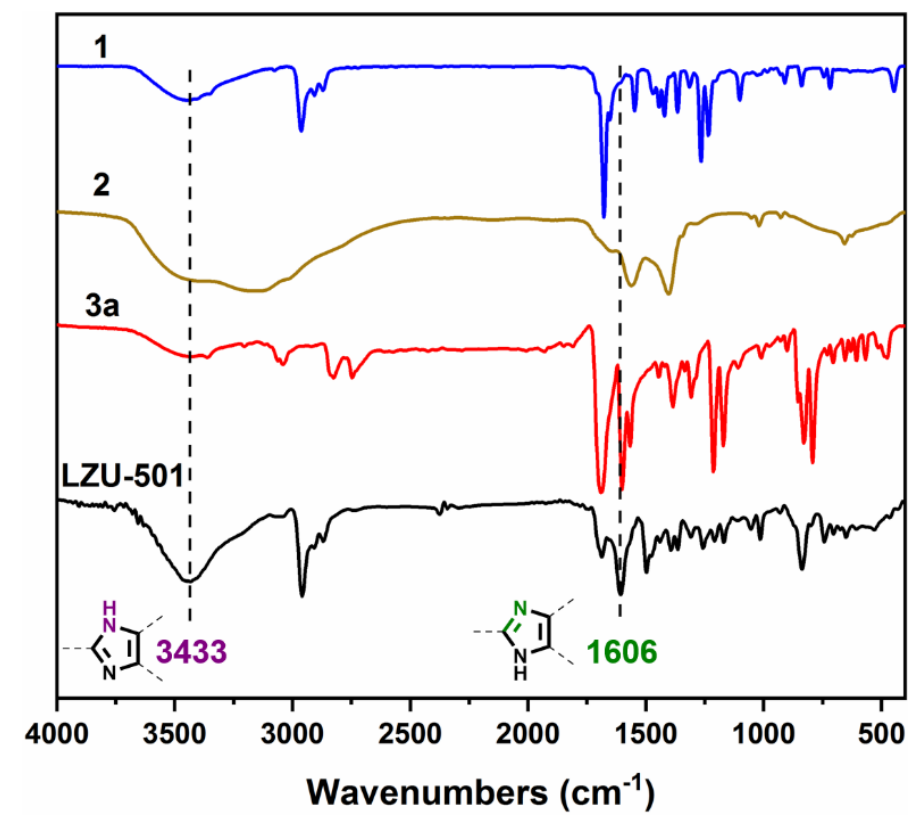

Figure S8. FT-IR spectra of monomer 1 (blue), monomer 2 (brown), monomer 3a (red), and LZU-501 (black). The FT-IR spectrum of LZU-501 (black) shows intense stretches at 3433 and $1606 \mathrm{~cm}^{-1}$, indicating the formation of the imidazole ring. 


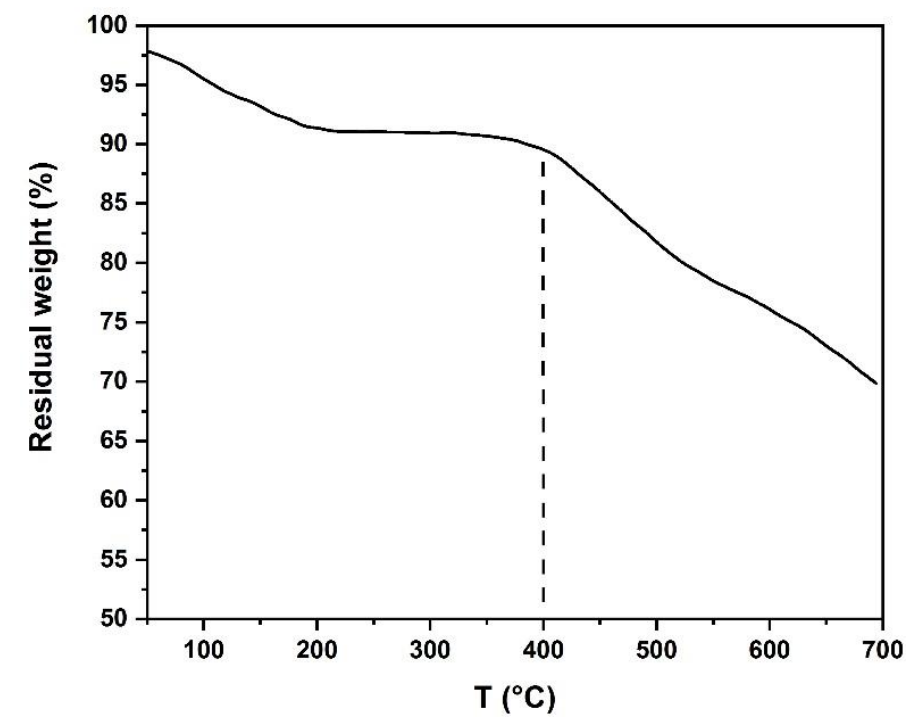

Figure S9. TGA data indicate that LZU-501 is thermally stable up to $400{ }^{\circ} \mathrm{C}$.
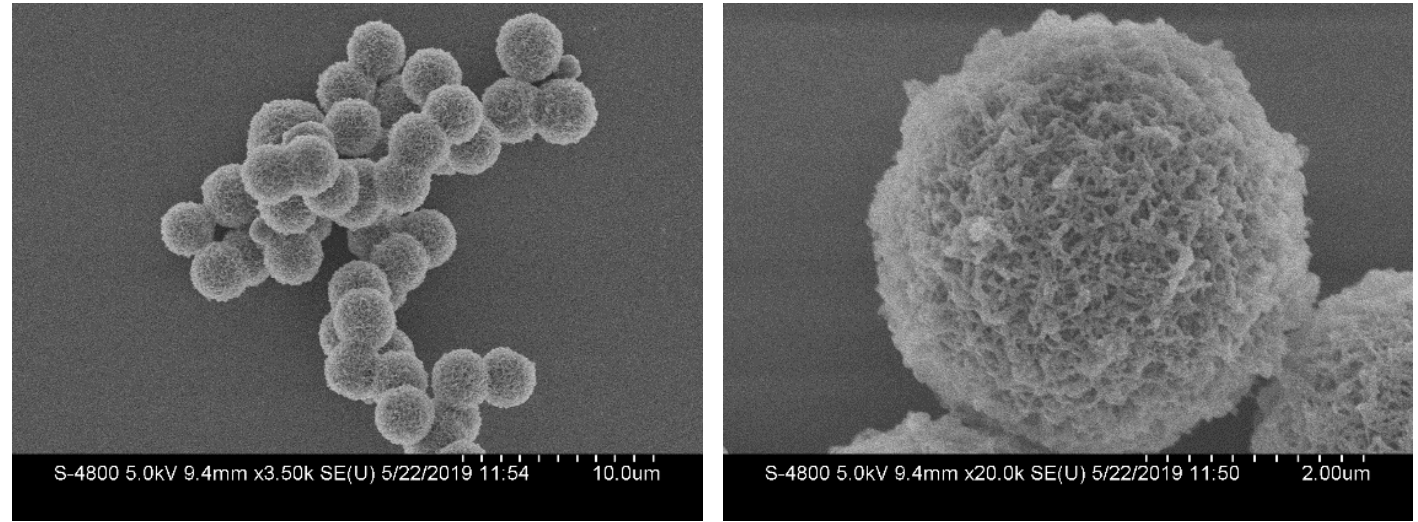

Figure S10. SEM images identify that LZU-501 possesses the uniform sphere-like morphology.

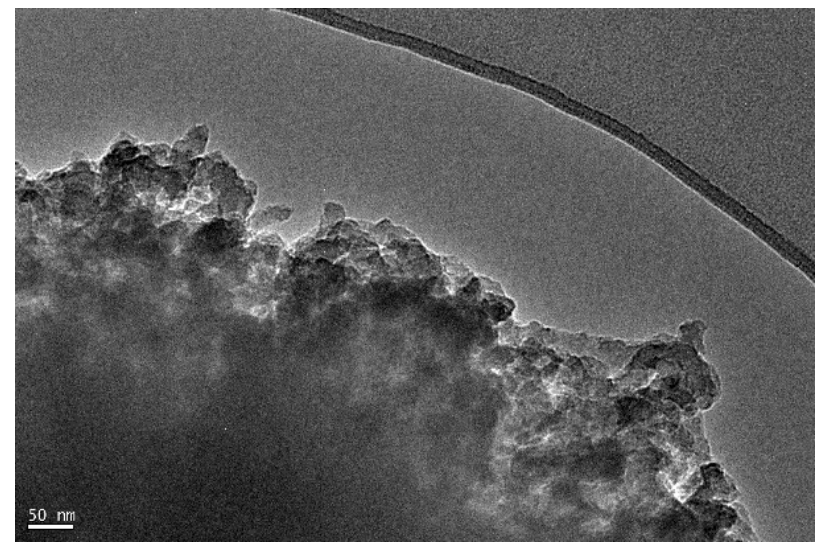

Figure S11. TEM image of LZU-501. 
Structural modeling of LZU-501 was generated by the Materials Studio (v.7.0) ${ }^{5}$ suite of programs. Possible stacking models (eclipsed and staggered) were constructed and optimized using the Forcite module. The calculated PXRD patterns were generated with the Reflex Plus module. Pawley refinement was applied for profile fitting, producing the refined PXRD profile with the lattice parameters of $a=b=$ $36.053( \pm 0.424) \AA$ and $c=5.371( \pm 0.063) \AA$. $R \mathrm{wp}$ and $R \mathrm{p}$ values converged to $4.87 \%$ and $3.30 \%$, respectively. Comparison of the observed and the simulated PXRD patterns (Figure S12) suggested that the preferable structure of LZU-501 is the eclipsed arrangement.
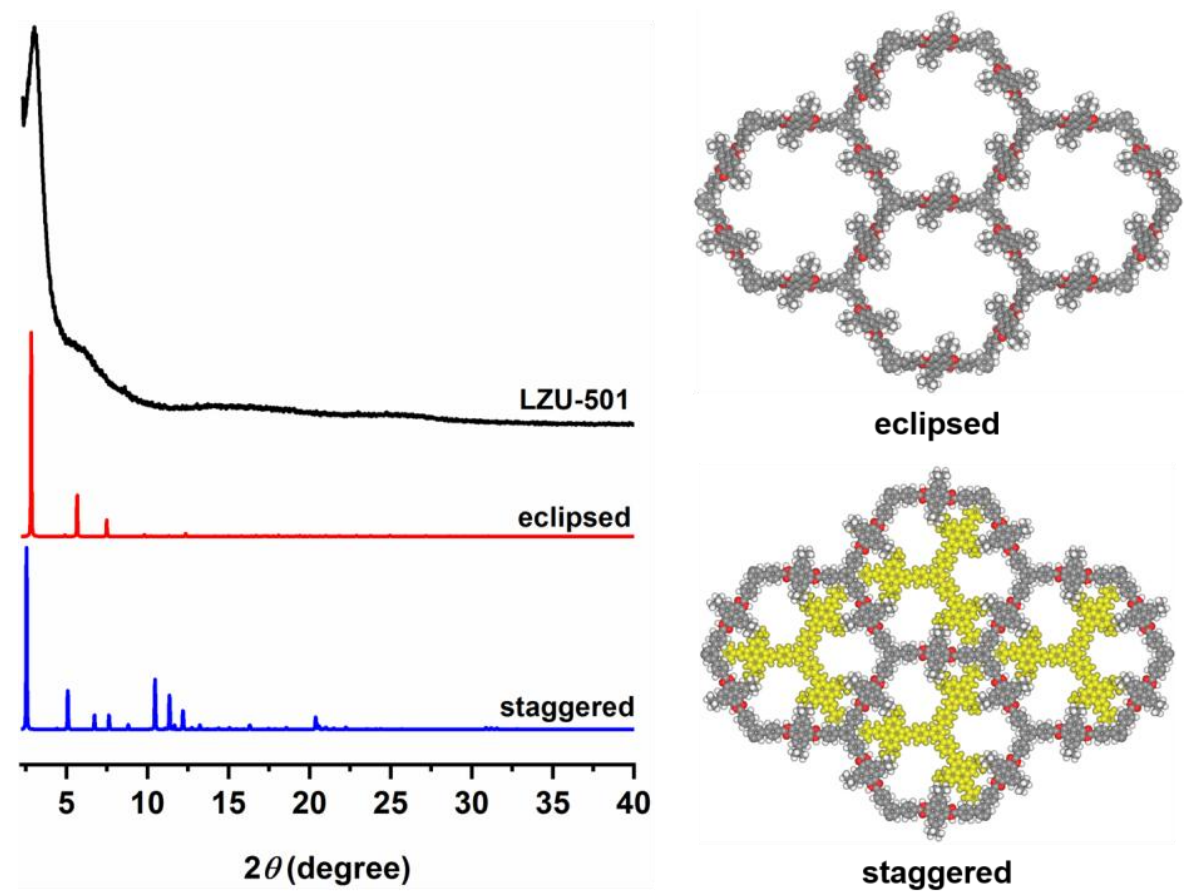

Figure S12. PXRD patterns of LZU-501: observed (black) and calculated with the eclipsed (red) or staggered (blue) stacking models. Comparison of the observed and the simulated PXRD patterns suggests that the preferable structure of LZU-501 is the eclipsed arrangement. 


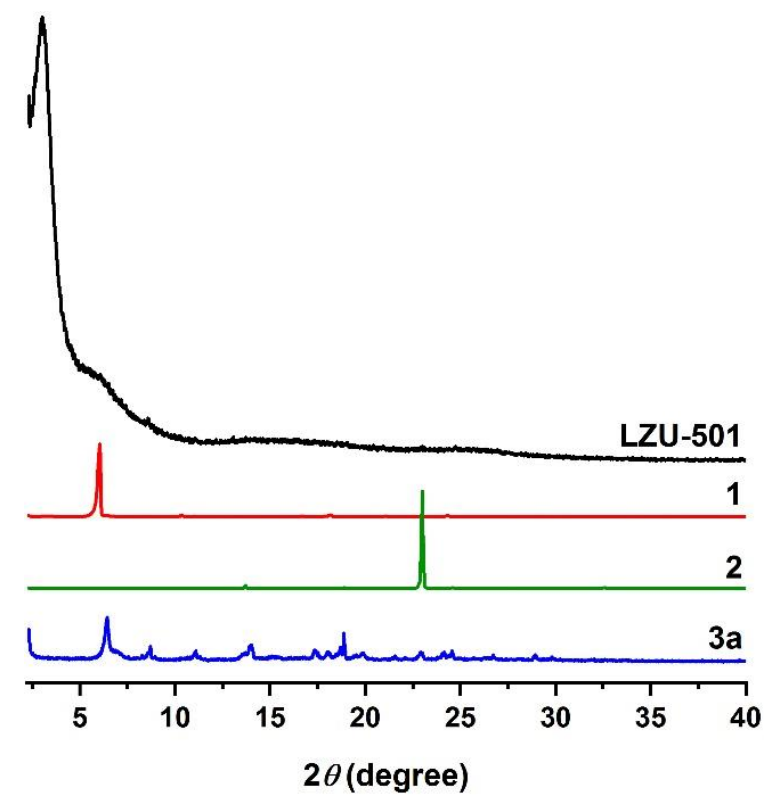

Figure S13. PXRD patterns of LZU-501 (black), monomer 1 (red), monomer 2 (green), and monomer 3a (blue). No diffraction peaks from monomer $\mathbf{1}$ (red), monomer 2 (green), and monomer 3a (blue) could be observed in the PXRD pattern of LZU-501 (black), indicating the sole formation of the crystalline LZU-501.

Table S1. Fractional atomic coordinates for the unit cell of LZU-501.

\begin{tabular}{|c|c|c|c|c|c|c|c|}
\hline \multicolumn{8}{|c|}{ Space group: $P 3$} \\
\hline Atom & $\mathbf{X}(\AA)$ & $\mathbf{Y}(\AA)$ & $\mathbf{Z}(\AA)$ & Atom & $\mathbf{X}(\AA)$ & $\mathbf{Y}(\AA)$ & $\mathbf{Z}(\AA)$ \\
\hline $\mathrm{C} 1$ & 1.33894 & 0.23589 & 0.89898 & $\mathrm{C} 41$ & 1.5652 & 0.30427 & -0.01799 \\
\hline $\mathrm{C} 2$ & 1.31802 & 0.19564 & 0.77283 & $\mathrm{C} 42$ & 1.52545 & 0.28132 & 0.08509 \\
\hline $\mathrm{C} 3$ & 1.34081 & 0.18843 & 0.58254 & $\mathrm{H} 43$ & 1.32056 & 0.24124 & 1.04298 \\
\hline $\mathrm{C} 4$ & 1.38384 & 0.21986 & 0.5419 & H44 & 1.43609 & 0.28298 & 0.63194 \\
\hline $\mathrm{C} 5$ & 1.40275 & 0.25883 & 0.67377 & $\mathrm{H} 45$ & 1.22659 & 0.05672 & 0.39148 \\
\hline C6 & & & 0.847 & & & & \\
\hline $\mathrm{C} 7$ & 1.27627 & 0.16239 & 0.81852 & $\mathrm{H} 47$ & 1.36487 & 0.29275 & 1.32012 \\
\hline $\mathrm{C} 8$ & 1.2586 & 0.12737 & 0.66953 & $\mathrm{H} 48$ & 1.3405 & 0.30915 & 1.08927 \\
\hline C9 & 1.27889 & 0.11972 & 0.47693 & H49 & 1.38687 & 0.34786 & 1.24695 \\
\hline $\mathrm{C} 10$ & 1.32184 & 0.15124 & 0.43551 & $\mathrm{H} 50$ & 1.46697 & 0.32498 & 0.94939 \\
\hline $\mathrm{C} 11$ & 1.34521 & 0.14308 & 0.25344 & H51 & 1.44056 & 0.30285 & 1.23521 \\
\hline $\mathrm{C} 12$ & 1.38721 & 0.17593 & 0.21017 & H52 & 1.45878 & 0.35728 & 1.16547 \\
\hline $\mathrm{C} 13$ & 1.40472 & 0.21129 & 0.35679 & H53 & 1.37673 & 0.33846 & 0.67763 \\
\hline $\mathrm{C} 14$ & 1.26006 & 0.08039 & 0.34917 & H54 & 1.42864 & 0.34615 & 0.61411 \\
\hline $\mathrm{C} 15$ & 1.28359 & 0.06977 & 0.19151 & H55 & 1.42207 & 0.37794 & 0.84188 \\
\hline
\end{tabular}




\begin{tabular}{|c|c|c|c||c|c|c|c|}
\hline C16 & 1.3249 & 0.10182 & 0.1387 & H56 & 1.32848 & 0.02712 & 0.08751 \\
\hline C17 & 1.40053 & 0.31272 & 0.96662 & H57 & 1.2835 & -0.02529 & 0.09079 \\
\hline C18 & 1.3714 & 0.31541 & 1.16664 & H58 & 1.29824 & 0.00635 & 0.3651 \\
\hline C19 & 1.44399 & 0.32489 & 1.08459 & H59 & 1.20867 & -0.03857 & 0.08697 \\
\hline C20 & 1.40731 & 0.34541 & 0.76292 & H60 & 1.19763 & 0.004 & 0.11127 \\
\hline C21 & 1.26614 & 0.0247 & 0.08342 & H61 & 1.21742 & -0.01105 & 0.37293 \\
\hline C22 & 1.29582 & 0.0075 & 0.16153 & H62 & 1.2955 & 0.0496 & -0.28404 \\
\hline C23 & 1.22006 & -0.00672 & 0.1701 & H63 & 1.24091 & 0.03618 & -0.25406 \\
\hline C24 & 1.26451 & 0.02684 & -0.19988 & H64 & 1.25418 & -0.00489 & -0.2813 \\
\hline N25 & 1.24509 & 0.15568 & 0.98528 & H65 & 1.24854 & 0.17308 & 1.13573 \\
\hline C26 & 1.21082 & 0.1175 & 0.9396 & H66 & 1.41587 & 0.16373 & -0.09663 \\
\hline N27 & 1.2174 & 0.09856 & 0.74147 & H67 & 1.1816 & 0.14167 & 1.35614 \\
\hline N28 & 1.41905 & 0.18151 & 0.05151 & C68 & 1.04573 & 0.02343 & 1.37825 \\
\hline C29 & 1.45373 & 0.21924 & 0.10025 & H69 & 1.14809 & 0.04084 & 0.80115 \\
\hline N30 & 1.44668 & 0.23892 & 0.29287 & H70 & 1.48348 & 0.19407 & -0.30919 \\
\hline C31 & 1.49414 & 0.24081 & -0.01313 & C71 & 1.6209 & 0.31032 & -0.31817 \\
\hline C32 & 1.1711 & 0.09495 & 1.05989 & H72 & 1.51764 & 0.29458 & 0.24835 \\
\hline C33 & 1.15884 & 0.11046 & 1.27497 & H73 & 1.11068 & 0.09982 & 1.54213 \\
\hline C34 & 1.1194 & 0.08697 & 1.38083 & H74 & 1.07782 & -0.00071 & 0.99036 \\
\hline C35 & 1.08869 & 0.04581 & 1.28538 & H75 & 1.58879 & 0.33475 & 0.06812 \\
\hline C36 & 1.10116 & 0.03011 & 1.07414 & H76 & 1.55521 & 0.23451 & -0.48691 \\
\hline C37 & 1.14035 & 0.05387 & 0.96572 & C77 & 1.02164 & 0.04463 & 1.39515 \\
\hline C38 & 1.50664 & 0.22487 & -0.22525 & C78 & 1.64458 & 0.28869 & -0.33483 \\
\hline C39 & 1.54657 & 0.24758 & -0.3263 & H79 & 1.03852 & 0.07948 & 1.36411 \\
\hline C40 & 1.57776 & 0.28833 & -0.22784 & H80 & 1.62734 & 0.25381 & -0.30486 \\
\hline
\end{tabular}


Synthesis of LZU-506

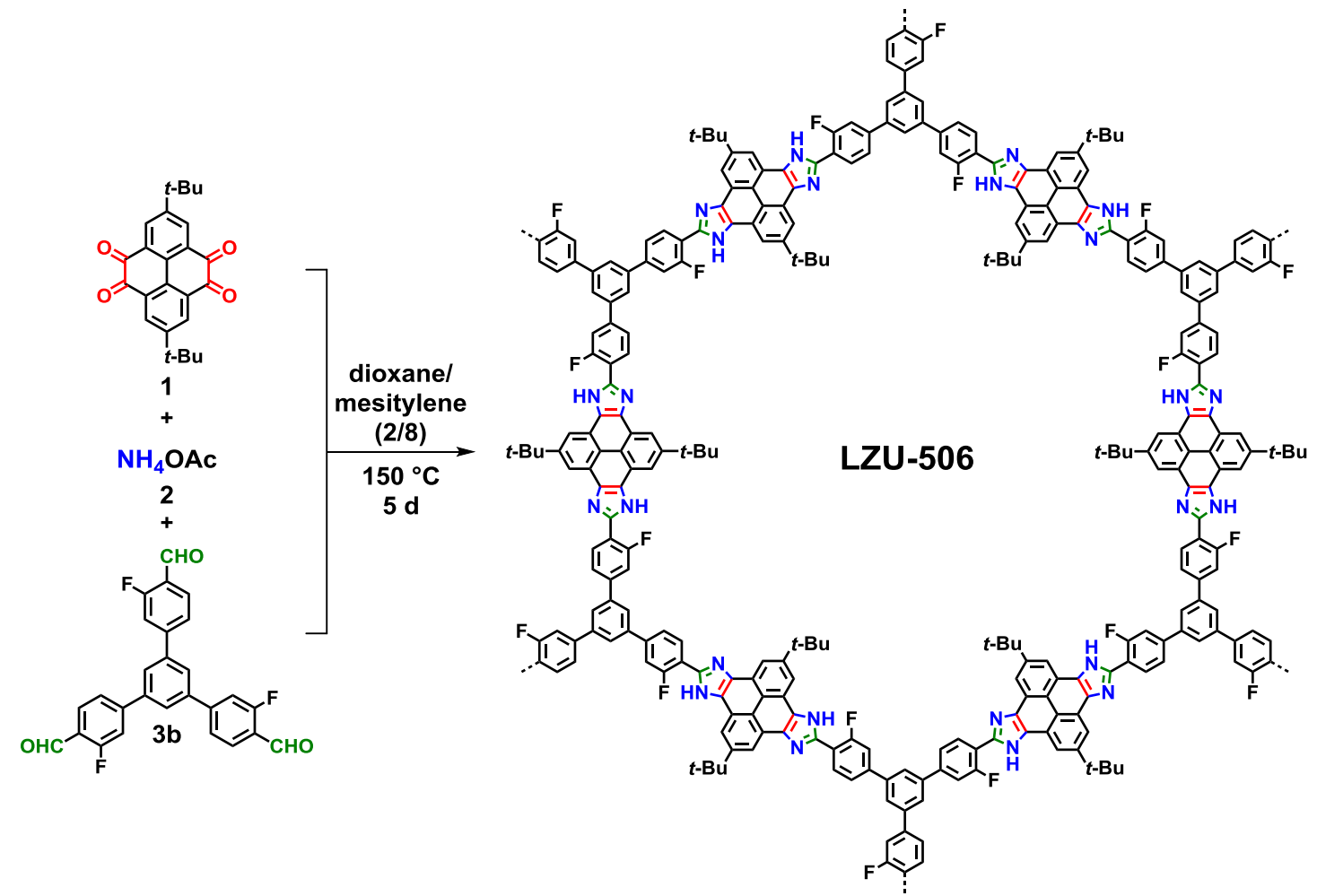

The synthetic conditions of LZU-506 were similar to that of LZU-501. Condensation of tertbutylpyrene tetraone $1(17 \mathrm{mg}, 0.045 \mathrm{mmol})$, ammonium acetate (21 mg, $0.270 \mathrm{mmol}$ ) 2, and 1,3,5-tris(3-fluoro-4-formylphenyl)benzene $\mathbf{3 b}$ (13 mg, $0.030 \mathrm{mmol}$ ) yielded LZU-506 as an olive powder (22 mg, 78\% yield). Anal. Cald for $\left(\mathrm{C}_{21} \mathrm{H}_{16} \mathrm{~N}_{2} \mathrm{~F}\right)_{\mathrm{n}}$ : C 80.00; $\mathrm{H} 5.08 ; \mathrm{N} 8.89$, found: $\mathrm{C} 78.99 ; \mathrm{H} 4.89 ; \mathrm{N}$ 5.29. The deviations from the calculated values are attributed to the incomplete combustion of the material (Figure S20) and the presence of the terminal groups. ${ }^{3}$ Characterization of LZU-506 has been presented in the main text and in this SI. 


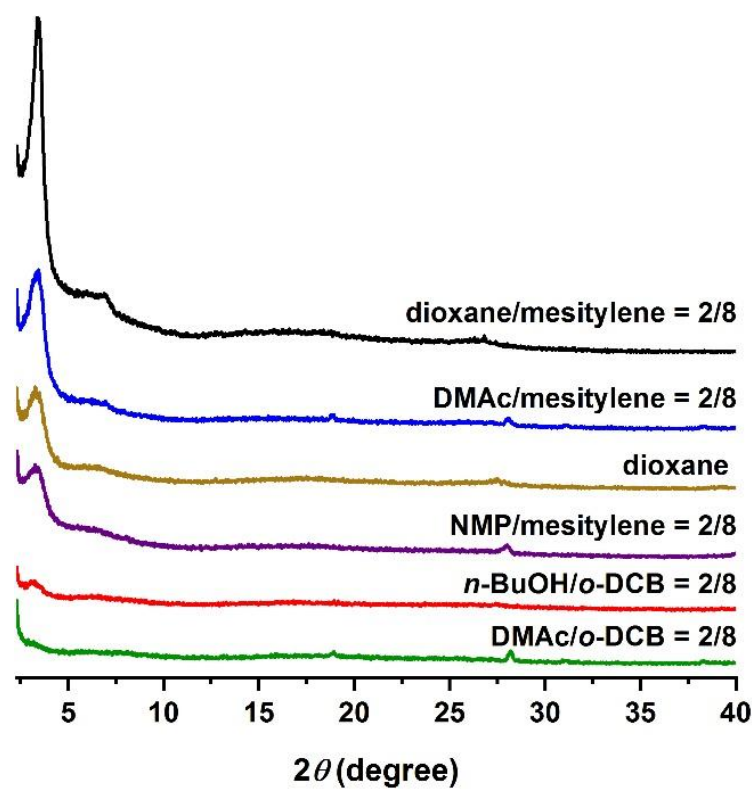

Figure S14. PXRD patterns of LZU-506 synthesized with indicated conditions. The optimized condition is using the mixed solvents of dioxane and mesitylene $\left(\mathrm{V}_{\text {dioxane }} / \mathrm{V}_{\text {mesitylene }}=2 / 8\right)$ at $150{ }^{\circ} \mathrm{C}$.

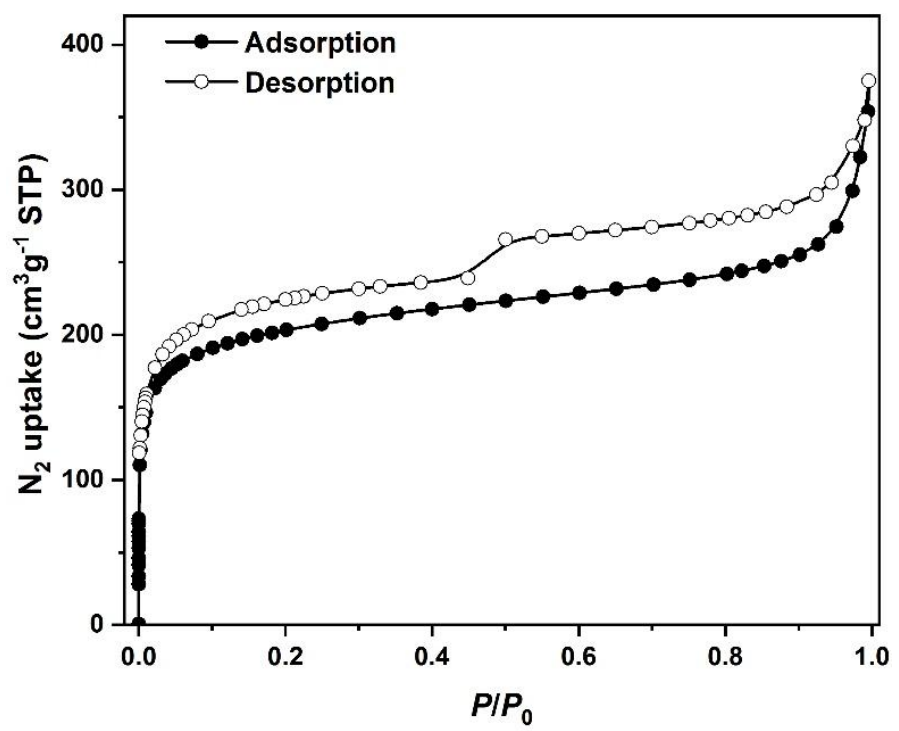

Figure S15. $\mathrm{N}_{2}$ adsorption and desorption isotherms of LZU-506. 


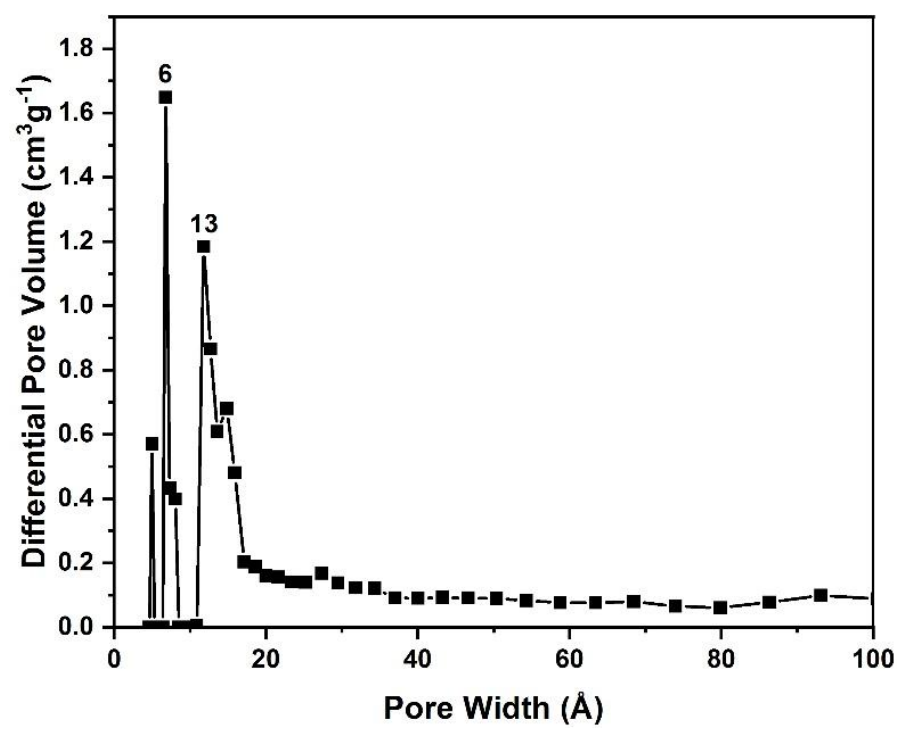

Figure S16. Pore size distribution of LZU-506 calculated by NLDFT (slit pores model). The deviation from the calculated pore size could be attributed to the presence of bulky $t$-Bu groups which makes it difficult for $\mathrm{N}_{2}$ to access the pores. ${ }^{4}$

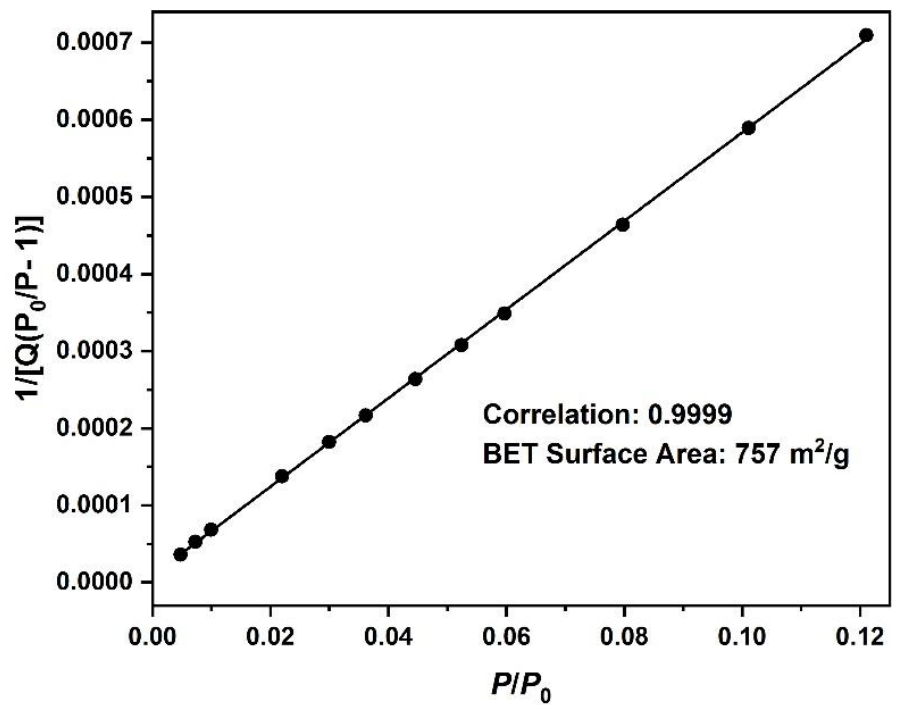

Figure S17. BET surface area plot for LZU-506 calculated from the adsorption isotherm. 


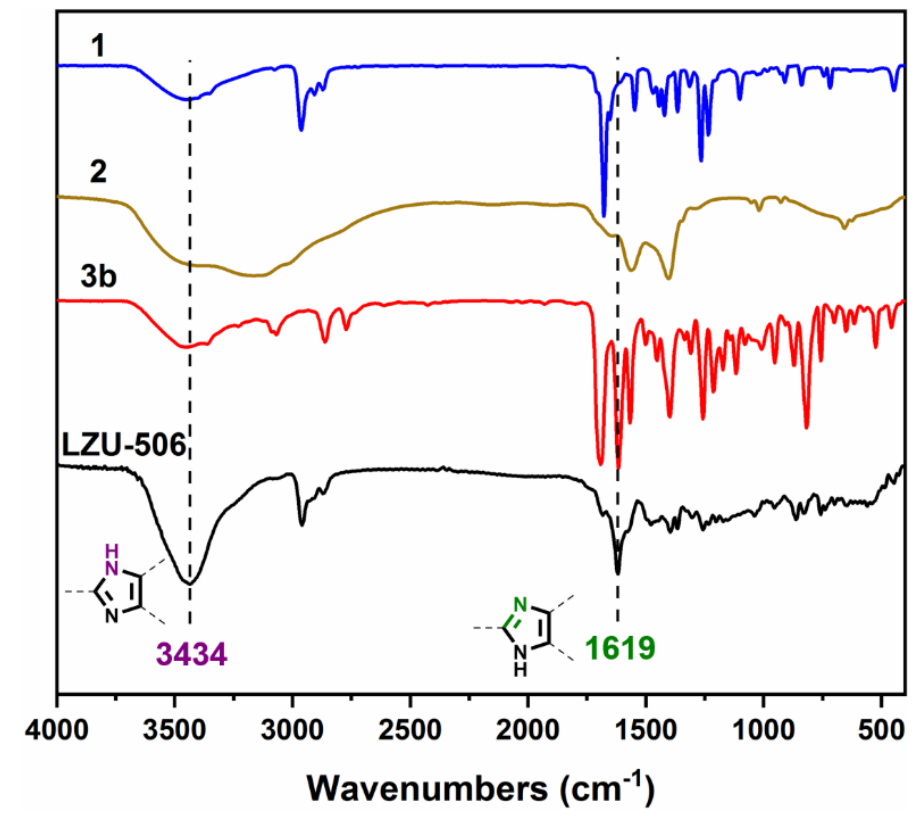

Figure S18. FT-IR spectra of monomer $\mathbf{1}$ (blue), monomer $\mathbf{2}$ (brown), monomer $\mathbf{3 b}$ (red), and LZU-506 (black). The FT-IR spectrum of LZU-506 (black) shows intense stretches at 3434 and $1619 \mathrm{~cm}^{-1}$, indicating the formation of the imidazole ring.

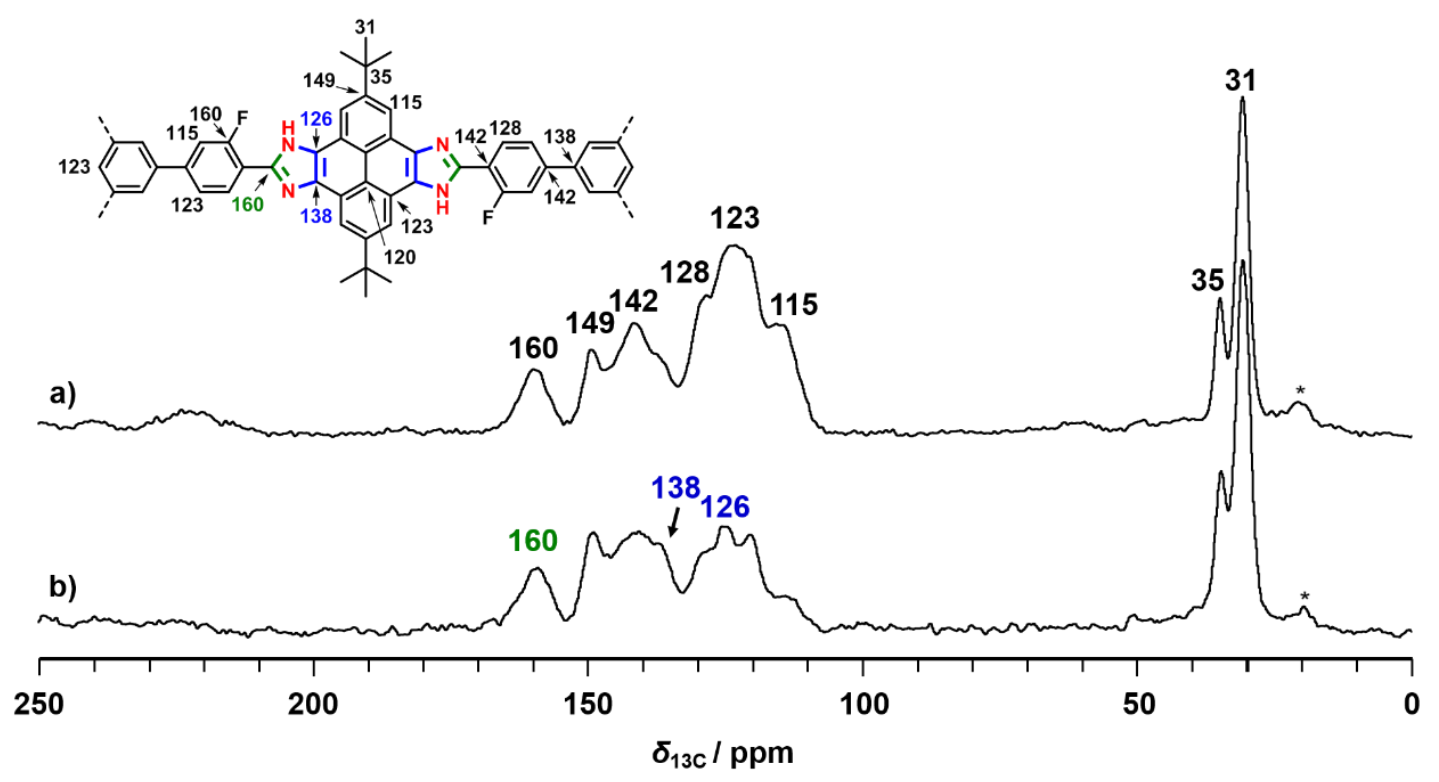

Figure S19. (a) ${ }^{13} \mathrm{C}$ CP/MAS and (b) NQS MAS NMR spectra of LZU-506. The assignments of ${ }^{13} \mathrm{C}$ chemical shifts are shown in the chemical structure. 


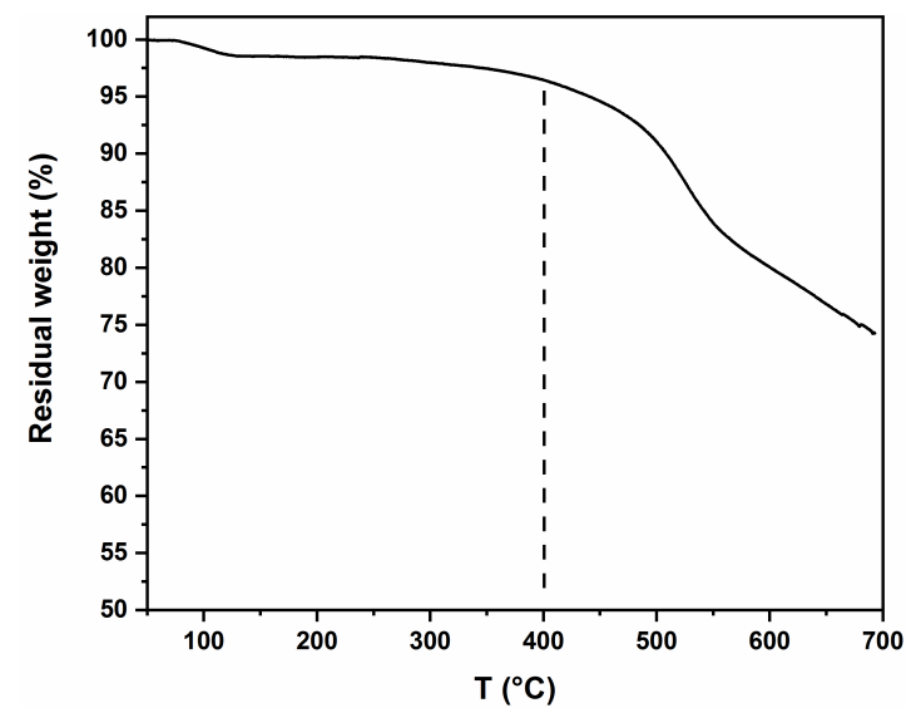

Figure S20. TGA data indicate that LZU-506 is thermally stable up to $400{ }^{\circ} \mathrm{C}$.
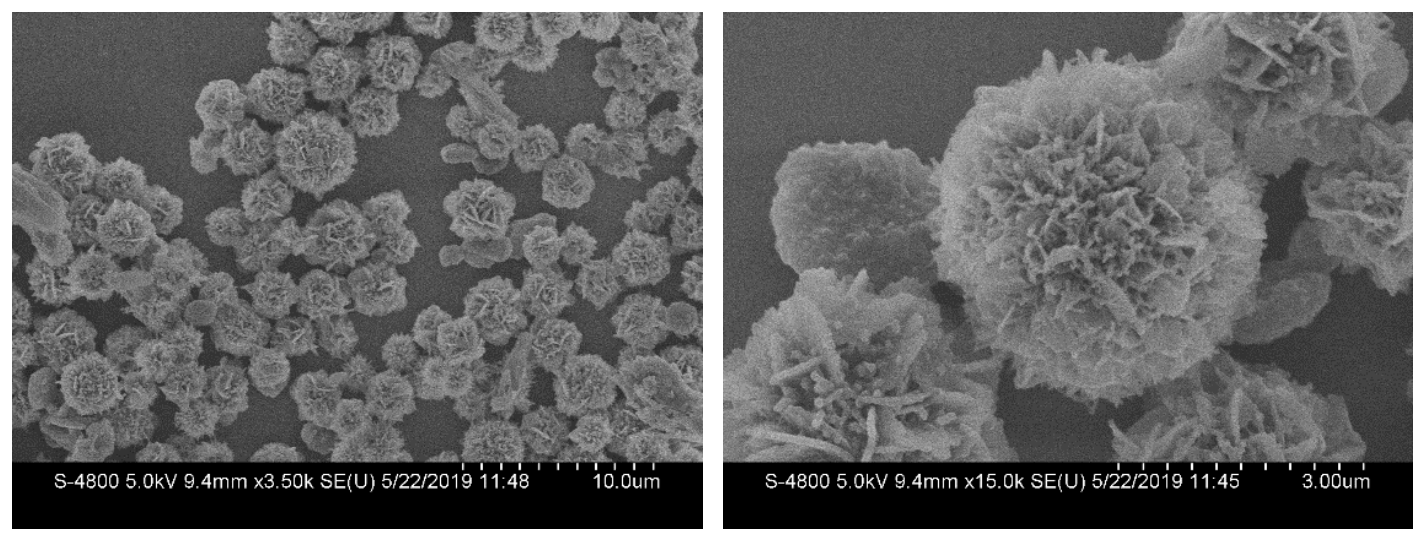

Figure S21. SEM images of LZU-506.

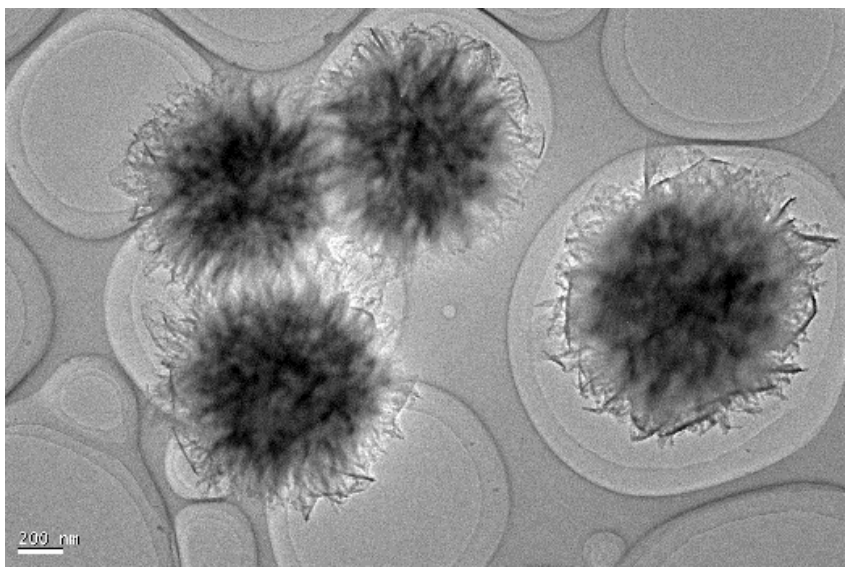

Figure S22. TEM image of LZU-506. 
The structural modeling of LZU-506 is similar to that of LZU-501. The Pawley refined lattice parameters were determined as: $a=b=30.399( \pm 0.424) \AA$ and $c=$ 5.551 ( \pm 0.063$) \AA .8 \mathrm{wp}$ and $R \mathrm{p}$ values converged to $5.69 \%$ and $3.98 \%$, respectively. Comparison of the observed and the simulated PXRD patterns (Figure S23) suggested that the preferable structure of LZU-506 is the eclipsed arrangement.
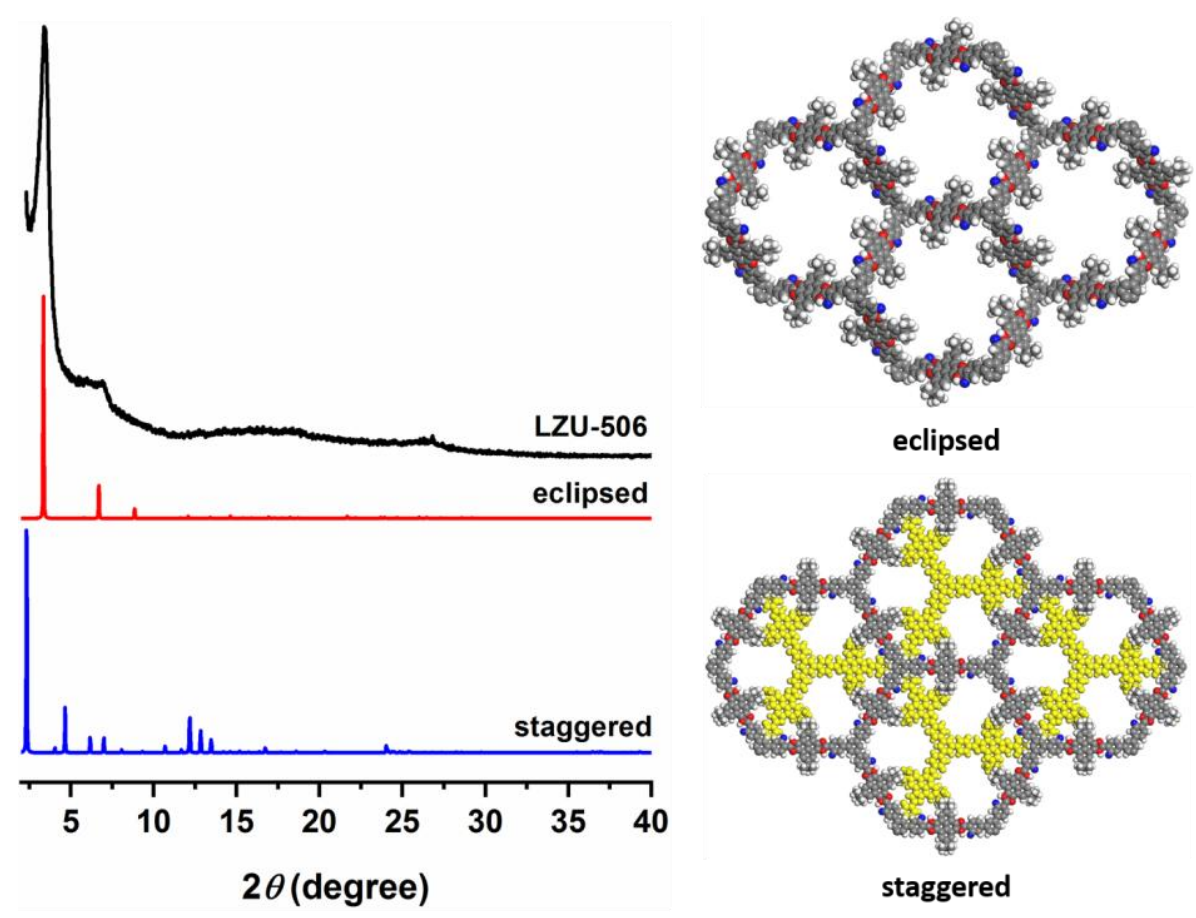

Figure S23. PXRD patterns of LZU-506: observed (black) and calculated with the eclipsed (red) or staggered (blue) stacking models. Comparison of the observed and the simulated PXRD patterns suggests that the preferable structure of LZU-506 is the eclipsed arrangement. 


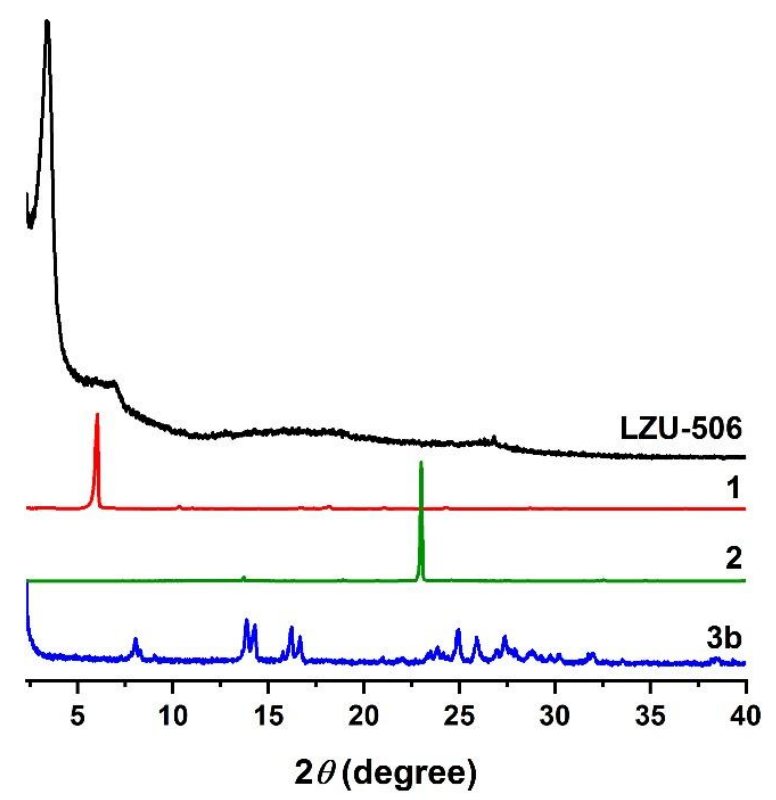

Figure S24. PXRD patterns of LZU-506 (black), monomer 1 (red), monomer 2 (green), and monomer 3b (blue). No diffraction peaks from monomer $\mathbf{1}$ (red), monomer 2 (green), and monomer 3b (blue) could be observed in the PXRD pattern of LZU-506 (black), indicating the sole formation of the crystalline LZU-506.

Table S2. Fractional atomic coordinates for the unit cell of LZU-506.

\begin{tabular}{|c|c|c|c||c|c|c|c|}
\hline \multicolumn{7}{|c|}{ Space group: $P 3$} \\
\hline Atom & $\mathbf{X}(\mathbf{\AA})$ & $\mathbf{Y ~}(\AA)$ & $\mathbf{Z}(\mathbf{\AA})$ & Atom & $\mathbf{X}(\AA)$ & $\mathbf{Y}(\mathbf{A})$ & $\mathbf{Z}(\mathbf{\AA})$ \\
\hline C1 & 1.35005 & 0.2649 & 0.81125 & C41 & 1.56132 & 0.31161 & -0.36328 \\
\hline C2 & 1.32372 & 0.21249 & 0.74869 & C42 & 1.52251 & 0.28852 & -0.20267 \\
\hline C3 & 1.34232 & 0.19682 & 0.55342 & H43 & 1.33514 & 0.27606 & 0.96432 \\
\hline C4 & 1.38631 & 0.23354 & 0.4346 & H44 & 1.44542 & 0.31227 & 0.41067 \\
\hline C5 & 1.41079 & 0.28484 & 0.50564 & H45 & 1.21524 & 0.03106 & 0.62452 \\
\hline C6 & 1.39292 & 0.30133 & 0.69324 & H46 & 1.32765 & 0.0646 & 0.08537 \\
\hline C7 & 1.28115 & 0.17448 & 0.86875 & H47 & 1.38405 & 0.34635 & 1.12038 \\
\hline C8 & 1.25903 & 0.1259 & 0.79052 & H48 & 1.35335 & 0.3603 & 0.88406 \\
\hline C9 & 1.2751 & 0.10909 & 0.59989 & H49 & 1.41122 & 0.40889 & 1.00578 \\
\hline C10 & 1.31889 & 0.1459 & 0.48027 & H50 & 1.49656 & 0.36644 & 0.74036 \\
\hline C11 & 1.33805 & 0.12981 & 0.28942 & H51 & 1.46782 & 0.34572 & 1.02671 \\
\hline C12 & 1.38087 & 0.16756 & 0.17139 & H52 & 1.49269 & 0.40988 & 0.93842 \\
\hline C13 & 1.40315 & 0.21628 & 0.24854 & H53 & 1.39088 & 0.38243 & 0.4734 \\
\hline C14 & 1.25017 & 0.05782 & 0.52935 & H54 & 1.45029 & 0.38742 & 0.40587 \\
\hline
\end{tabular}




\begin{tabular}{|c|c|c|c||c|c|c|c|}
\hline C15 & 1.26884 & 0.04093 & 0.34715 & H55 & 1.44721 & 0.43133 & 0.6025 \\
\hline C16 & 1.31225 & 0.07707 & 0.23184 & H56 & 1.31656 & -0.0141 & 0.26621 \\
\hline C17 & 1.42062 & 0.35741 & 0.76795 & H57 & 1.26287 & -0.0752 & 0.30673 \\
\hline C18 & 1.39048 & 0.36861 & 0.95484 & H58 & 1.28527 & -0.03172 & 0.54889 \\
\hline C19 & 1.47223 & 0.37052 & 0.87375 & H59 & 1.17368 & -0.08707 & 0.32074 \\
\hline C20 & 1.42768 & 0.39123 & 0.5492 & H60 & 1.16536 & -0.03364 & 0.33537 \\
\hline C21 & 1.24411 & -0.01503 & 0.27476 & H61 & 1.19169 & -0.04947 & 0.5824 \\
\hline C22 & 1.27918 & -0.03497 & 0.35323 & H62 & 1.27177 & 0.00104 & -0.10097 \\
\hline C23 & 1.19103 & -0.04775 & 0.3854 & H63 & 1.2111 & -0.00542 & -0.05141 \\
\hline C24 & 1.2364 & -0.01971 & 0.00225 & H64 & 1.21854 & -0.05975 & -0.05199 \\
\hline N25 & 1.25313 & 0.173 & 1.0629 & H65 & 1.26041 & 0.20122 & 1.17452 \\
\hline C26 & 1.21603 & 0.12531 & 1.09586 & H66 & 1.40201 & 0.13961 & -0.12781 \\
\hline N27 & 1.21779 & 0.09415 & 0.92887 & F67 & 1.20183 & 0.18198 & 1.48074 \\
\hline N28 & 1.40929 & 0.16829 & -0.01875 & C68 & 1.05371 & 0.02861 & 1.7611 \\
\hline C29 & 1.4471 & 0.2157 & -0.05097 & H69 & 1.14728 & 0.02824 & 1.10848 \\
\hline N30 & 1.44526 & 0.24743 & 0.11288 & F70 & 1.45833 & 0.15745 & -0.43741 \\
\hline C31 & 1.48588 & 0.23632 & -0.22172 & C71 & 1.61281 & 0.30674 & -0.70175 \\
\hline C32 & 1.17774 & 0.10347 & 1.2685 & H72 & 1.52041 & 0.31113 & -0.05361 \\
\hline C33 & 1.17113 & 0.13169 & 1.46048 & H73 & 1.12748 & 0.12732 & 1.76845 \\
\hline C34 & 1.13279 & 0.10595 & 1.62349 & H74 & 1.07906 & -0.01439 & 1.39236 \\
\hline C35 & 1.09875 & 0.05302 & 1.61259 & H75 & 1.58982 & 0.35155 & -0.33338 \\
\hline C36 & 1.10587 & 0.02609 & 1.41917 & H76 & 1.53497 & 0.20946 & -0.71753 \\
\hline C37 & 1.14365 & 0.0506 & 1.25458 & C77 & 1.02429 & 0.0524 & 1.79199 \\
\hline C38 & 1.49136 & 0.2073 & -0.41355 & C78 & 1.64029 & 0.28085 & -0.732 \\
\hline C39 & 1.53082 & 0.23156 & -0.57226 & H79 & 1.04301 & 0.09306 & 1.7475 \\
\hline C40 & 1.56723 & 0.28397 & -0.55684 & H80 & 1.62002 & 0.24008 & -0.68903 \\
\hline
\end{tabular}




\section{F. Synthesis, Characterization, and Structural Modeling of LZU-508}

Synthesis of LZU-508
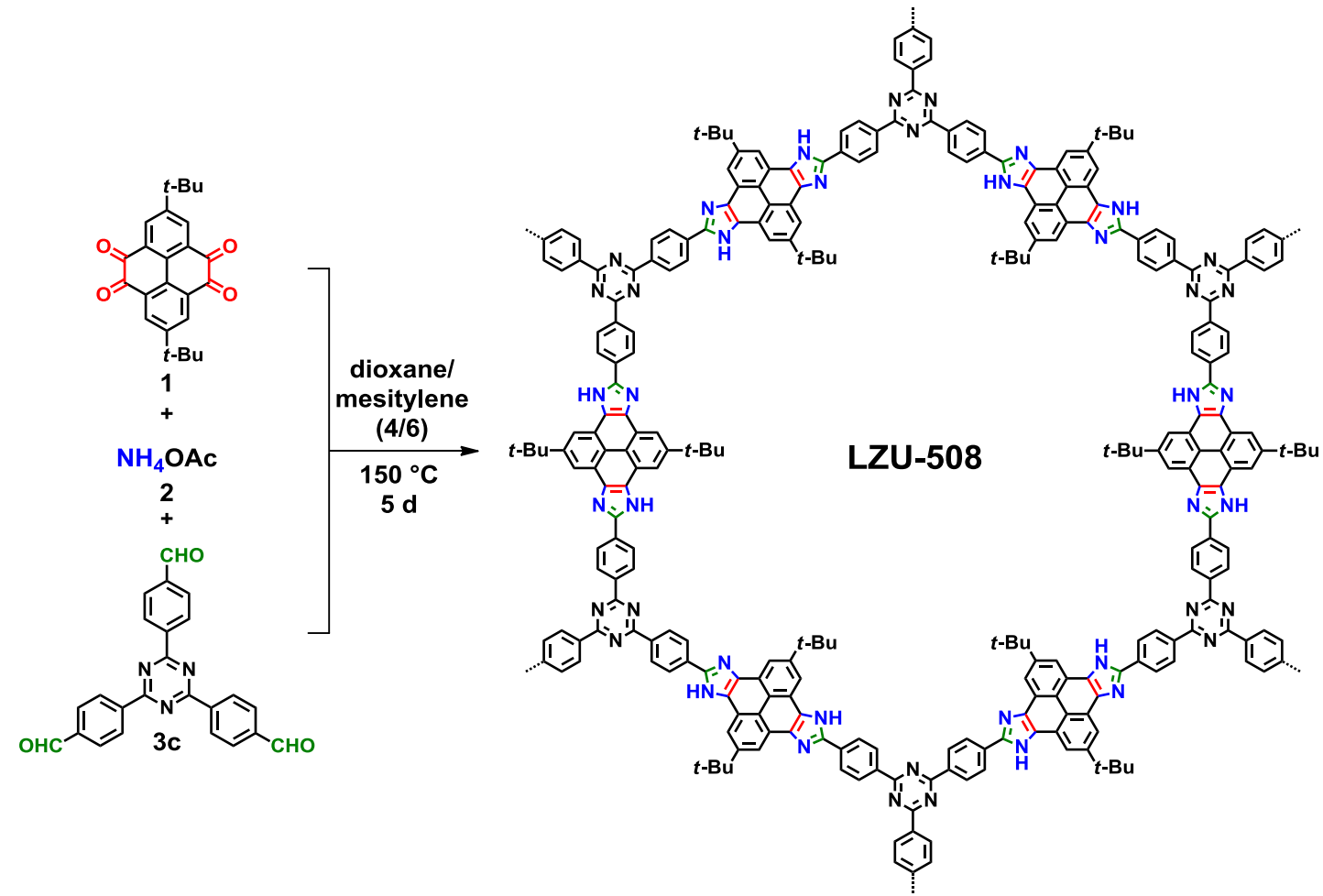

The synthetic conditions of LZU-508 were similar to that of LZU-501. Condensation of tertbutylpyrene tetraone 1 (17 mg, $0.045 \mathrm{mmol})$, ammonium acetate 2 (21 mg, $0.269 \mathrm{mmol})$, and 1,3,5-tris-(4-formylphenyl)triazine 3c (12 mg, 0.030 mmol) yielded LZU-508 as a brown powder (22 mg, 82\% yield). Anal. Cald for $\left(\mathrm{C}_{20} \mathrm{H}_{16} \mathrm{~N}_{3}\right)_{n}$ : C 80.54; H 5.37; N 14.09, found: C 74.44; H 5.02; N 11.01. The deviations from the calculated values are attributed to the incomplete combustion of the material (Figure S31) and the presence of the terminal groups. ${ }^{3}$ Characterization of LZU-508 has been presented in the main text and in this SI. 


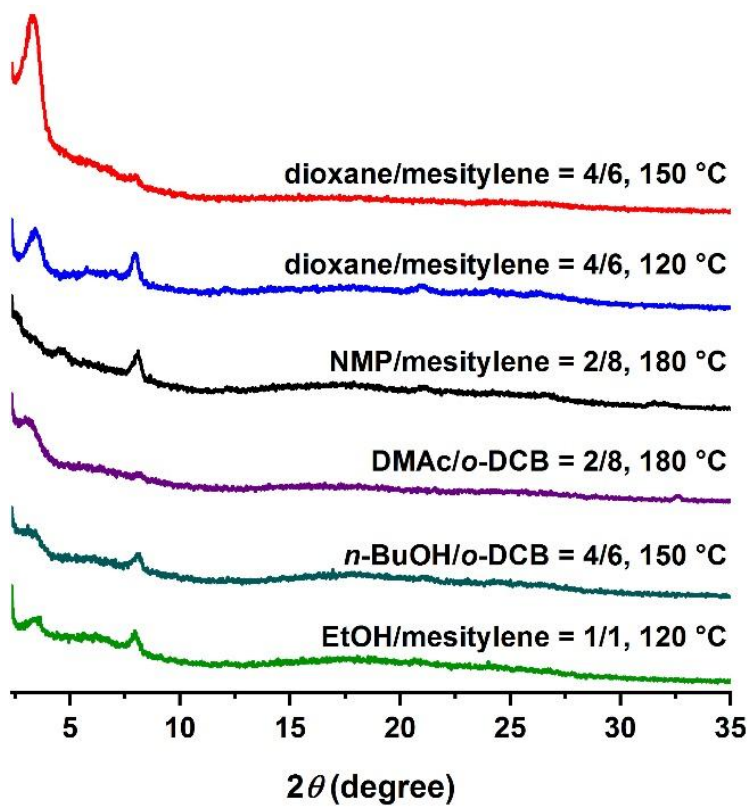

Figure S25. PXRD patterns of LZU-508 synthesized with indicated conditions. The optimized condition is using the mixed solvents of dioxane and mesitylene $\left(\mathrm{V}_{\text {dioxane }} / \mathrm{V}_{\text {mesitylene }}=4 / 6\right)$ at $150^{\circ} \mathrm{C}$.

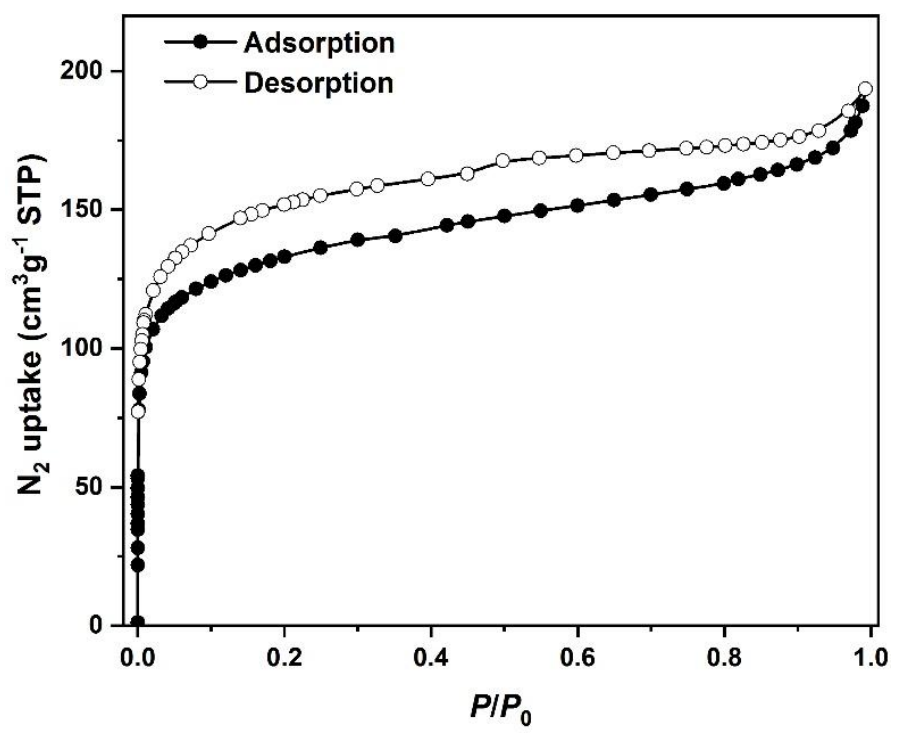

Figure S26. $\mathrm{N}_{2}$ adsorption and desorption isotherms of LZU-508. 


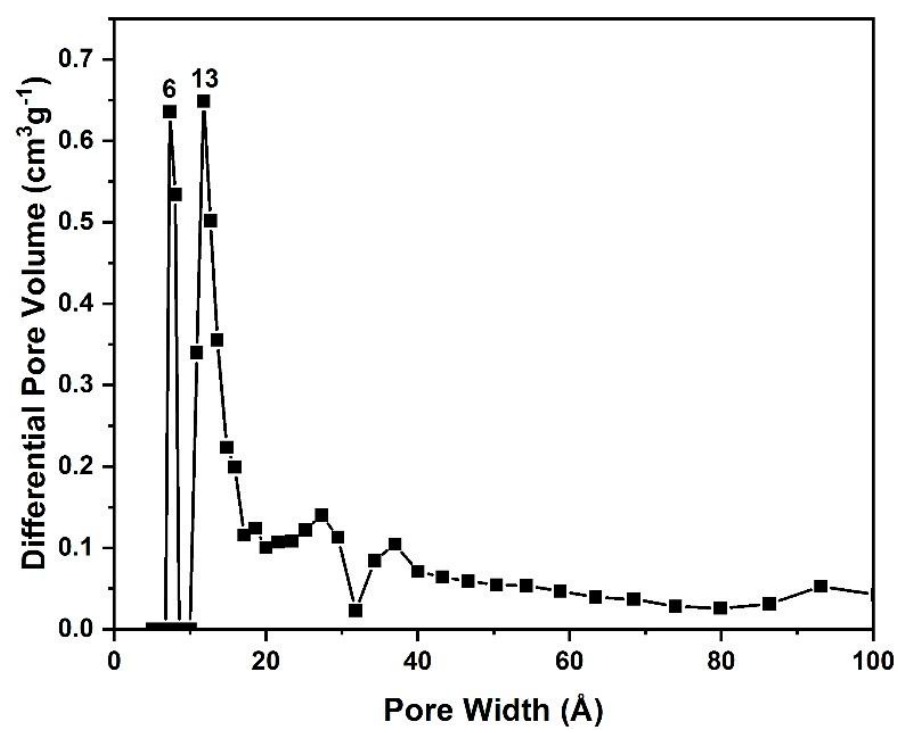

Figure S27. Pore size distribution of LZU-508 calculated by NLDFT (slit pores model). The deviation from the calculated pore size could be attributed to the presence of bulky $t$-Bu groups which makes it difficult for $\mathrm{N}_{2}$ to access the pores. ${ }^{4}$

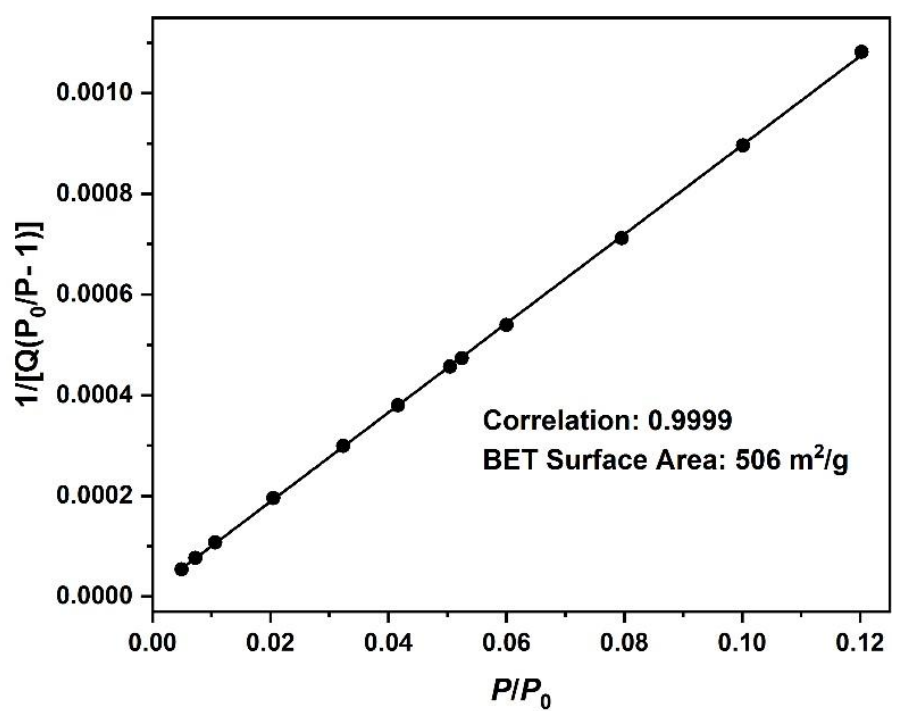

Figure S28. BET surface area plot for LZU-508 calculated from the adsorption isotherm. 


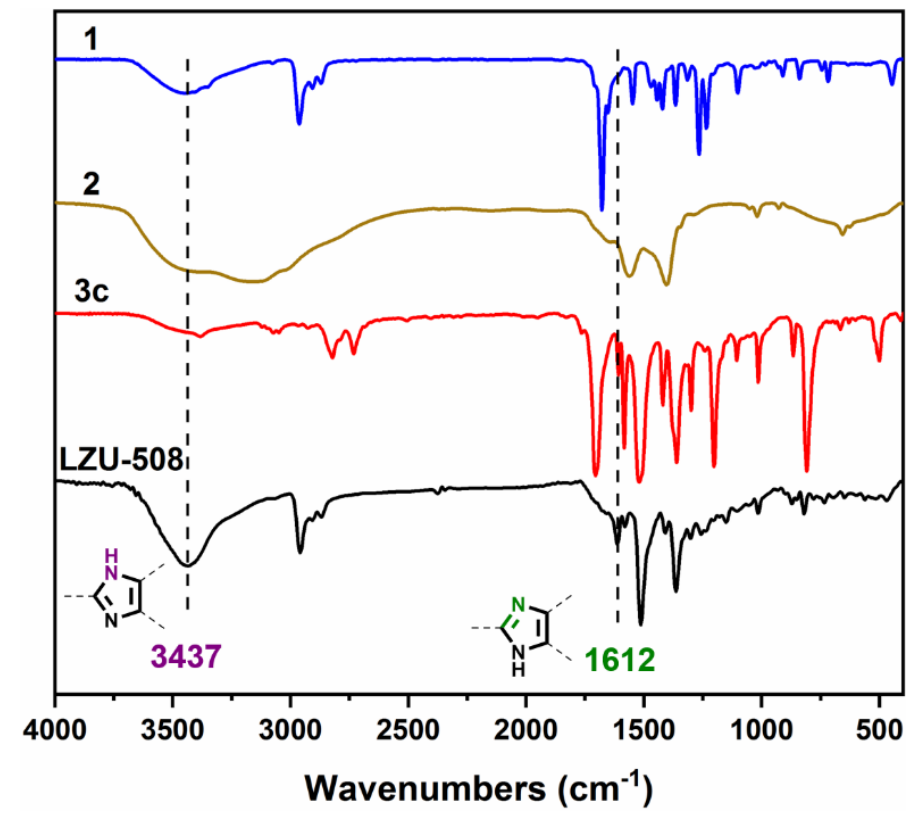

Figure S29. FT-IR spectra of monomer 1 (blue), monomer 2 (brown), monomer 3c (red), and LZU-508 (black). The FT-IR spectrum of LZU-508 (black) shows intense stretches at 3437 and $1612 \mathrm{~cm}^{-1}$, indicating the formation of the imidazole ring.

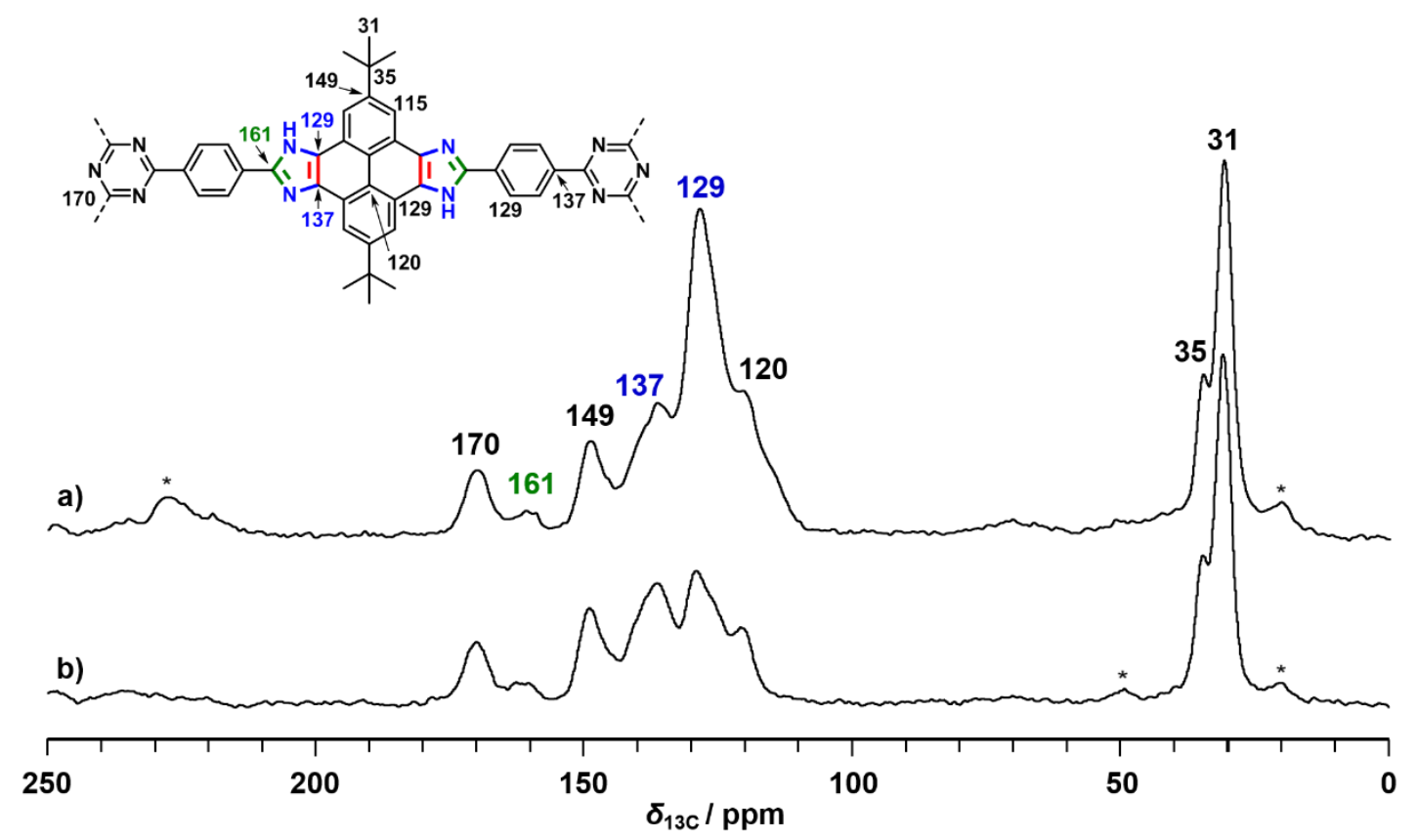

Figure S30. (a) ${ }^{13} \mathrm{C}$ CP/MAS NMR and (b) NQS MAS NMR spectra of LZU-508. The assignments of ${ }^{13} \mathrm{C}$ chemical shifts have been shown in the chemical structure. 


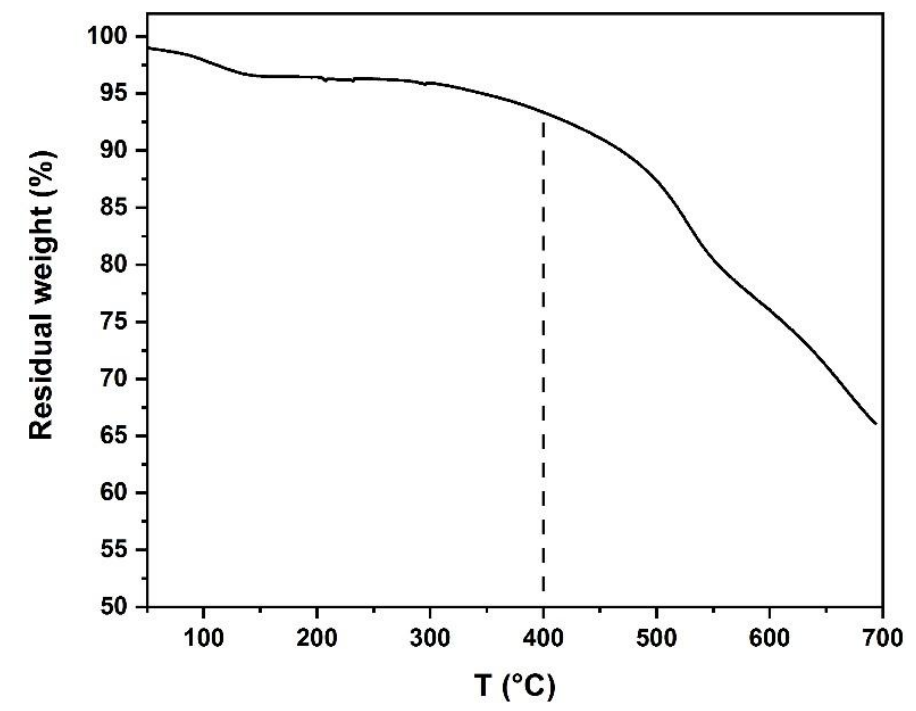

Figure S31. TGA data indicate that LZU-508 is thermally stable up to $400{ }^{\circ} \mathrm{C}$.
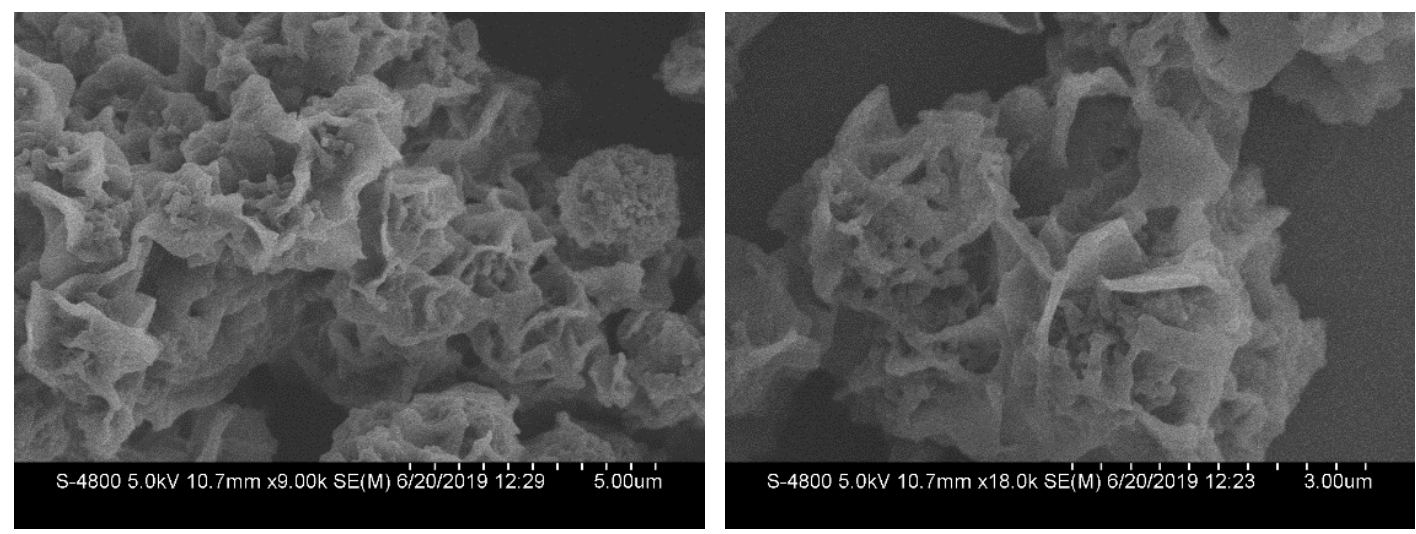

Figure S32. SEM images of LZU-508.

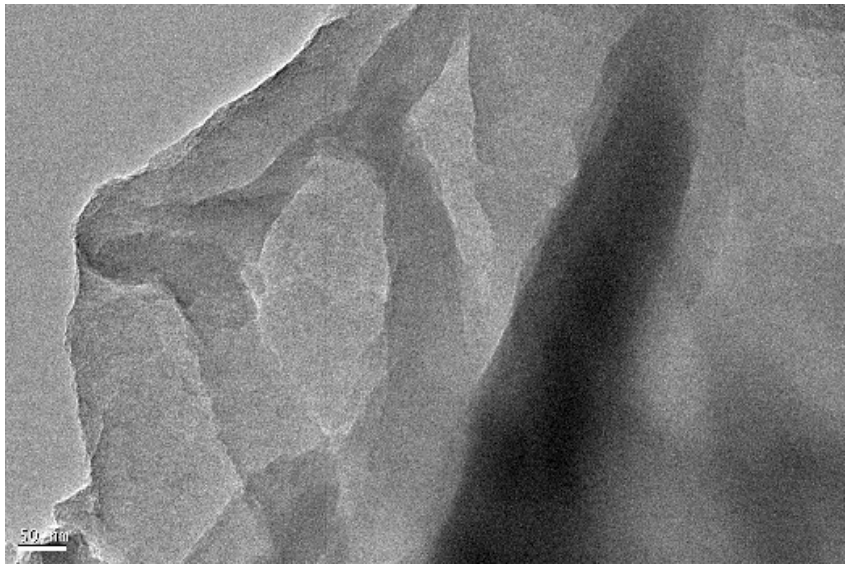

Figure S33. TEM image of LZU-508. 
The structural modeling of LZU-508 is similar to that of LZU-501. The Pawley refined lattice parameters were determined as: $a=b=30.385( \pm 0.469) \AA$ and $c=$ 5.585 ( \pm 0.086$) \AA$. $R \mathrm{wp}$ and $R \mathrm{p}$ values converged to $5.89 \%$ and $4.17 \%$, respectively. Comparison of the observed and the simulated PXRD patterns (Figure S34) suggested that the preferable structure of LZU-508 is the eclipsed arrangement.
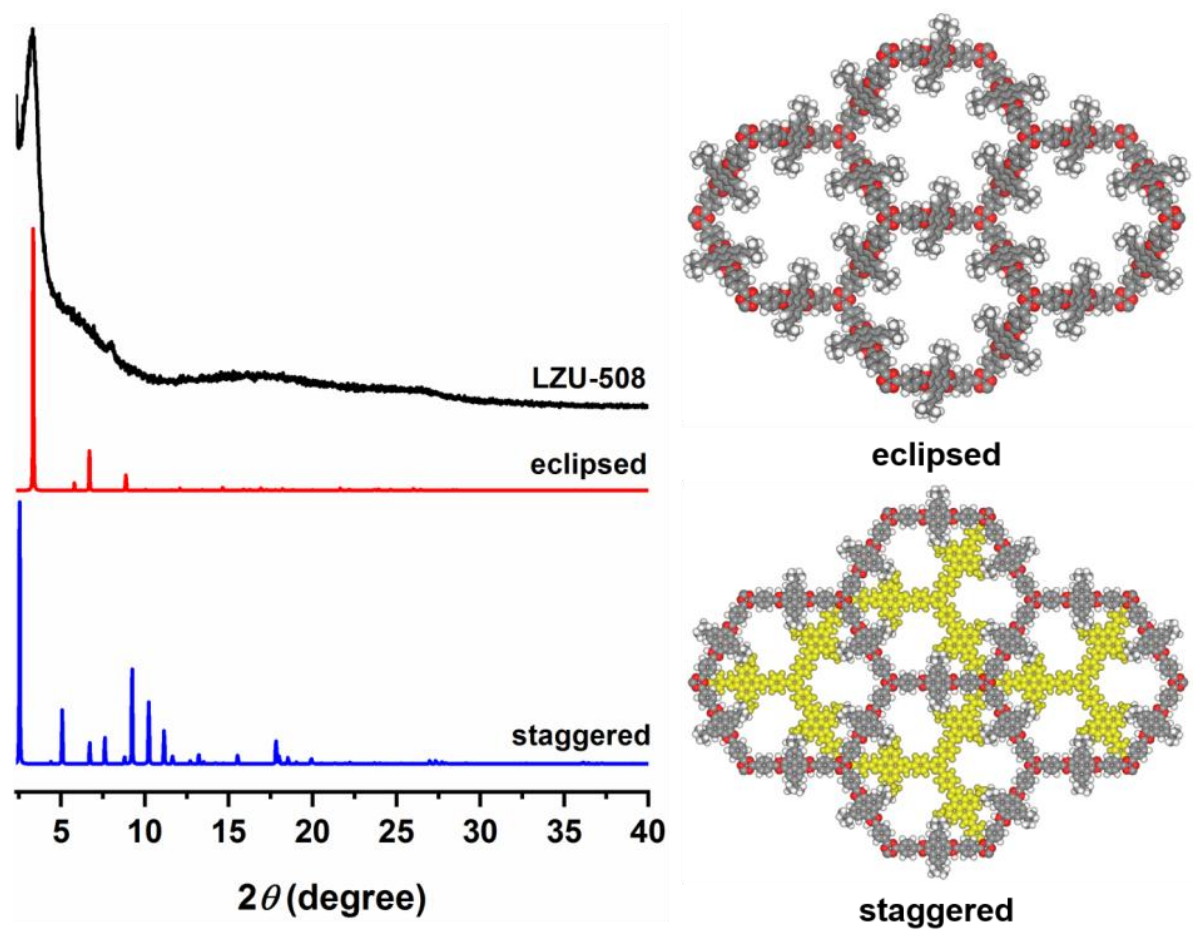

Figure S34. PXRD patterns of LZU-508: observed (black) and calculated with the eclipsed (red) or staggered (blue) stacking models. Comparison of the observed and the simulated PXRD patterns suggests that the preferable structure of LZU-508 is the eclipsed arrangement. 


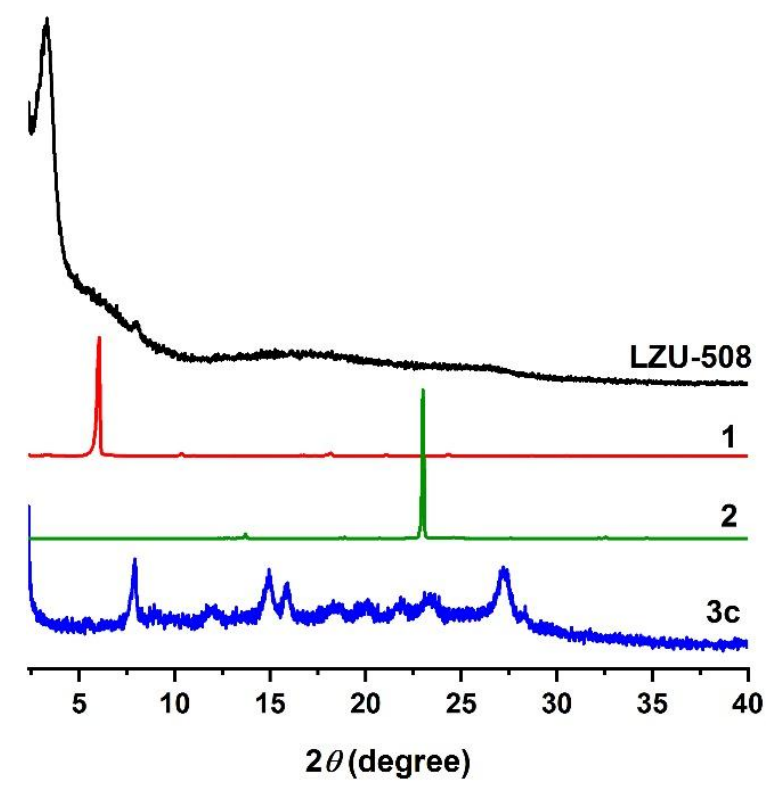

Figure S35. PXRD patterns of LZU-508 (black), monomer 1 (red), monomer 2 (green), and monomer 3c (blue). No diffraction peaks from monomer 1 (red), monomer 2 (green), and monomer 3c (blue) could be observed in the PXRD pattern of LZU-508 (black), indicating the sole formation of the crystalline LZU-508. 


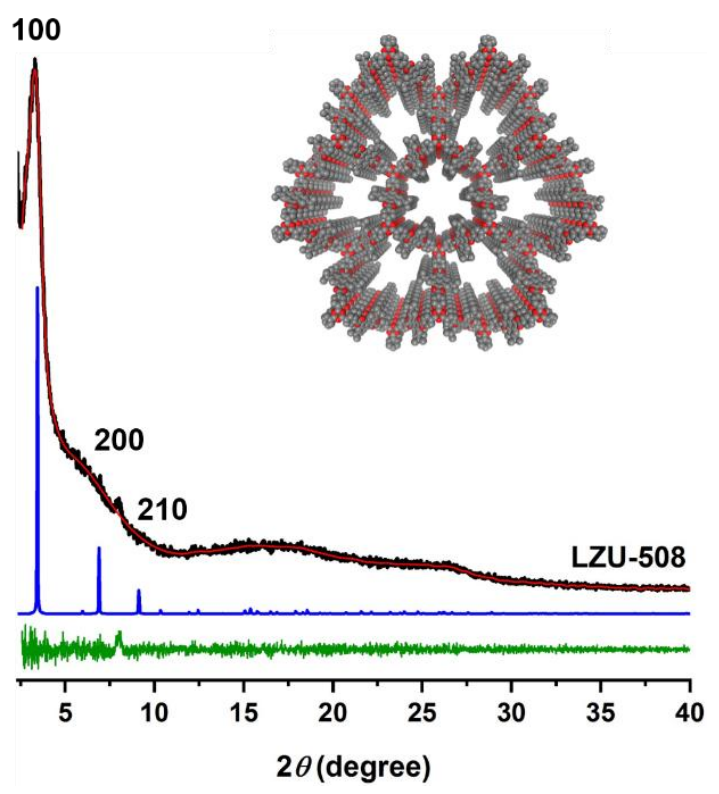

Figure S36. Indexed experimental (black), Pawley-refined (red), and predicted (blue) PXRD patterns of LZU-508. The difference plots are presented in green. Top inset: eclipsed structure proposed for LZU-508.

Table S3. Fractional atomic coordinates for the unit cell of LZU-508.

\begin{tabular}{|c|c|c|c|c|c|c|c|}
\hline \multicolumn{8}{|c|}{$\begin{array}{c}\text { Space group: } P 3 \\
a=b=29.575 \AA, c=5.760 \AA, \alpha=\beta=90^{\circ}, \gamma=120^{\circ}\end{array}$} \\
\hline Atom & $\mathbf{X}(\AA)$ & $\mathbf{Y}(\AA)$ & $\mathbf{Z}(\AA)$ & Atom & $\mathbf{X}(\AA)$ & $\mathbf{Y}(\AA)$ & $\mathbf{Z}(\AA)$ \\
\hline $\mathrm{C} 1$ & 1.32867 & 0.27358 & 0.7655 & $\mathrm{C} 41$ & 1.54524 & 0.3228 & -0.40336 \\
\hline $\mathrm{C} 2$ & 1.30699 & 0.22065 & 0.72108 & $\mathrm{C} 42$ & 1.50083 & 0.30073 & -0.27478 \\
\hline C3 & 1.32636 & 0.20557 & 0.52664 & H43 & 1.3135 & 0.28419 & 0.91934 \\
\hline $\mathrm{C} 4$ & 1.36594 & 0.2436 & 0.38818 & $\mathrm{H} 44$ & 1.41799 & 0.32367 & 0.3366 \\
\hline $\mathrm{C} 5$ & 1.38598 & 0.29537 & 0.44338 & $\mathrm{H} 45$ & 1.21525 & 0.03689 & 0.66146 \\
\hline C6 & 1.36768 & 0.31115 & 0.63216 & H46 & 1.325 & 0.07392 & 0.1066 \\
\hline $\mathrm{C} 7$ & 1.26828 & 0.18188 & 0.8568 & $\mathrm{H} 47$ & 1.35422 & 0.35716 & 1.04677 \\
\hline $\mathrm{C} 8$ & 1.25071 & 0.13278 & 0.79613 & $\mathrm{H} 48$ & 1.3201 & 0.36426 & 0.80472 \\
\hline $\mathrm{C} 9$ & 1.26826 & 0.11629 & 0.6099 & H49 & 1.37592 & 0.41765 & 0.91726 \\
\hline $\mathrm{C} 10$ & 1.30831 & 0.15422 & 0.47472 & $\mathrm{H} 50$ & 1.46961 & 0.38317 & 0.67197 \\
\hline $\mathrm{C} 11$ & 1.32932 & 0.13877 & 0.28957 & H51 & 1.44185 & 0.36317 & 0.96116 \\
\hline $\mathrm{C} 12$ & 1.36896 & 0.17753 & 0.15853 & H52 & 1.46158 & 0.4257 & 0.85996 \\
\hline $\mathrm{C} 13$ & 1.38479 & 0.22687 & 0.20781 & H53 & 1.35791 & 0.38742 & 0.39585 \\
\hline $\mathrm{C} 14$ & 1.24777 & 0.06452 & 0.55579 & H54 & 1.41912 & 0.39605 & 0.32907 \\
\hline $\mathrm{C} 15$ & 1.2674 & 0.04836 & 0.37514 & H55 & 1.41321 & 0.43961 & 0.51756 \\
\hline
\end{tabular}




\begin{tabular}{|l|c|c|c||c|c|c|c|}
\hline C16 & 1.30839 & 0.08566 & 0.25028 & H56 & 1.32132 & -0.00145 & 0.30518 \\
\hline C17 & 1.39113 & 0.36765 & 0.69501 & H57 & 1.27036 & -0.06388 & 0.35652 \\
\hline C18 & 1.35836 & 0.37688 & 0.87596 & H58 & 1.29145 & -0.01829 & 0.59102 \\
\hline C19 & 1.44387 & 0.38578 & 0.80283 & H59 & 1.17888 & -0.08193 & 0.37053 \\
\hline C20 & 1.39563 & 0.39907 & 0.47092 & H60 & 1.16621 & -0.03101 & 0.37652 \\
\hline C21 & 1.24618 & -0.0078 & 0.3143 & H61 & 1.19521 & -0.04272 & 0.62657 \\
\hline C22 & 1.2845 & -0.02353 & 0.39649 & H62 & 1.2718 & 0.00654 & -0.06467 \\
\hline C23 & 1.19396 & -0.04239 & 0.42986 & H63 & 1.20951 & -0.00413 & -0.01351 \\
\hline C24 & 1.23724 & -0.01529 & 0.04284 & H64 & 1.22161 & -0.05557 & -0.00435 \\
\hline N25 & 1.2407 & 0.18009 & 1.05264 & H65 & 1.24553 & 0.20923 & 1.15256 \\
\hline C26 & 1.20802 & 0.13159 & 1.1039 & H66 & 1.39581 & 0.14865 & -0.11159 \\
\hline N27 & 1.21258 & 0.10025 & 0.94772 & F67 & 1.1887 & 0.18844 & 1.47065 \\
\hline N28 & 1.39866 & 0.17846 & -0.02548 & C68 & 1.05344 & 0.03158 & 1.80458 \\
\hline C29 & 1.4308 & 0.22668 & -0.08346 & H69 & 1.14774 & 0.033 & 1.15058 \\
\hline N30 & 1.42386 & 0.25883 & 0.05688 & H70 & 1.46471 & 0.1751 & -0.37141 \\
\hline C31 & 1.47093 & 0.24703 & -0.24938 & C71 & 1.61742 & 0.31349 & -0.5253 \\
\hline C32 & 1.17171 & 0.10925 & 1.28471 & H72 & 1.48932 & 0.32499 & -0.17974 \\
\hline C33 & 1.16248 & 0.13752 & 1.46713 & H73 & 1.11974 & 0.13308 & 1.77727 \\
\hline C34 & 1.12669 & 0.1114 & 1.63972 & H74 & 1.08327 & -0.01081 & 1.44921 \\
\hline C35 & 1.09719 & 0.05771 & 1.64692 & H75 & 1.56903 & 0.3644 & -0.4001 \\
\hline C36 & 1.10671 & 0.03068 & 1.46268 & H76 & 1.54765 & 0.21445 & -0.56342 \\
\hline C37 & 1.14219 & 0.05554 & 1.28919 & C77 & 1.02113 & 0.05213 & 1.83893 \\
\hline C38 & 1.48703 & 0.21667 & -0.38172 & N78 & 1.63572 & 0.28153 & -0.52563 \\
\hline C39 & 1.53346 & 0.23871 & -0.49154 & H79 & 1.03728 & 0.09263 & 1.79601 \\
\hline C40 & 1.56524 & 0.29239 & -0.49173 & & & & \\
\hline
\end{tabular}


Synthesis of LZU-512
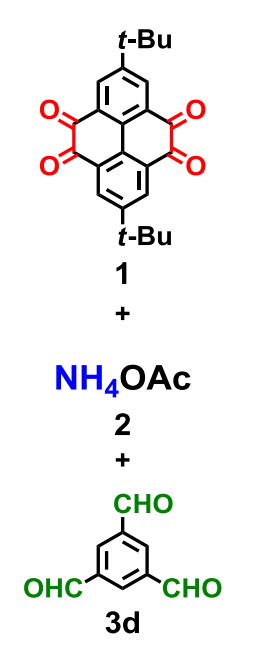

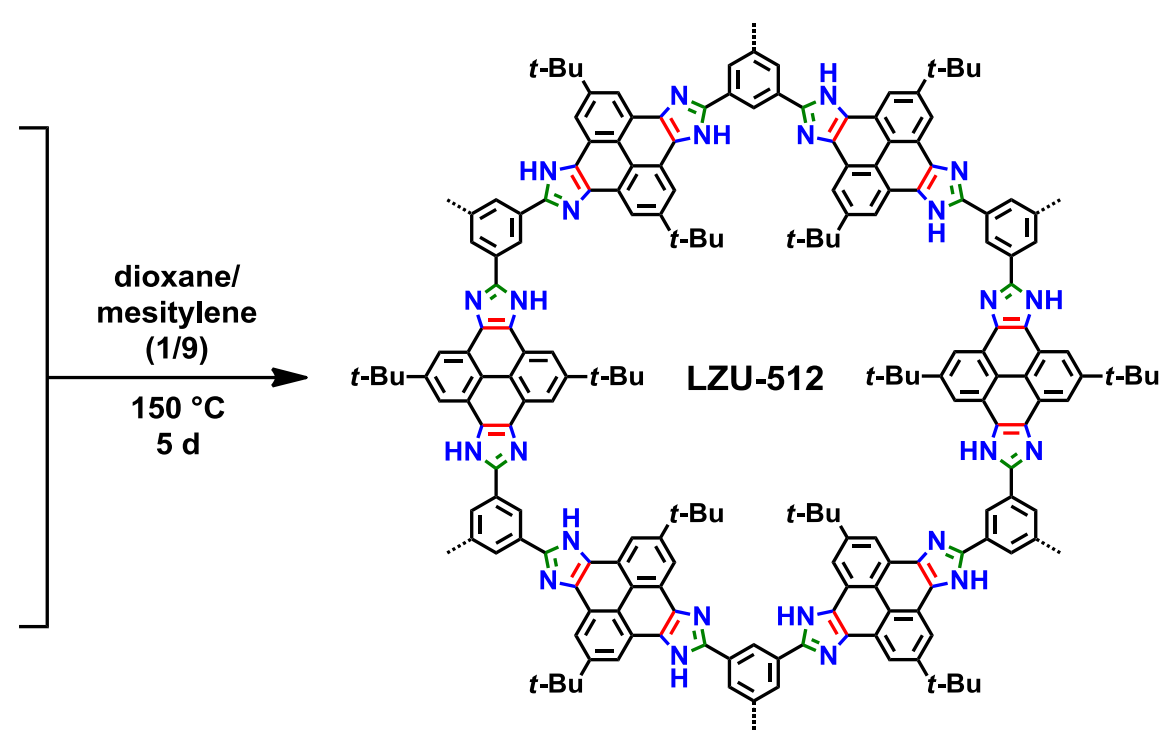

The synthetic conditions of LZU-512 were similar to that of LZU-501. Condensation of tertbutylpyrene tetraone 1 (18 $\mathrm{mg}, 0.048 \mathrm{mmol})$, ammonium acetate (22 mg, $0.288 \mathrm{mmol}) \mathbf{2}$, and 1,3,5-trisforylbenzene 3d (5 mg, $0.032 \mathrm{mmol}$ ) yielded LZU-512 as a yellow powder (20 mg, 94\% yield). Anal. Cald for $\left(\mathrm{C}_{15} \mathrm{H}_{13} \mathrm{~N}_{2}\right)_{\mathrm{n}}$ : C 81.45; H 5.88; N 12.67, found: C 76.95; H 5.93; N 7.28. The deviations from the calculated values are attributed to the incomplete combustion of the material (Figure S43) and the presence of the terminal groups. ${ }^{3}$ Characterization of LZU-512 has been presented in the main text and in this SI. 


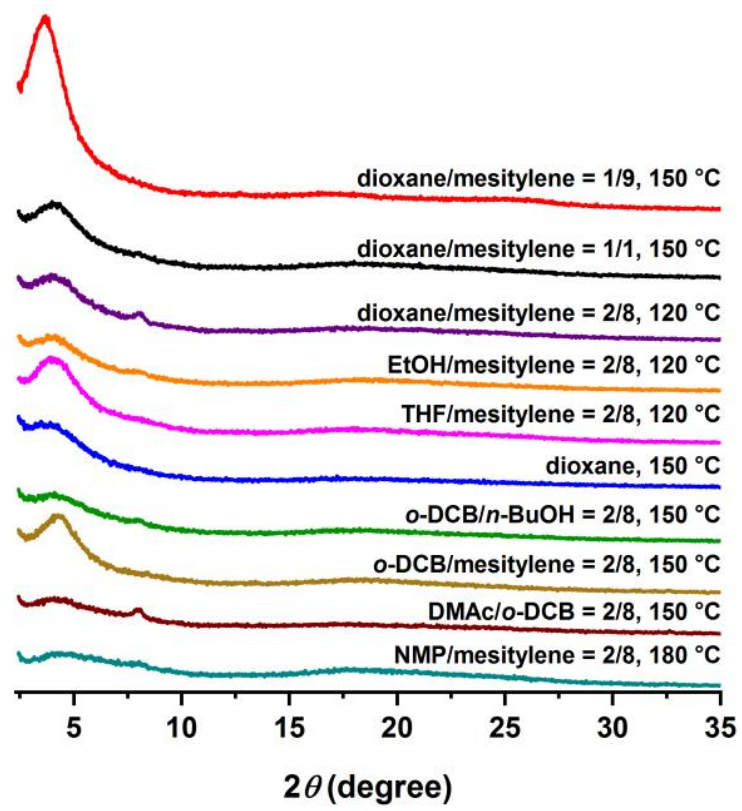

Figure S37. PXRD patterns of LZU-512 synthesized with indicated conditions. The optimized condition is using the mixed solvents of dioxane and mesitylene $\left(\mathrm{V}_{\text {dioxane }} / \mathrm{V}_{\text {mesitylene }}=1 / 9\right)$ at $150^{\circ} \mathrm{C}$.

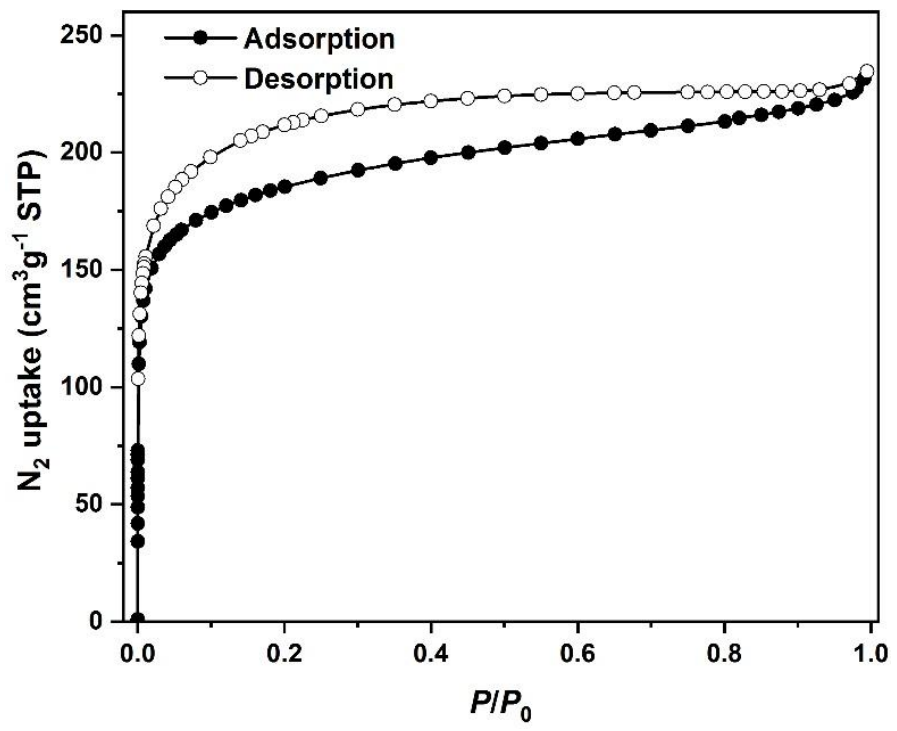

Figure S38. $\mathrm{N}_{2}$ adsorption and desorption isotherms of LZU-512. 


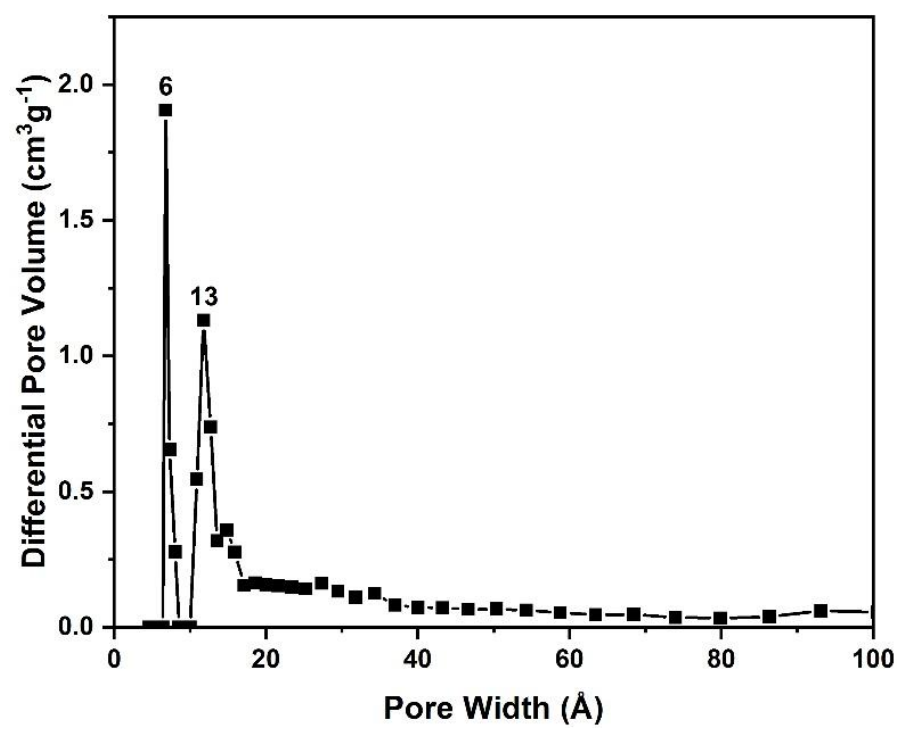

Figure S39. Pore size distribution of LZU-512 calculated by NLDFT (slit pores model). The deviation from the calculated pore size could be attributed to the presence of bulky $t$-Bu groups which makes it difficult for $\mathrm{N}_{2}$ to access the pores. ${ }^{4}$

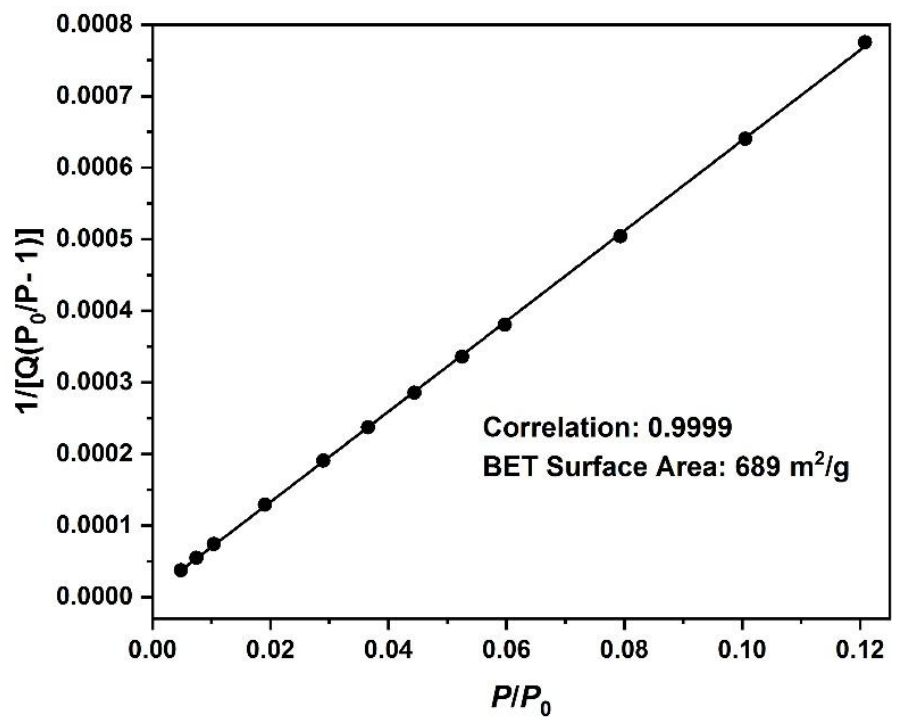

Figure S40. BET surface area plot for LZU-512 calculated from the adsorption isotherm. 


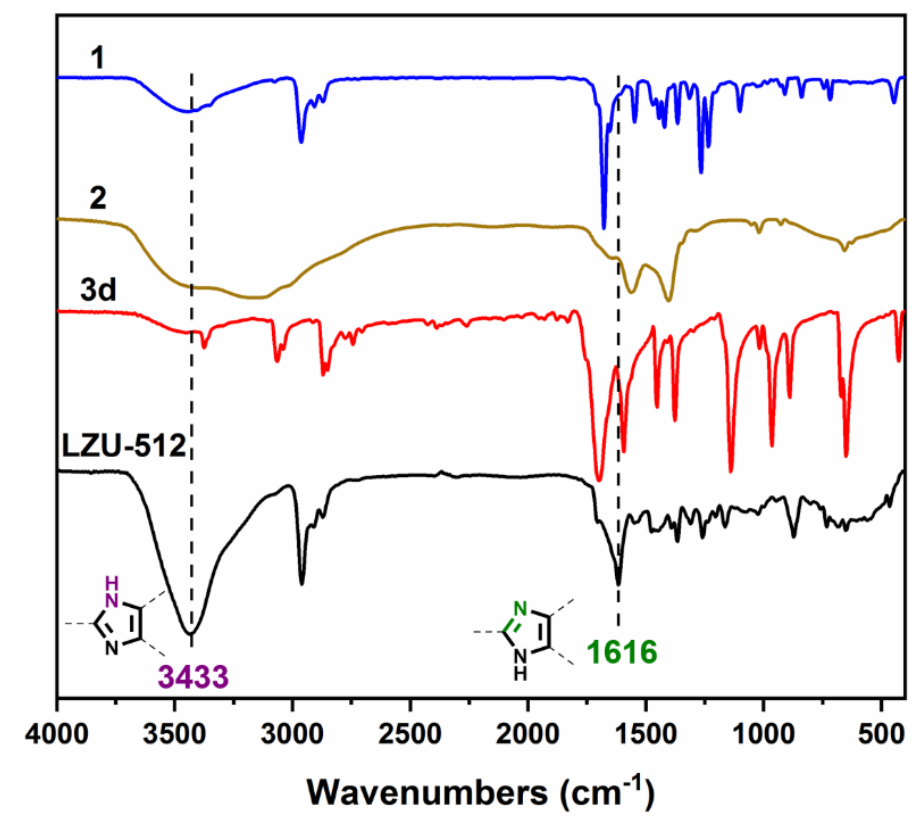

Figure S41. FT-IR spectra of monomer 1 (blue), monomer 2 (brown), monomer 3d (red), and LZU-512 (black). The FT-IR spectrum of LZU-512 (black) shows intense stretches at 3433 and $1616 \mathrm{~cm}^{-1}$, indicating the formation of the imidazole ring.

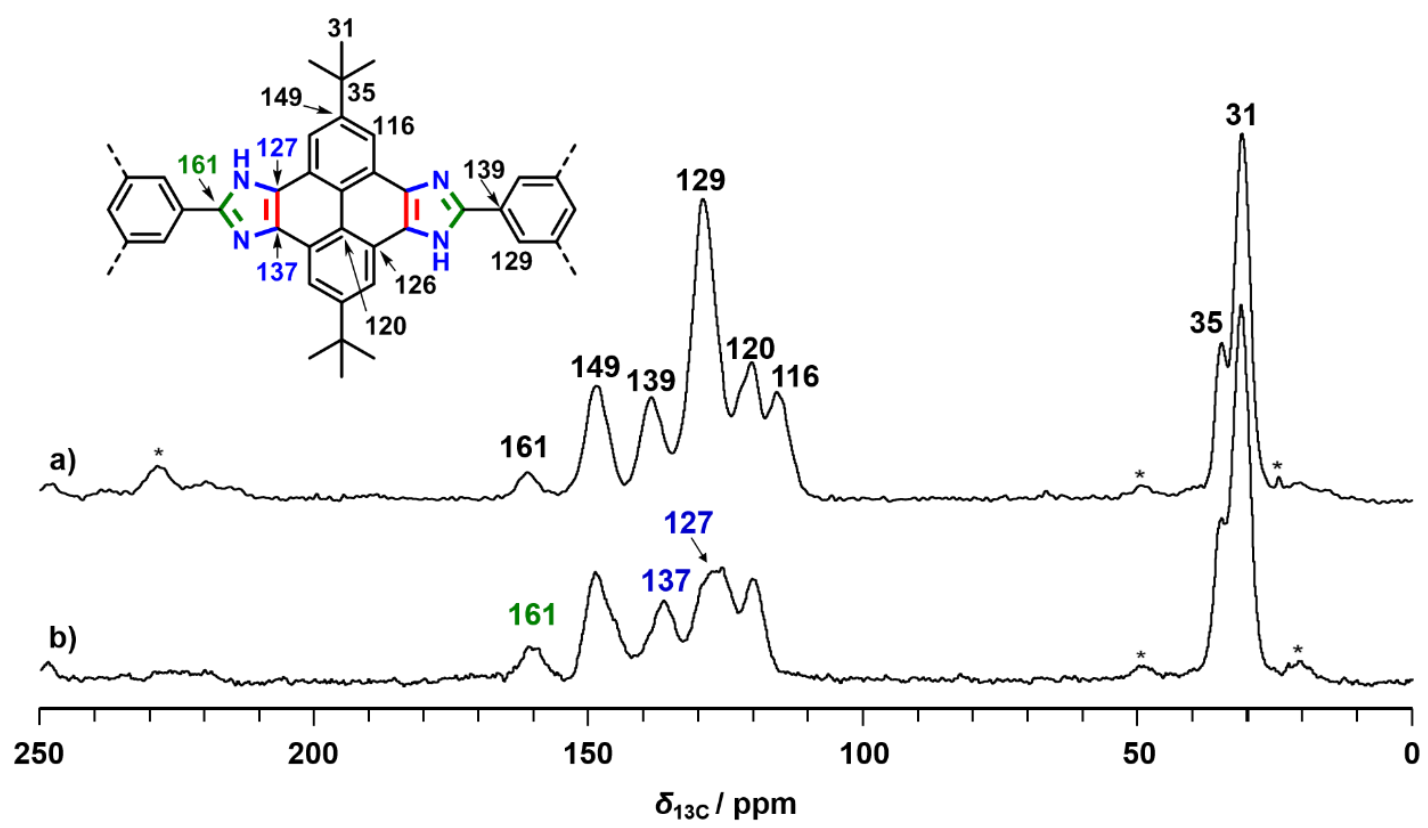

Figure S42. (a) ${ }^{13} \mathrm{C}$ CP/MAS NMR and (b) NQS MAS NMR spectra of LZU-512. The assignments of ${ }^{13} \mathrm{C}$ chemical shifts have been shown in the chemical structure. 


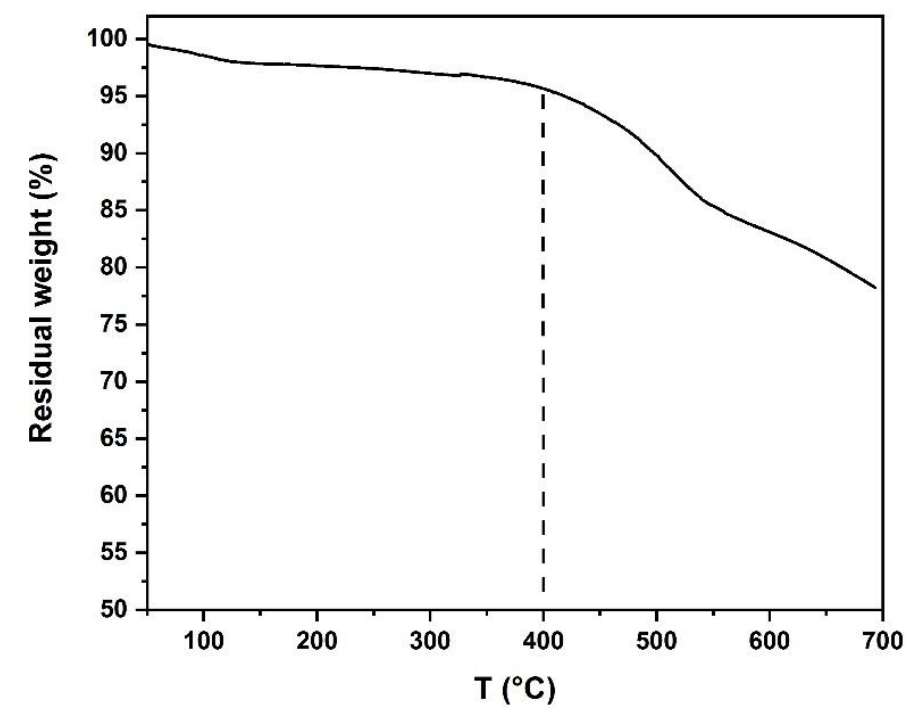

Figure S43. TGA data indicate that LZU-512 is thermally stable up to $400{ }^{\circ} \mathrm{C}$.
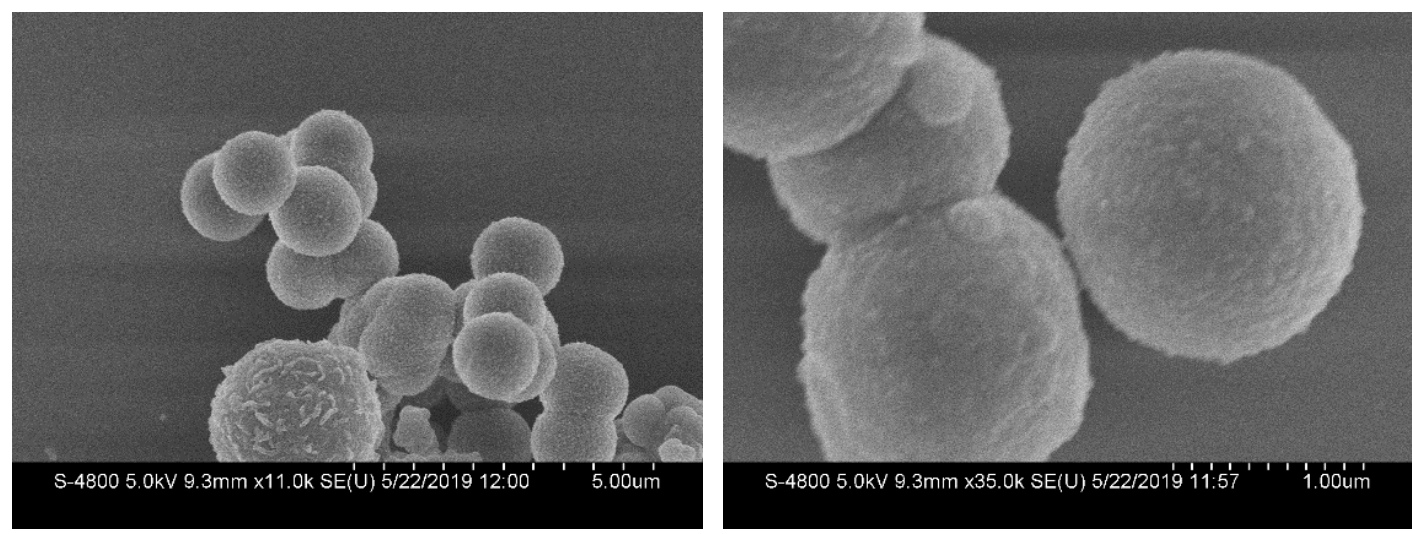

Figure S44. SEM images of LZU-512.

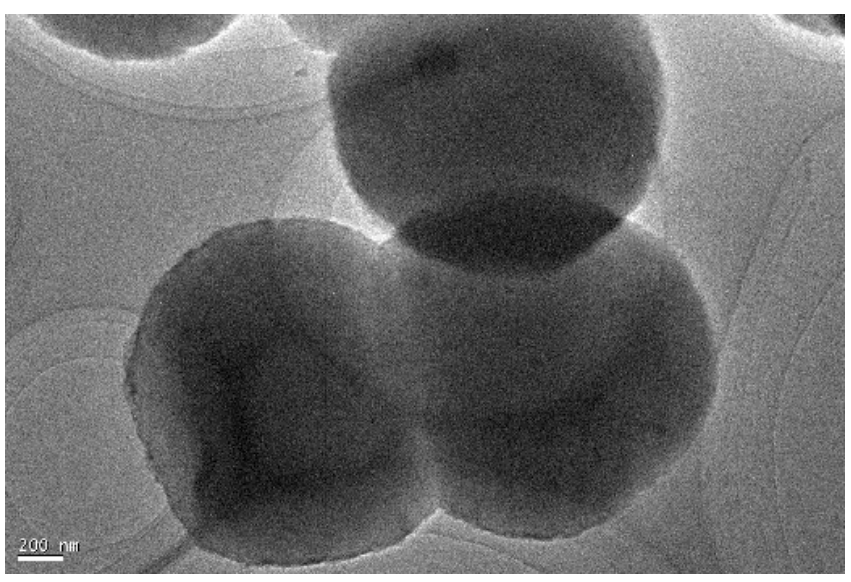

Figure S45. TEM image of LZU-512. 
The structural modeling of LZU-512 is similar to that of LZU-501. The Pawley refined lattice parameters were determined as: $a=b=27.772( \pm 0.428) \AA$ and $c=$ 3.721 ( \pm 0.059$) \AA$. $R \mathrm{wp}$ and $R \mathrm{p}$ values converged to $5.16 \%$ and $3.45 \%$, respectively. Comparison of the observed and the simulated PXRD patterns (Figure S46) suggests that the preferable structure of LZU-512 is the eclipsed arrangement.
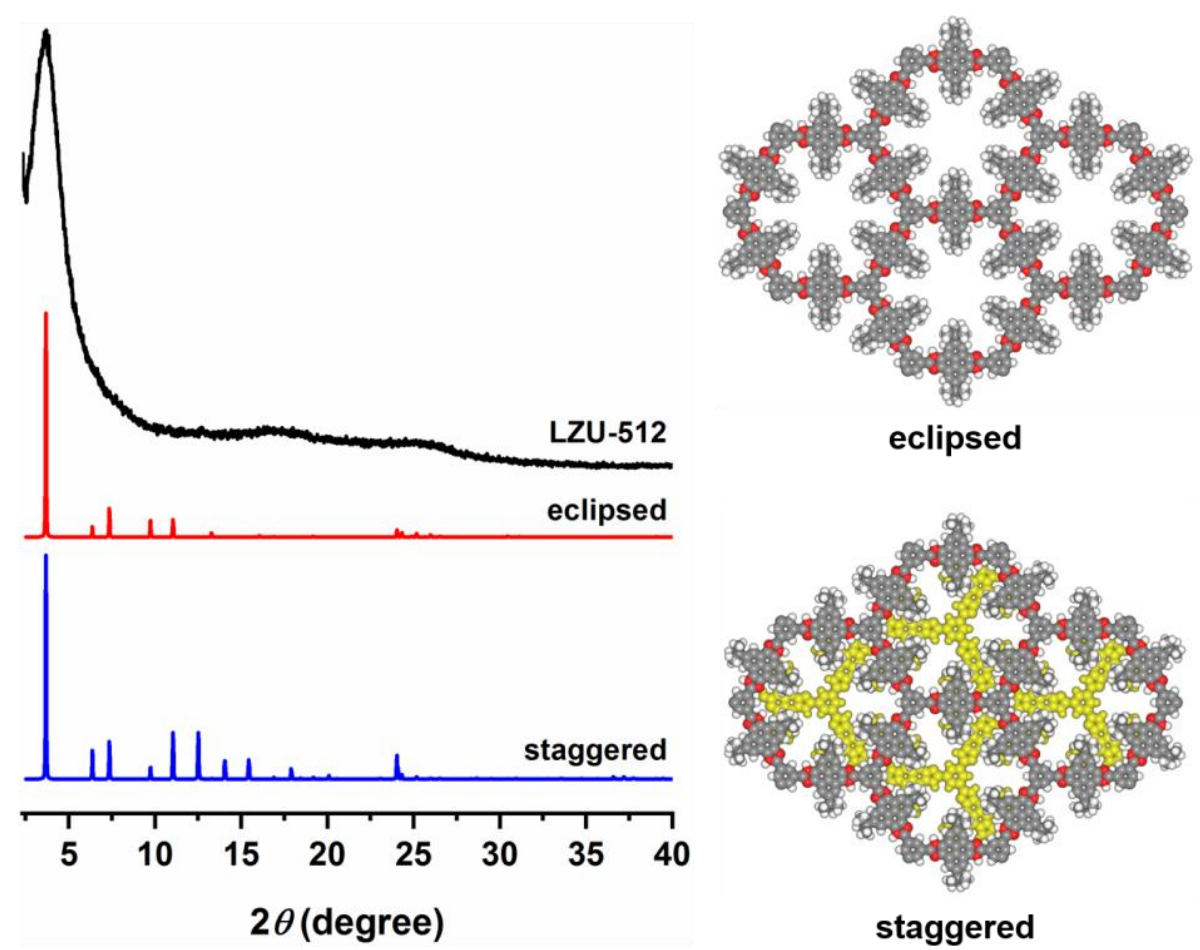

Figure S46. PXRD patterns of LZU-512: observed (black) and calculated with the eclipsed (red) or staggered (blue) stacking models. Comparison of the observed and the simulated PXRD patterns suggests that the preferable structure of LZU-512 is the eclipsed arrangement. 


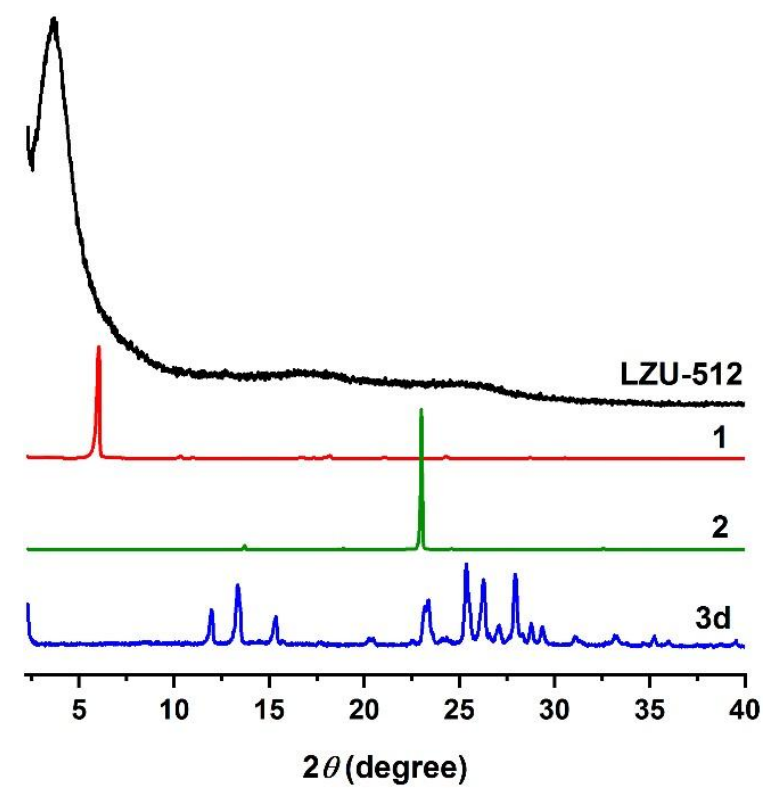

Figure S47. PXRD patterns of LZU-512 (black), monomer 1 (red), monomer 3d (blue), and monomer 2 (green). No diffraction peaks from monomer 1 (red), monomer 3d (blue), and monomer 2 (green) could be observed in the PXRD pattern of LZU-512 (black), indicating the sole formation of the crystalline LZU-512.

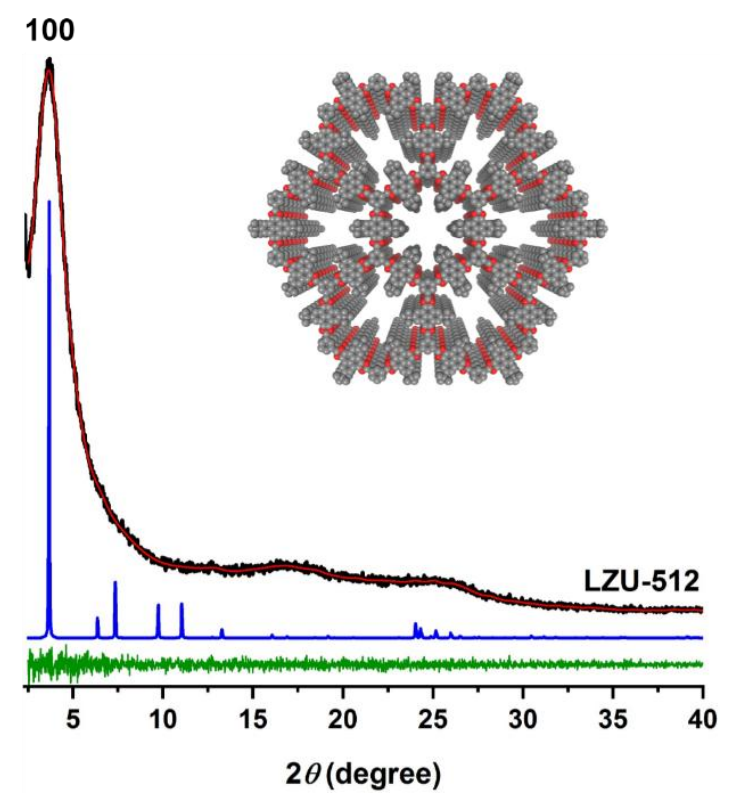

Figure S48. Indexed experimental (black), Pawley-refined (red), and predicted (blue) PXRD patterns of LZU-512. The difference plots are presented in green. Top inset: eclipsed structure proposed for LZU-512. 
Table S4. Fractional atomic coordinates for the unit cell of LZU-512.

\begin{tabular}{|c|c|c|c|c|c|c|c|}
\hline \multicolumn{8}{|c|}{$\begin{array}{c}\text { Space group: } P 3 \\
a=b=27.745 \AA \text { 的 } c=3.700 \AA, \alpha=\beta=90^{\circ}, \gamma=120^{\circ}\end{array}$} \\
\hline Atom & $\mathbf{X}(\AA)$ & $\mathbf{Y}(\AA)$ & $\mathbf{Z}(\AA)$ & Atom & $\mathbf{X}(\AA)$ & $\mathbf{Y}(\AA)$ & $\mathbf{Z}(\AA)$ \\
\hline $\mathrm{C} 1$ & 2.28274 & & 0.40514 & & 2.60243 & 0.30112 & 0.37749 \\
\hline $\mathrm{C} 2$ & & & & & & & \\
\hline $\mathrm{C} 3$ & 2.33342 & & 0.36952 & & & 0.05982 & \\
\hline $\mathrm{C} 4$ & 2.38678 & 0.24403 & 0.38264 & & 2.63685 & 0.27352 & 0.37748 \\
\hline $\mathrm{C} 5$ & 2.38467 & 293 & 0.42438 & & .24231 & 0.23871 & 1908 \\
\hline C6 & 2.33378 & 594 & 4376 & & 2.42523 & 2931 & 0.45076 \\
\hline $\mathrm{C} 7$ & 2.22638 & & 37046 & & 2.24143 & 403 & \\
\hline $\mathrm{C} 8$ & 2.22621 & & & & & & \\
\hline C9 & & & & & & & \\
\hline $\mathrm{C} 10$ & & & & & & & \\
\hline $\mathrm{C} 11$ & 2.38643 & 0.14222 & 3752 & & 25782 & 5028 & 0.90874 \\
\hline $\mathrm{C} 12$ & 2.44029 & 0.19537 & 0.37046 & & 2.42418 & 0044 & 0.60332 \\
\hline $\mathrm{C} 13$ & 2.44046 & 0.24455 & 7533 & & 011 & 5794 & 0.97 \\
\hline $\mathrm{C} 14$ & 2.28199 & 0.04034 & 2438 & $\mathrm{H} 44$ & 2.40237 & 2254 & 0.93 \\
\hline $\mathrm{C} 15$ & & & & & & & \\
\hline & & & & & & & \\
\hline $\mathrm{C} 17$ & 2.33331 & 0.35078 & 598 & & 2.42363 & 0.02145 & \\
\hline $\mathrm{C} 18$ & 2.27333 & 0.32533 & 7732 & $\mathrm{H} 48$ & 2.40885 & -0.01695 & 0.90 \\
\hline $\mathrm{C} 19$ & 2.39024 & 0.38273 & 0.80698 & H49 & 2.4053 & 0.0445 & 0.93687 \\
\hline $\mathrm{C} 20$ & 2.33702 & 0.40515 & 0.41774 & $\mathrm{H} 50$ & 2.2643 & -0.0892 & 0.93843 \\
\hline $\mathrm{C} 21$ & 2.33335 & -0.01745 & & & 2.24248 & -0.06711 & 0.60332 \\
\hline $\mathrm{C} 22$ & 2.39333 & 0.00801 & 0.77321 & & 2.26556 & -0.02461 & 0.97061 \\
\hline $\mathrm{C} 23$ & 2.27643 & -0.0494 & 0.80698 & & 2.3418 & -0.07239 & 0.14857 \\
\hline $\mathrm{C} 24$ & 2.32964 & -0.07182 & 0.41774 & & 2.28818 & -0.11055 & 0.42334 \\
\hline N25 & 2.17057 & 0.12545 & 0.37261 & H55 & 2.15733 & 0.15463 & 0.37106 \\
\hline $\mathrm{C} 26$ & 2.13509 & 0.06763 & 0.37681 & H56 & 2.50934 & 0.1787 & 0.37106 \\
\hline $\mathrm{N} 27$ & 2.17045 & 0.04505 & 0.38043 & & 2.05216 & 0.10481 & 0.37731 \\
\hline N28 & 2.4961 & 0.20788 & 0.37261 & & 2.6145 & 0.22852 & 0.37731 \\
\hline $\mathrm{C} 29$ & 2.53157 & 0.2657 & 0.37681 & H59 & 0.3127 & 0.42062 & 1.56709 \\
\hline N30 & 2.49622 & 0.28828 & 0.38043 & H60 & 0.55876 & 0.64604 & 1.56709 \\
\hline
\end{tabular}


H. Stability Tests of LZU-501 and LZU-506

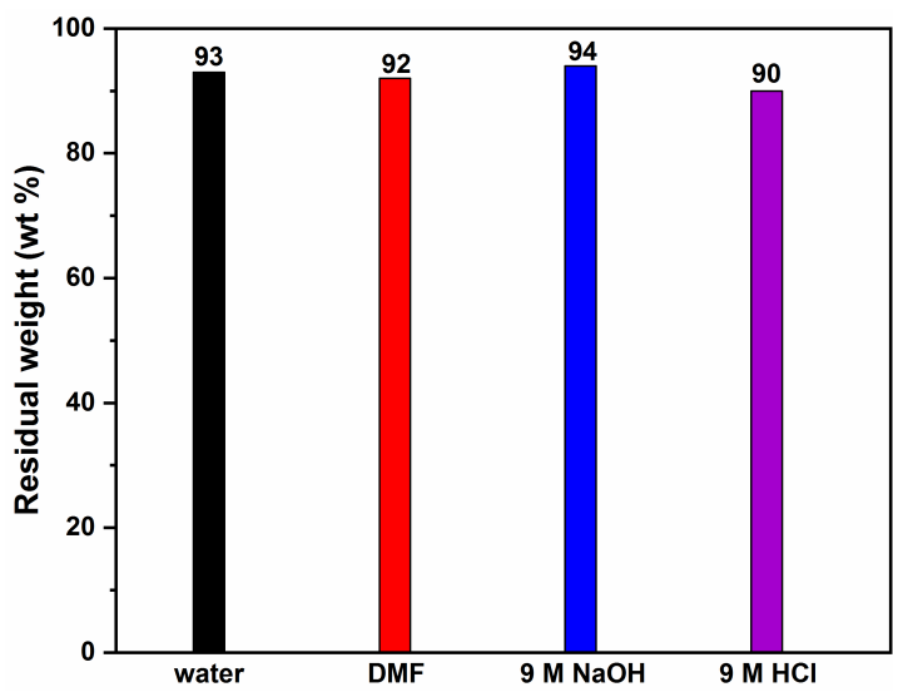

Figure S49. Residue weight percentages of LZU-501 after treatment with water, DMF, $9 \mathrm{M} \mathrm{NaOH}$, and $9 \mathrm{M} \mathrm{HCl}$. The almost unchanged weights indicate that LZU-501 is stable in these conditions. 

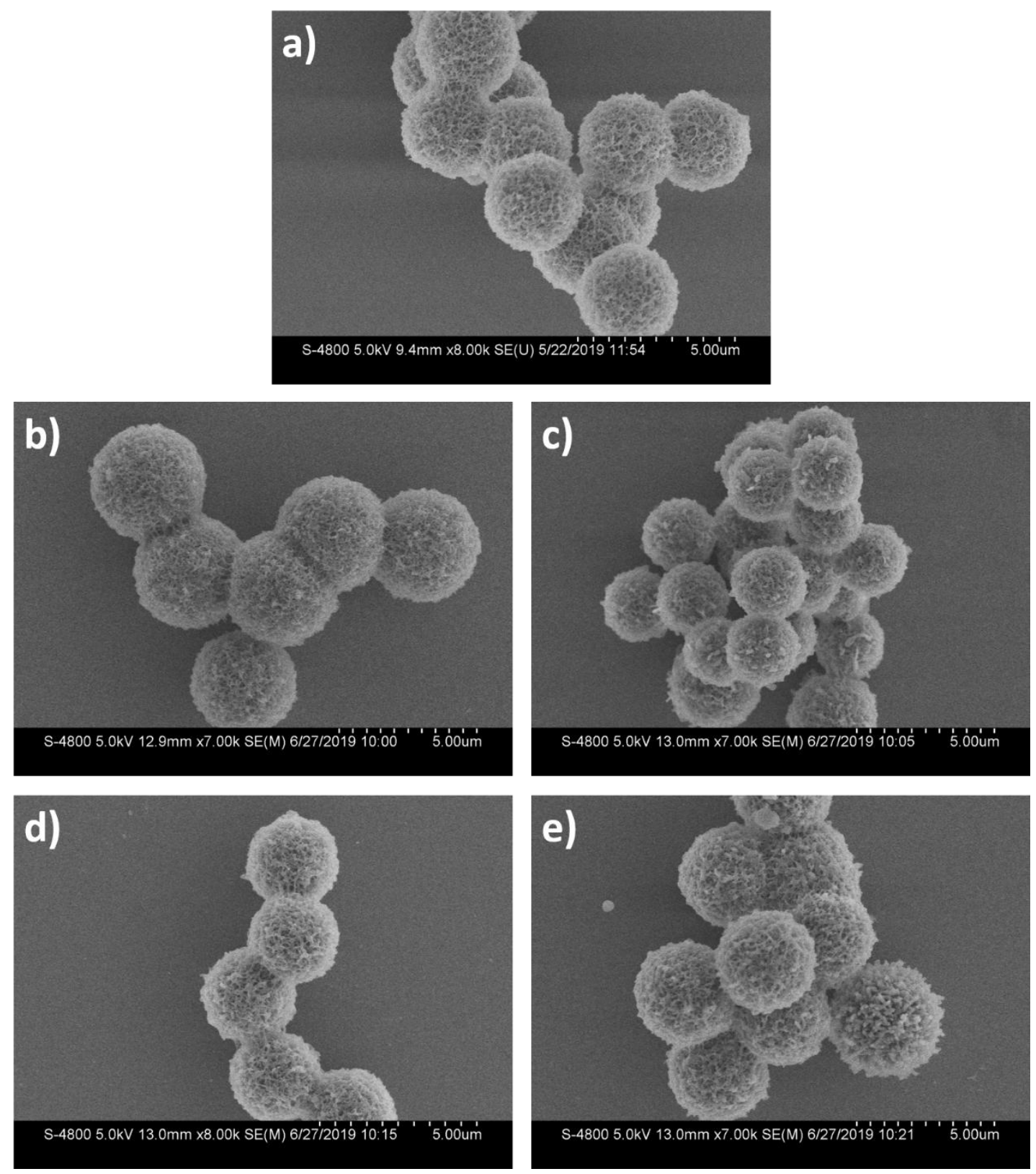

Figure S50. SEM images of LZU-501 before (a) and after treatment with $9 \mathrm{M} \mathrm{HCl}$ (b), $9 \mathrm{M} \mathrm{NaOH}(\mathrm{c}), \mathrm{DMF}$ (d), and water (e). The almost unchanged morphologies indicate that LZU-501 is stable in these conditions. 


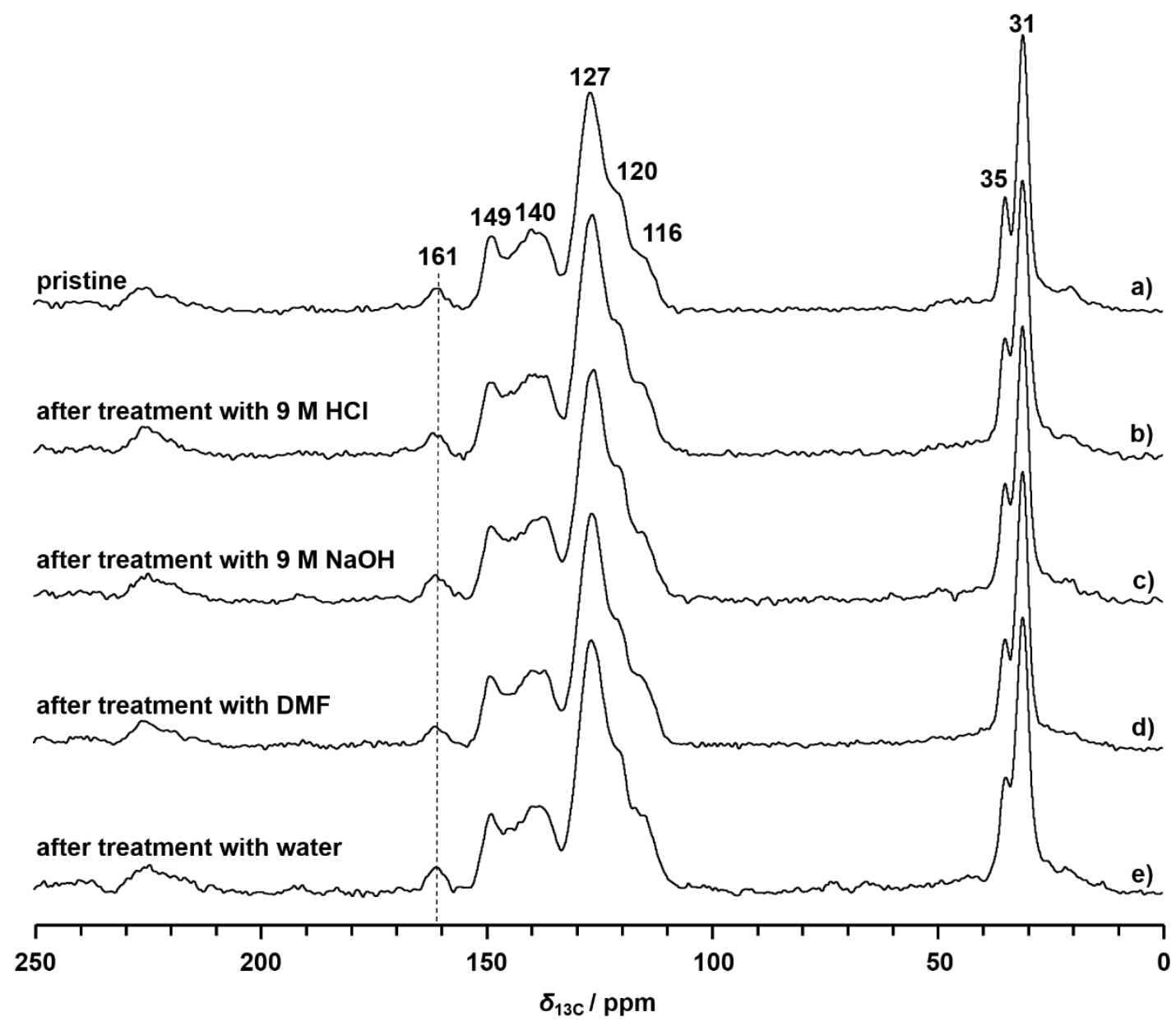

Figure S51. ${ }^{13} \mathrm{C}$ CP/MAS NMR spectra of LZU-501 before (a) and after treatment with $9 \mathrm{M} \mathrm{HCl}$ (b), $9 \mathrm{M} \mathrm{NaOH}$ (c), DMF (d), and water (e). The almost unchanged ${ }^{13} \mathrm{C}$ CP/MAS NMR spectra indicate that LZU-501 is stable in these conditions. 


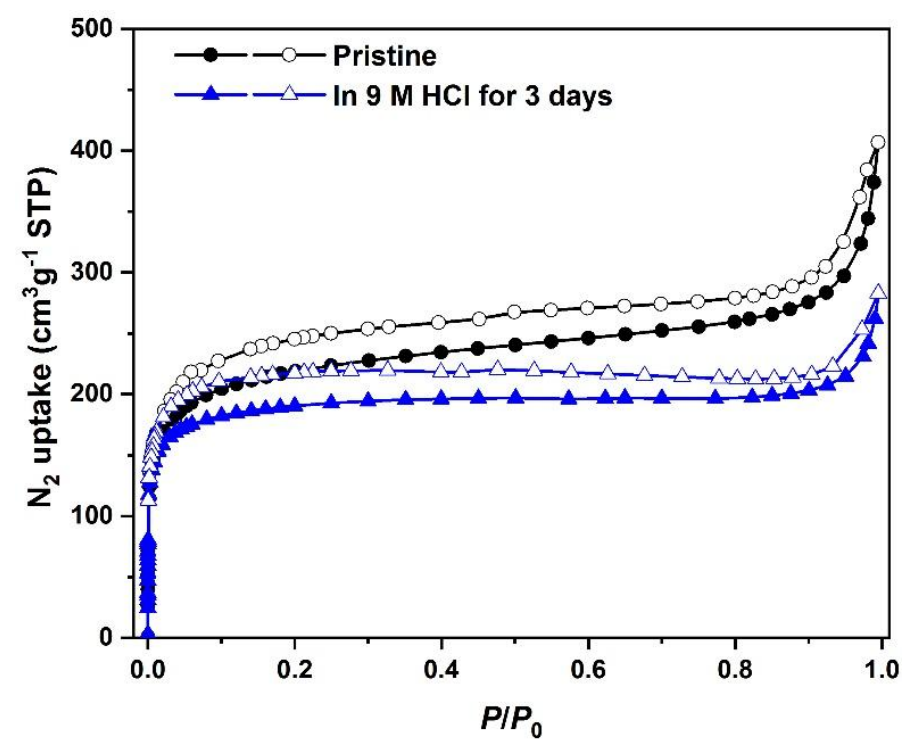

Figure S52. $\mathrm{N}_{2}$ adsorption (filled shapes) and desorption (open shapes) isotherms of LZU-501 before (black) and after treatment with $9 \mathrm{M} \mathrm{HCl}$ for 3 days (blue).

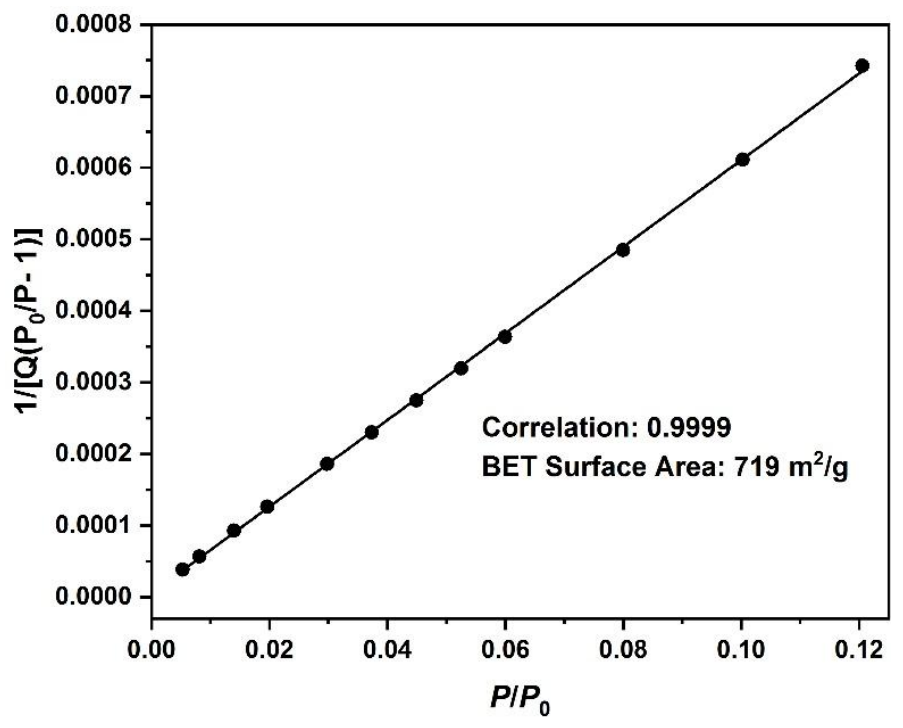

Figure S53. BET surface area plot for LZU-501 after treatment with $9 \mathrm{M} \mathrm{HCl}$ for 3 days. 


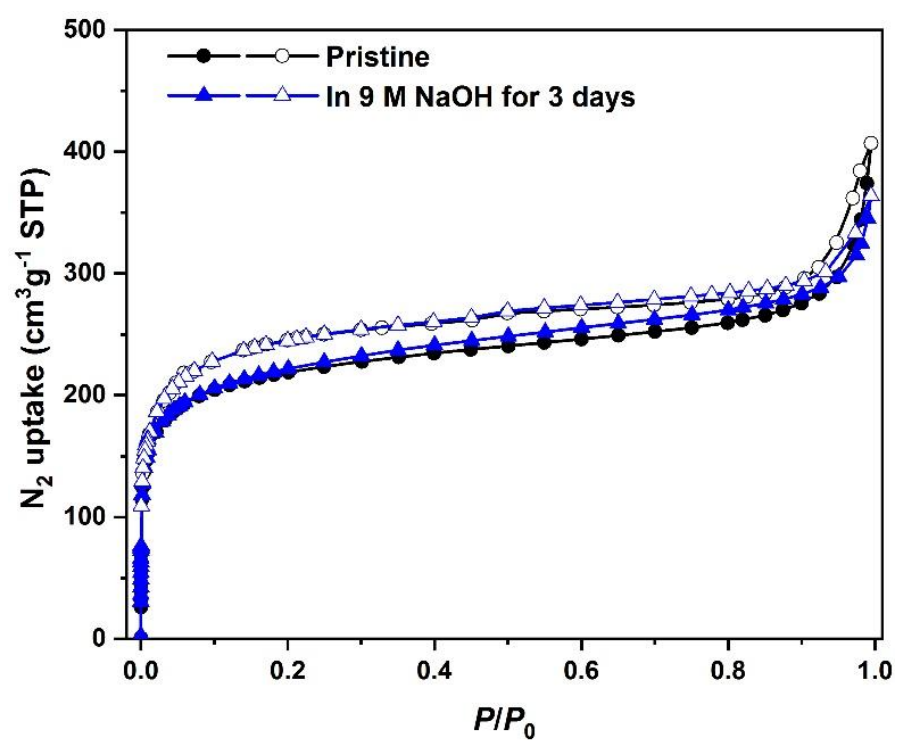

Figure S54. $\mathrm{N}_{2}$ adsorption (filled shapes) and desorption (open shapes) isotherms of LZU-501 before (black) and after treatment with $9 \mathrm{M} \mathrm{NaOH}$ for 3 days (blue).

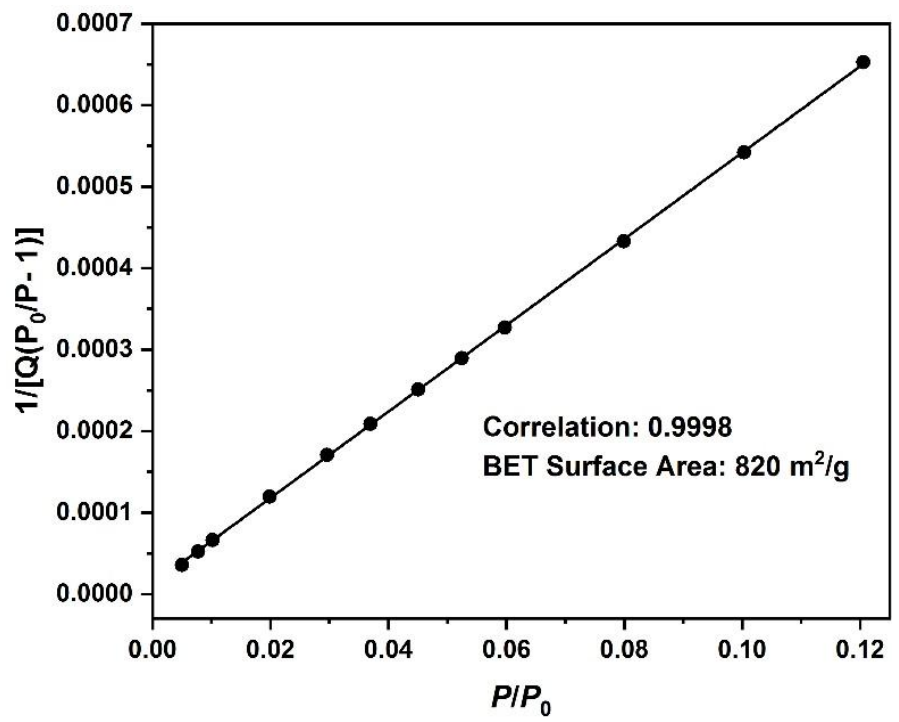

Figure S55. BET surface area plot for LZU-501 after treatment with $9 \mathrm{M} \mathrm{NaOH}$ for 3 days. 


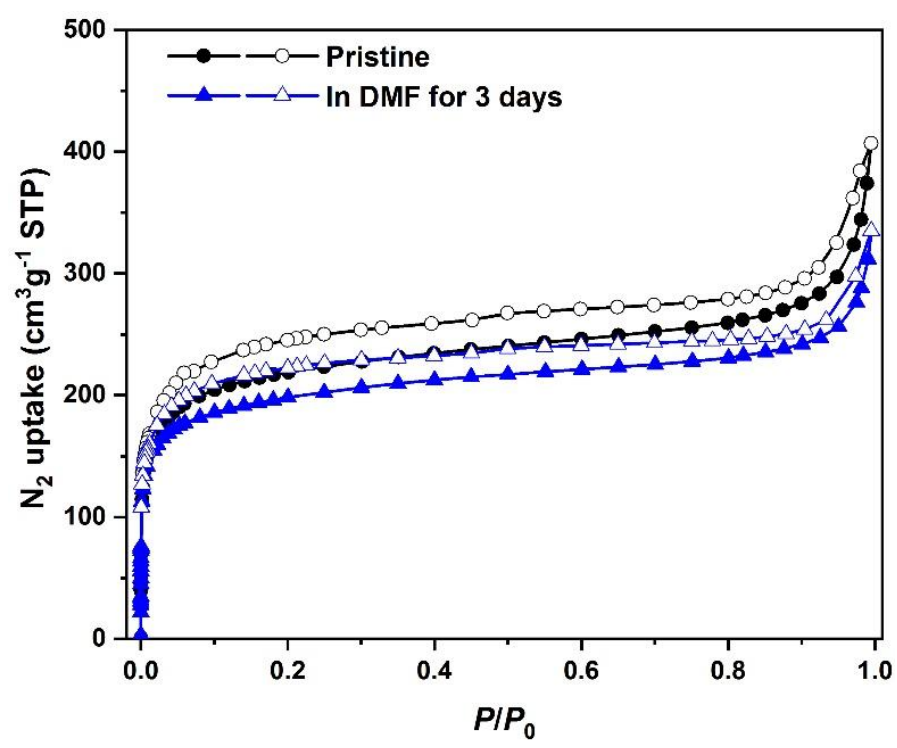

Figure S56. $\mathrm{N}_{2}$ adsorption (filled shapes) and desorption (open shapes) isotherms of LZU-501 before (black) and after treatment with DMF for 3 days (blue).

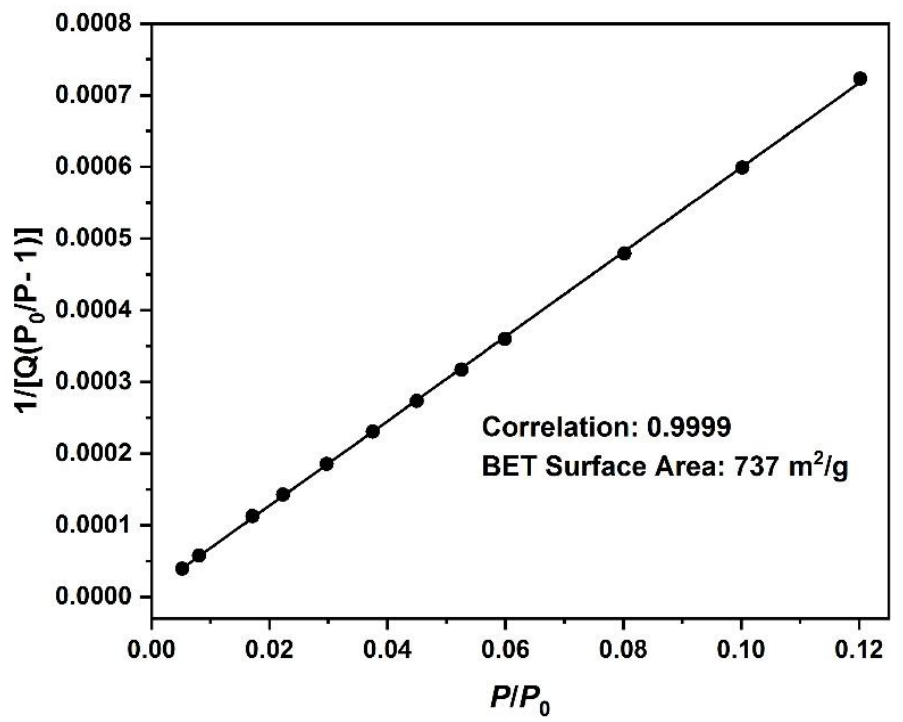

Figure S57. BET surface area plot for LZU-501 after treatment with DMF for 3 days. 


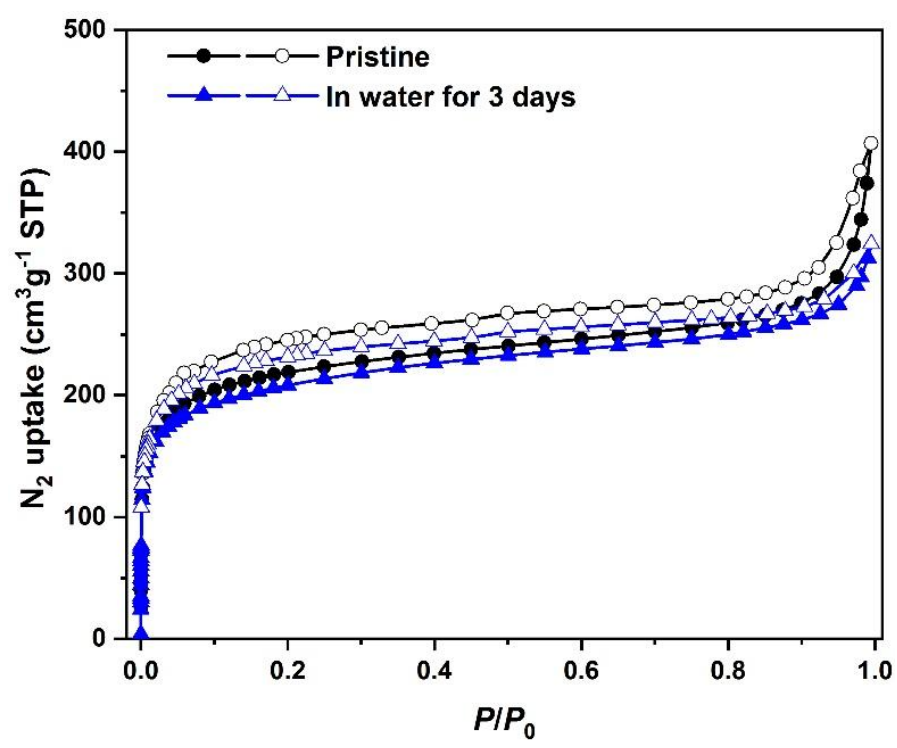

Figure S58. $\mathrm{N}_{2}$ adsorption (filled shapes) and desorption (open shapes) isotherms of LZU-501 before (black) and after treatment with water for 3 days (blue).

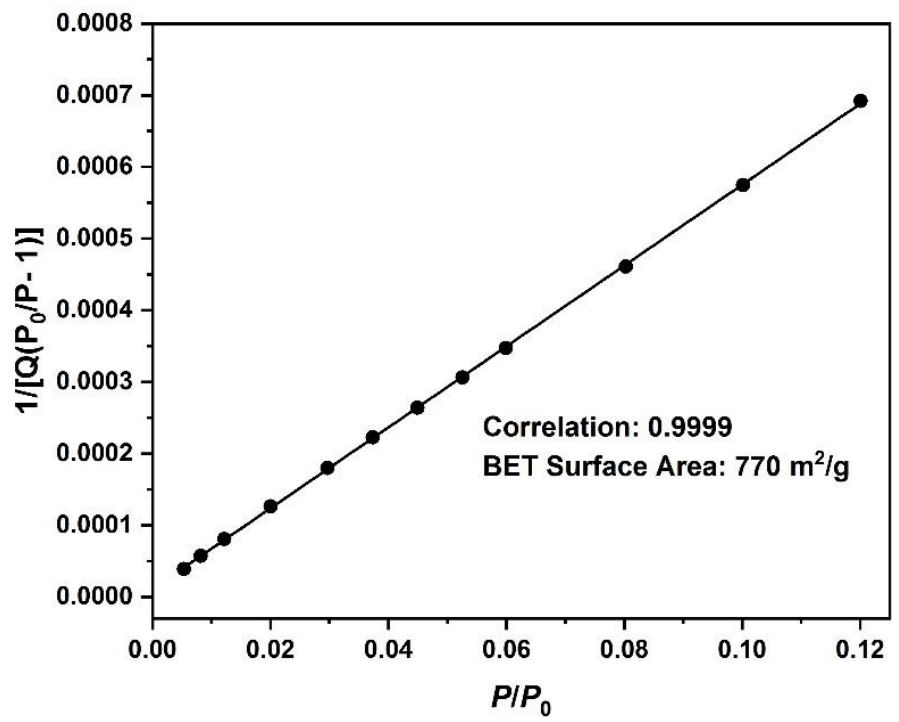

Figure S59. BET surface area plot for LZU-501 after treatment with water for 3 days. 


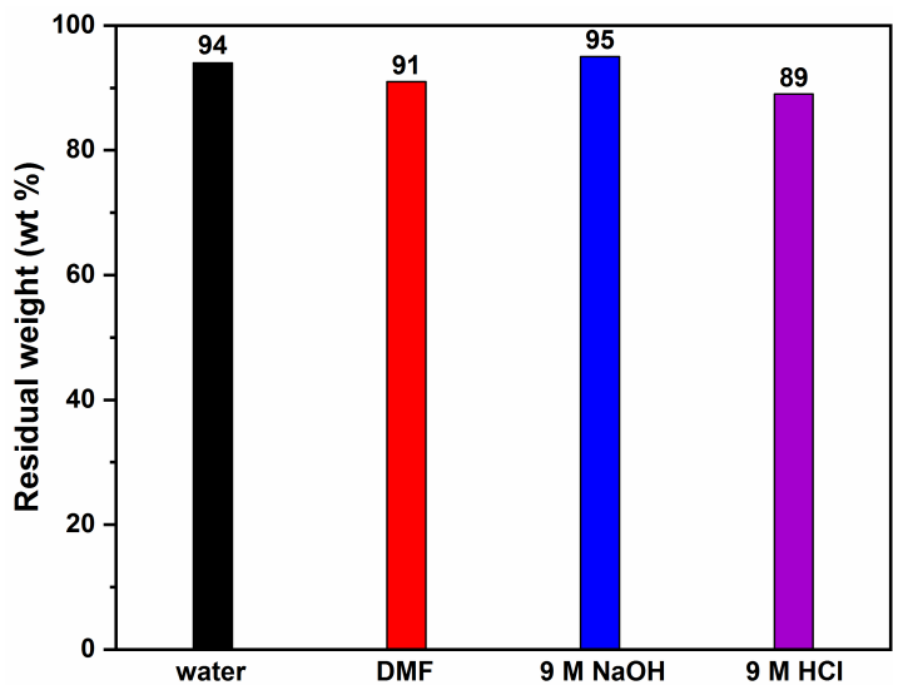

Figure S60. Residue weight percentages of LZU-506 after treatment with water, DMF, $9 \mathrm{M} \mathrm{NaOH}$, and $9 \mathrm{M} \mathrm{HCl}$. The almost unchanged weights indicate that LZU-506 is stable in these conditions. 

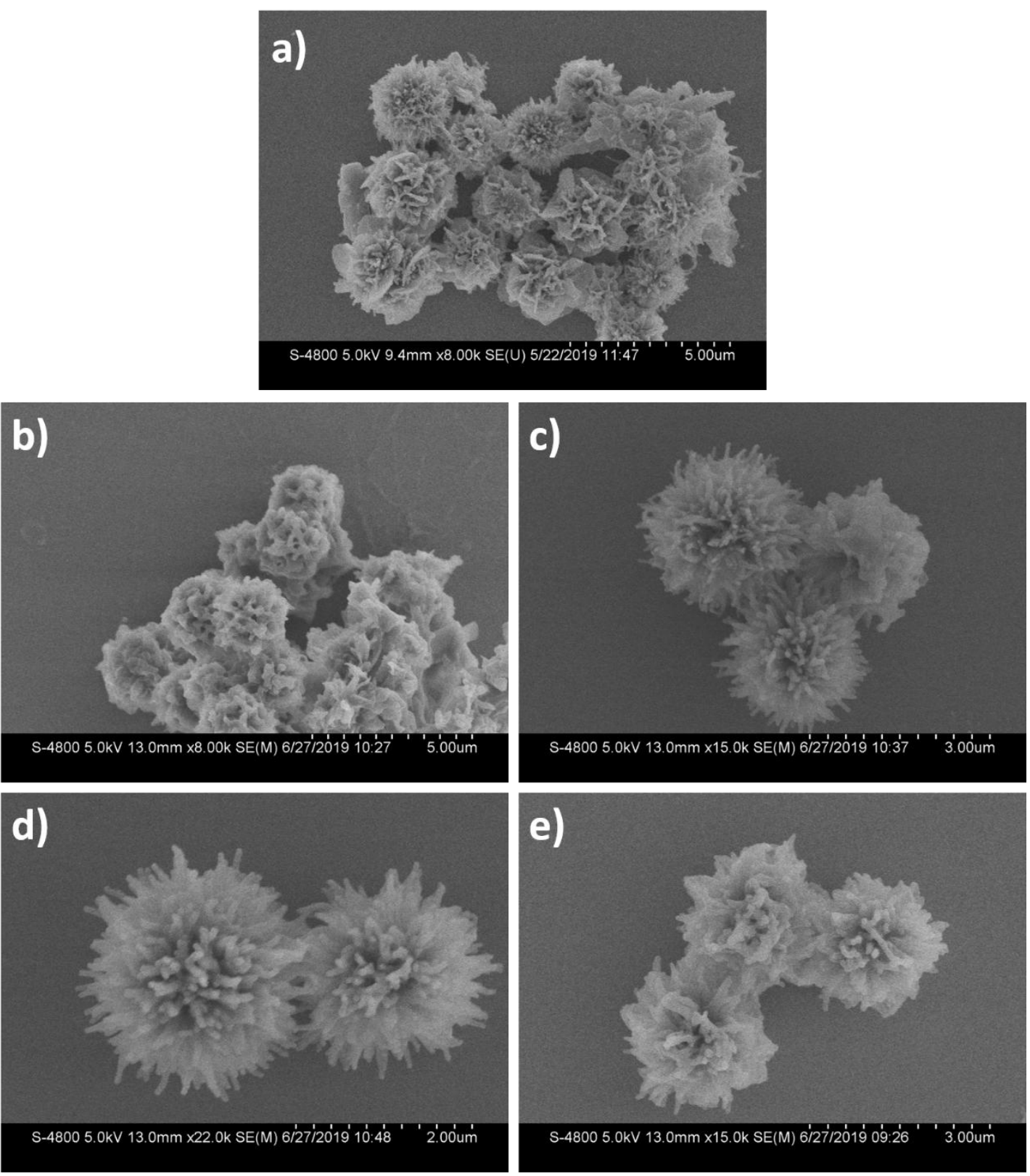

Figure S61. SEM images of LZU-506 before (a) and after treatment with $9 \mathrm{M} \mathrm{HCl}$ (b), $9 \mathrm{M} \mathrm{NaOH}$ (c), DMF (d), and water (e). 


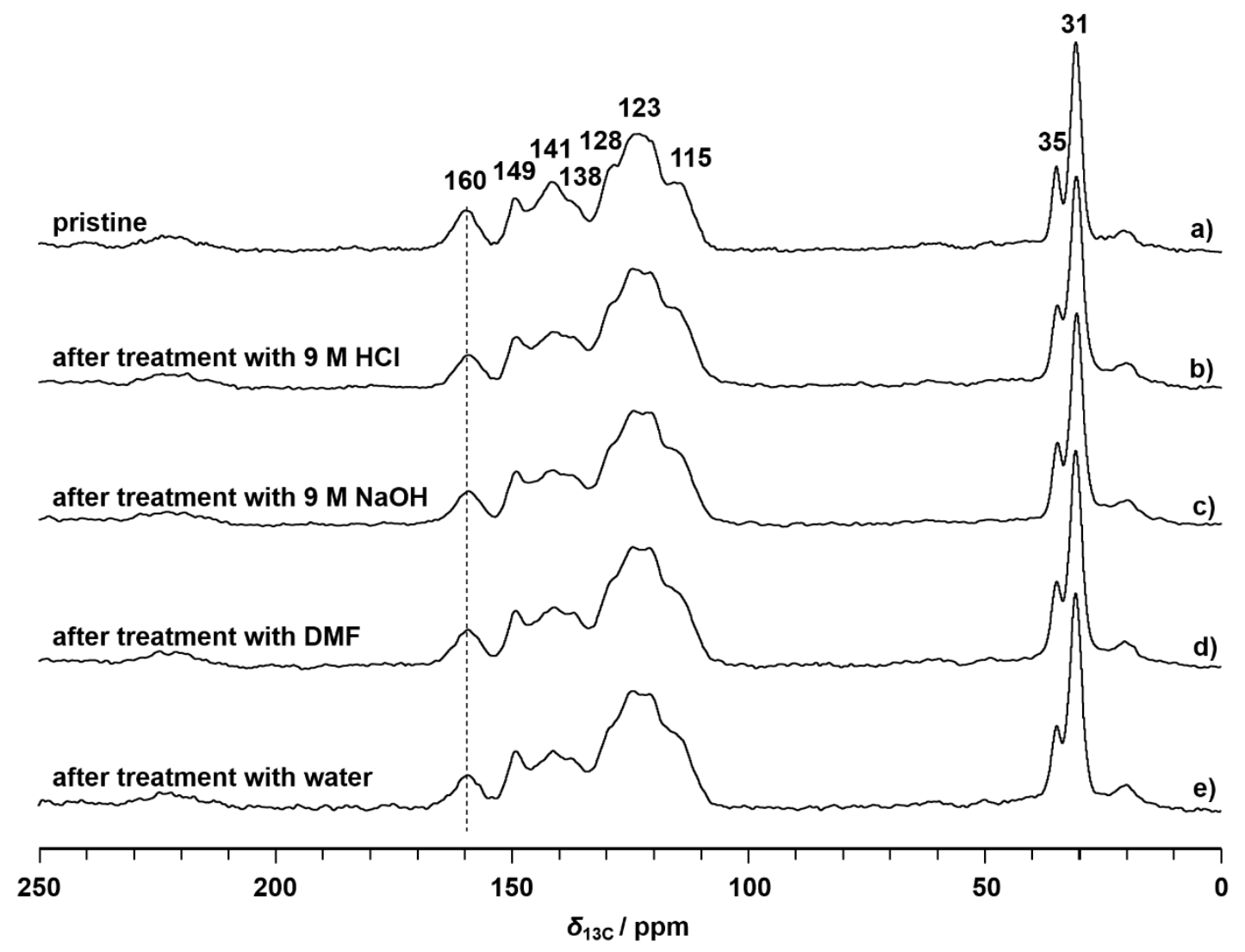

Figure S62. ${ }^{13} \mathrm{C}$ CP/MAS NMR spectra of LZU-506 before (a) and after treatment with $9 \mathrm{M} \mathrm{HCl}$ (b), $9 \mathrm{M} \mathrm{NaOH}$ (c), DMF (d), and water (e). The almost unchanged ${ }^{13} \mathrm{C}$ CP/MAS NMR spectra indicate that LZU-506 is stable in these conditions. 


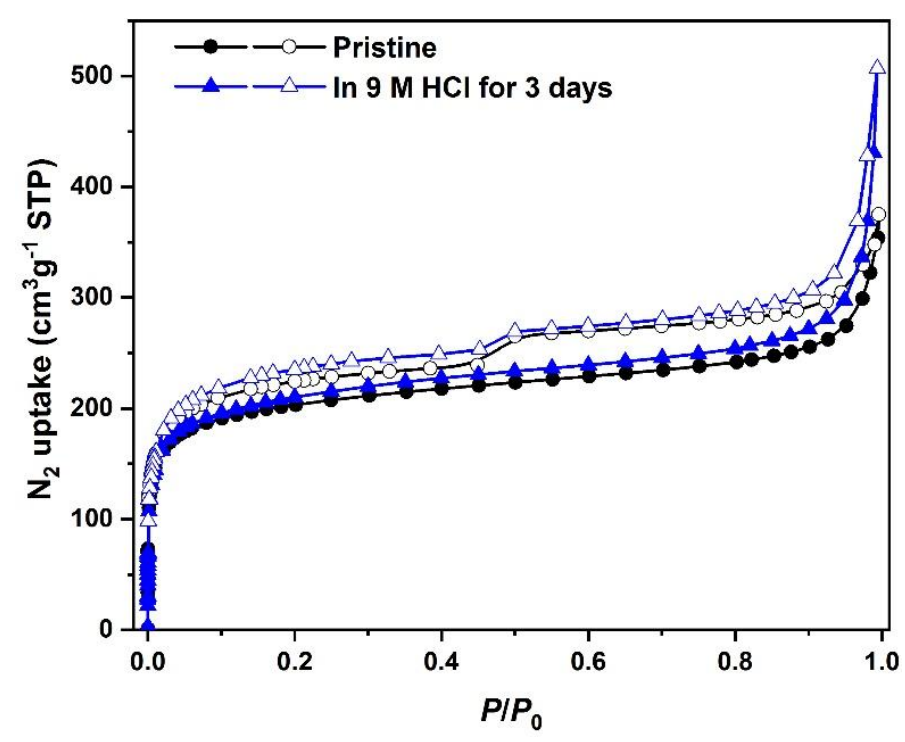

Figure S63. $\mathrm{N}_{2}$ adsorption (filled shapes) and desorption (open shapes) isotherms of LZU-506 after treatment with $9 \mathrm{M} \mathrm{HCl}$ for 3 days (blue).

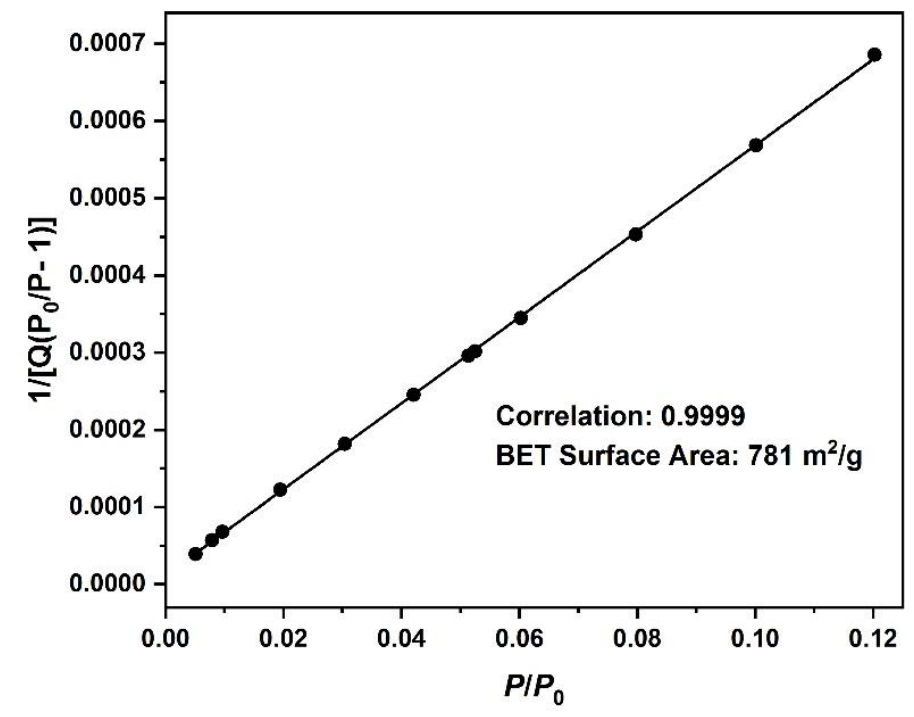

Figure S64. BET surface area plot for LZU-506 after treatment with $9 \mathrm{M} \mathrm{HCl}$ for 3 days. 


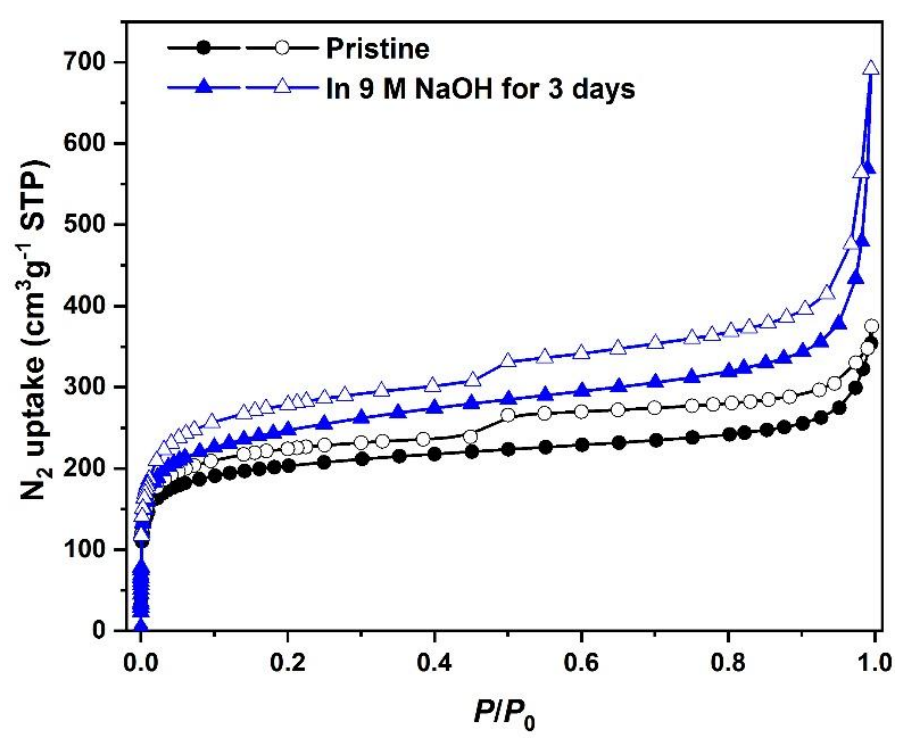

Figure S65. $\mathrm{N}_{2}$ adsorption (filled shapes) and desorption (open shapes) isotherms of LZU-506 before (black) and after treatment with $9 \mathrm{M} \mathrm{NaOH}$ for 3 days (blue).

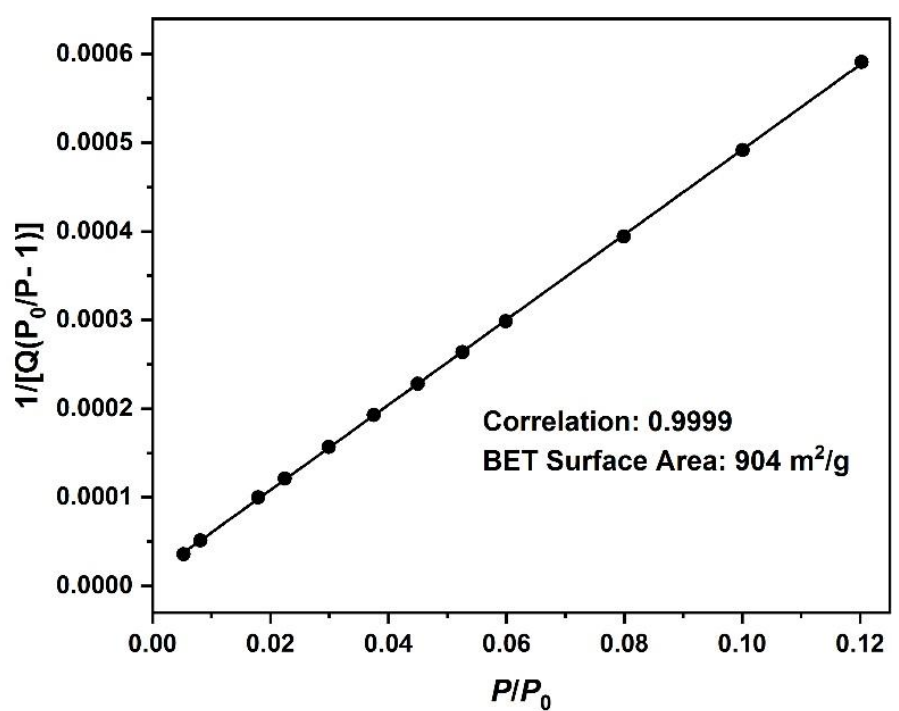

Figure S66. BET surface area plot for LZU-506 after treatment with $9 \mathrm{M} \mathrm{NaOH}$ for 3 days. 


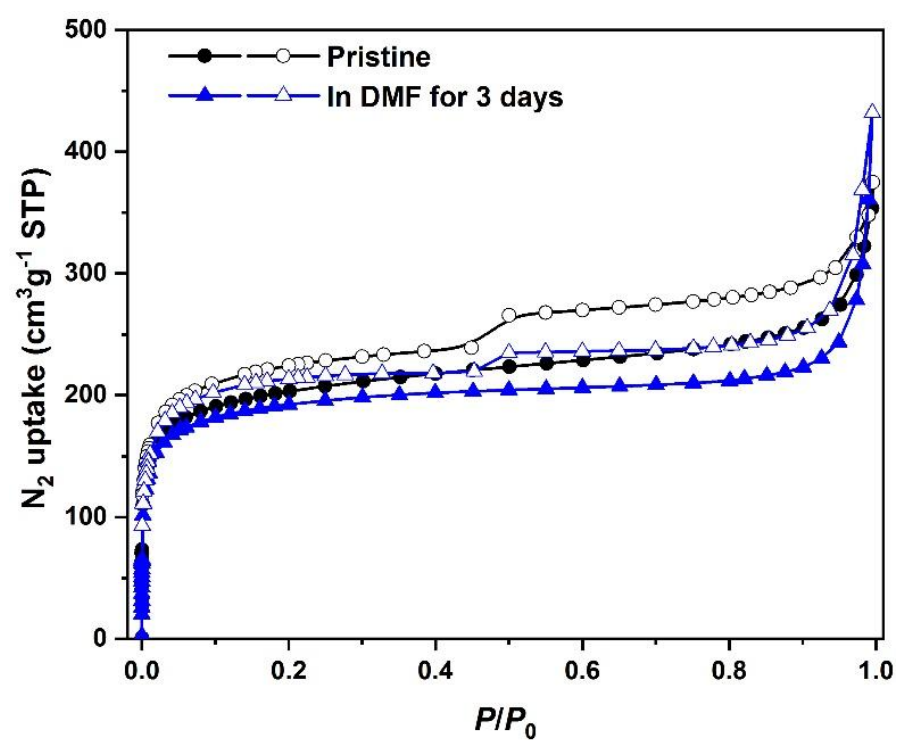

Figure S67. $\mathrm{N}_{2}$ adsorption (filled shapes) and desorption (open shapes) isotherms of LZU-506 before (black) and after treatment with DMF for 3 days (blue).

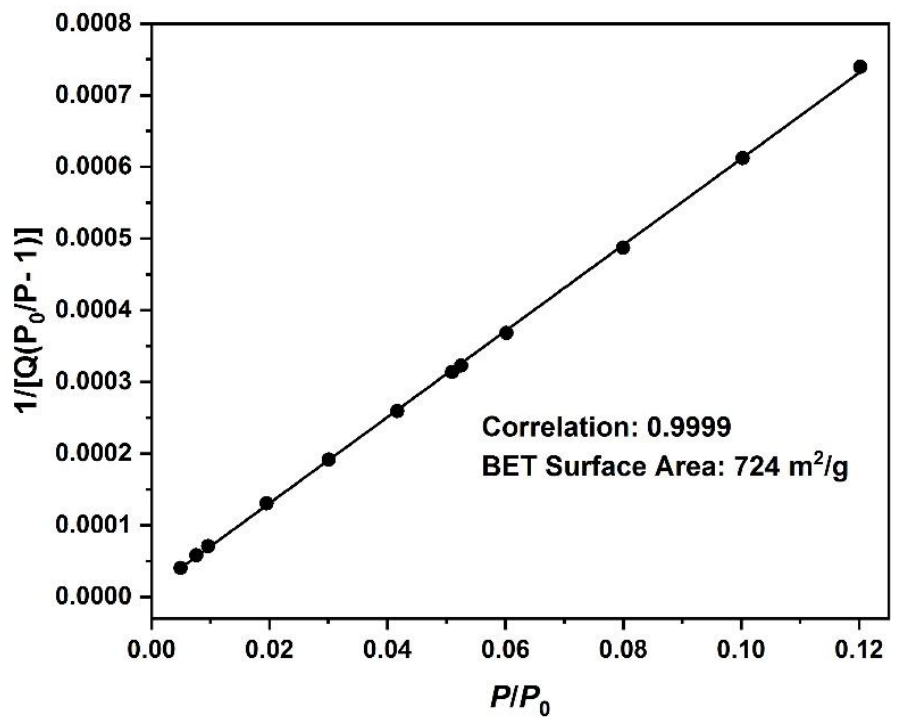

Figure S68. BET surface area plot for LZU-506 after treatment with DMF for 3 days. 


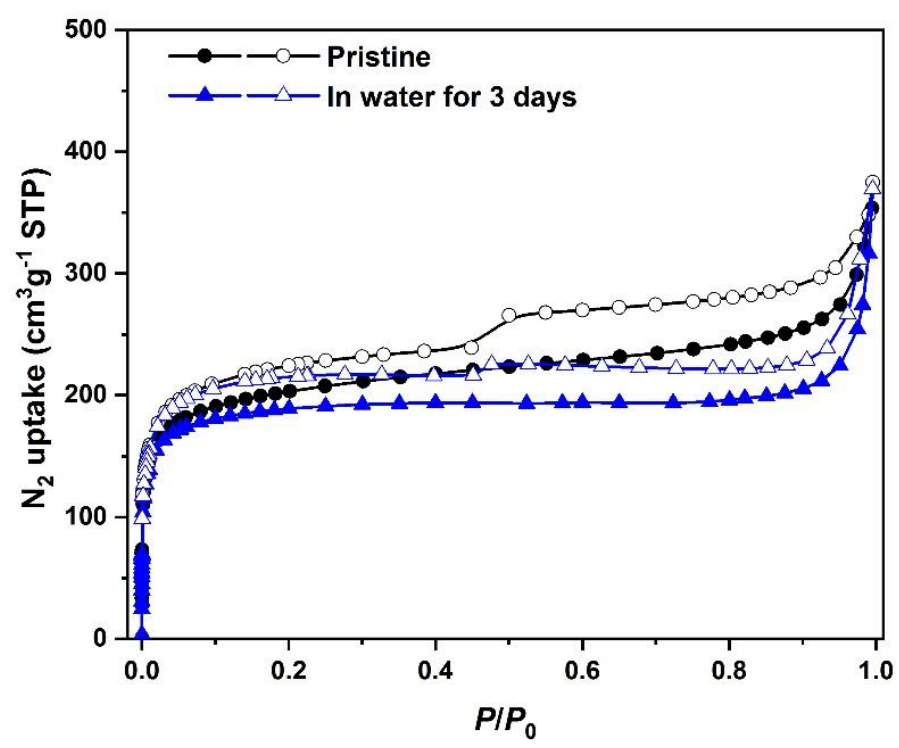

Figure S69. $\mathrm{N}_{2}$ adsorption (filled shapes) and desorption (open shapes) isotherms of LZU-506 before (black) and after treatment with water for 3 days (blue).

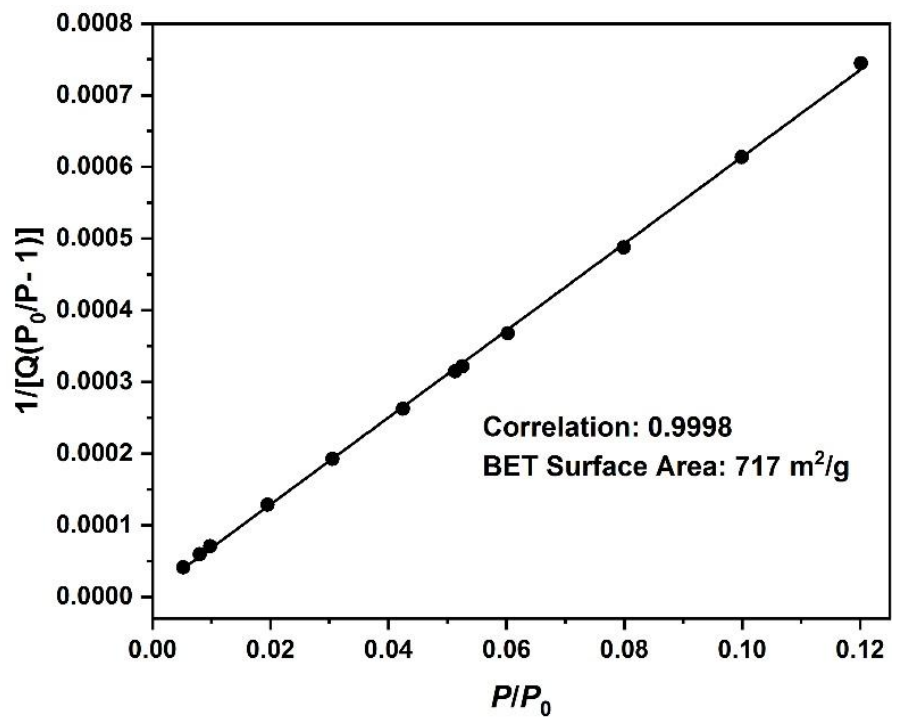

Figure S70. BET surface area plot for LZU-506 after treatment with water for 3 days. 
I. UV/Vis Absorption Spectra of LZU-501, LZU-506, LZU-508 and LZU-512

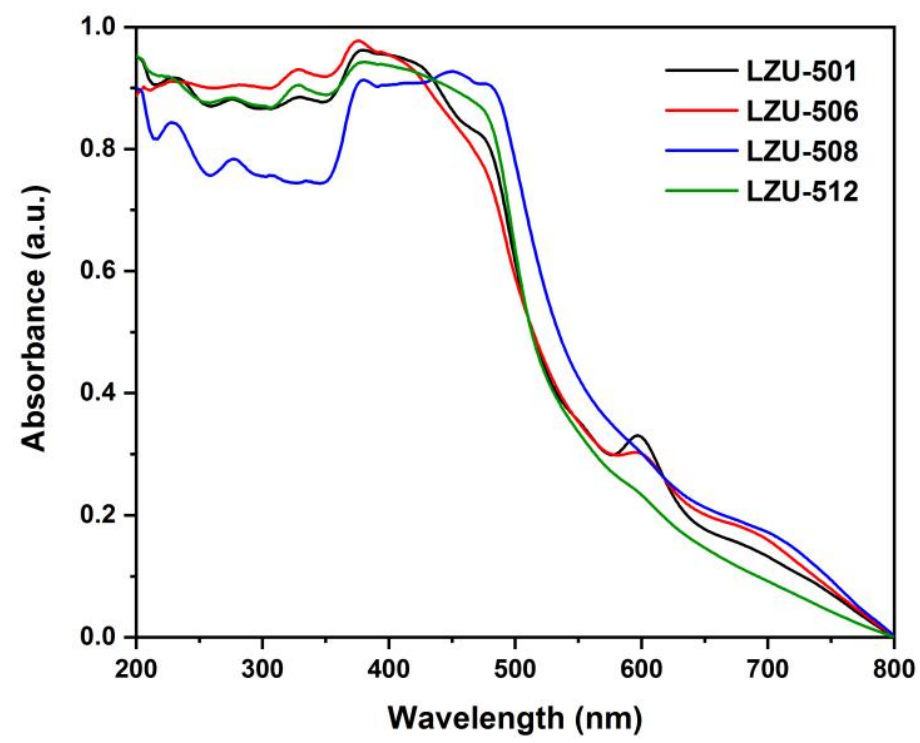

Figure S71. UV/Vis absorption spectra of LZU-501 (black), LZU-506 (red), LZU-508 (blue), and LZU-512 (green) in the solid state. The results indicate that all of them can absorb light in the UV and visible regions. 


\section{J. Postmodification}

Synthesis of the LZU-501-FGs

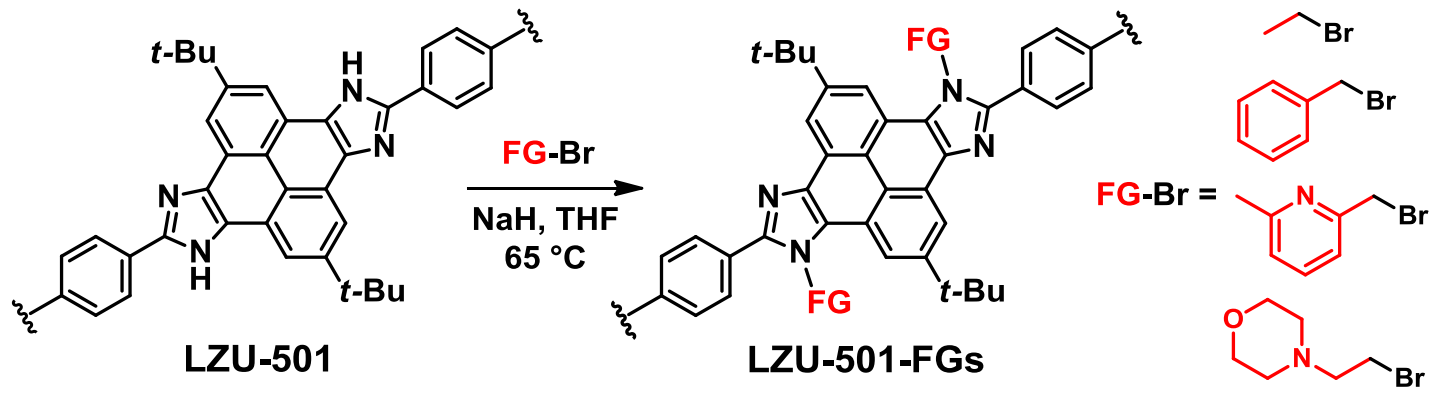

LZU-501 (30 mg, $0.10 \mathrm{mmol}$ ), $\mathrm{NaH}$ (60\% dispersion in mineral oil, $20 \mathrm{mg}, 0.50$ $\mathrm{mmol})$, and corresponding brominated reactants $(1.50 \mathrm{mmol})$ were weighed into a pressure tube (volume of $c a .15 \mathrm{~mL}$, body length of $7 \mathrm{~cm}$ ). To the mixture was added anhydrous THF $(2.0 \mathrm{~mL})$. The mixture was stirring at $65^{\circ} \mathrm{C}$ for 2 days. After cooling down to room temperature, water $(2.0 \mathrm{~mL})$ was added to the mixture. The mixture was filtered, and the residue was washed with water and THF to afford LZU-501-FGs. 


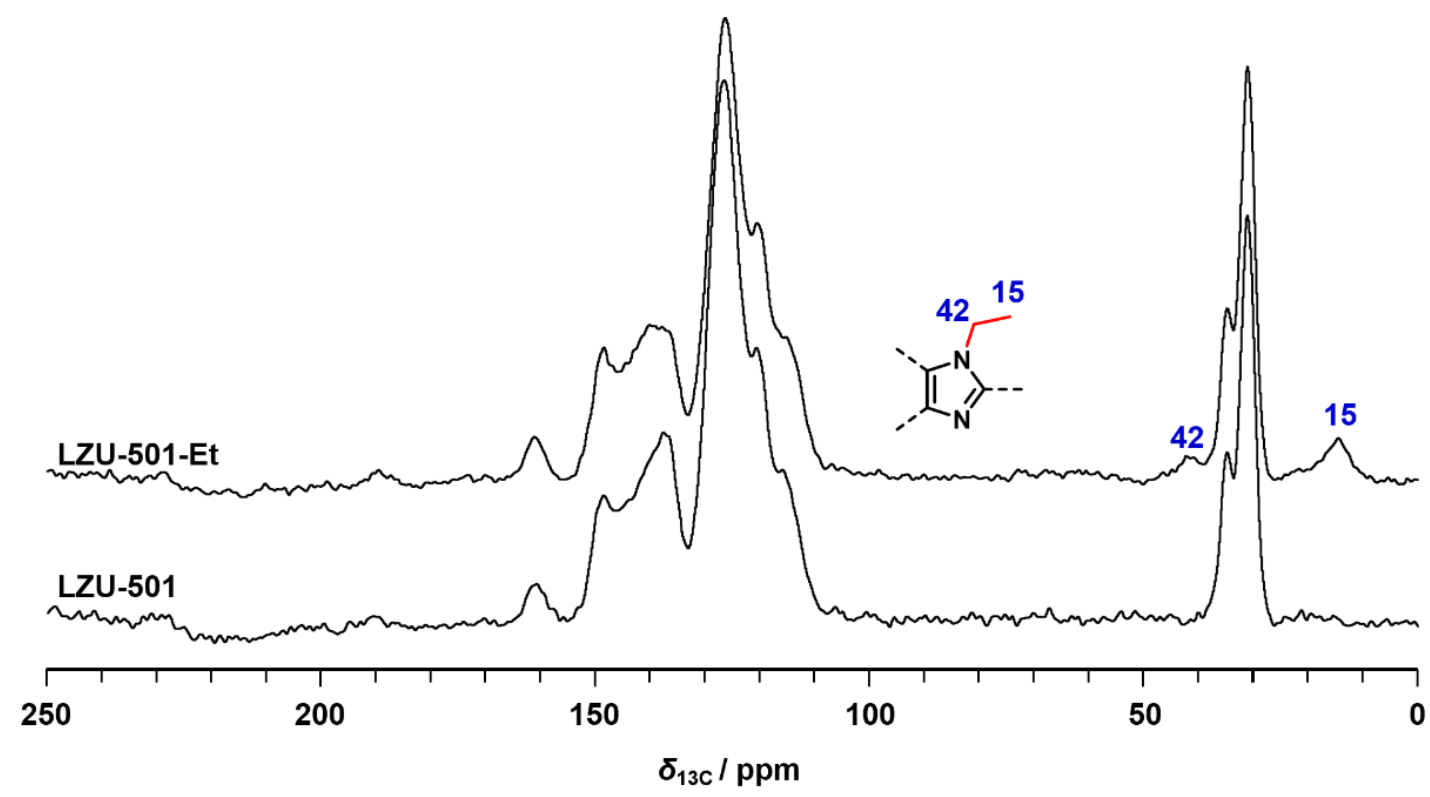

Figure S72. ${ }^{13} \mathrm{C}$ CP-TOSS MAS NMR spectra of LZU-501 and LZU-501-Et. The new peaks appearing at 42 and $15 \mathrm{ppm}$ indicate the successful formation of $N$-ethyl imidazole.

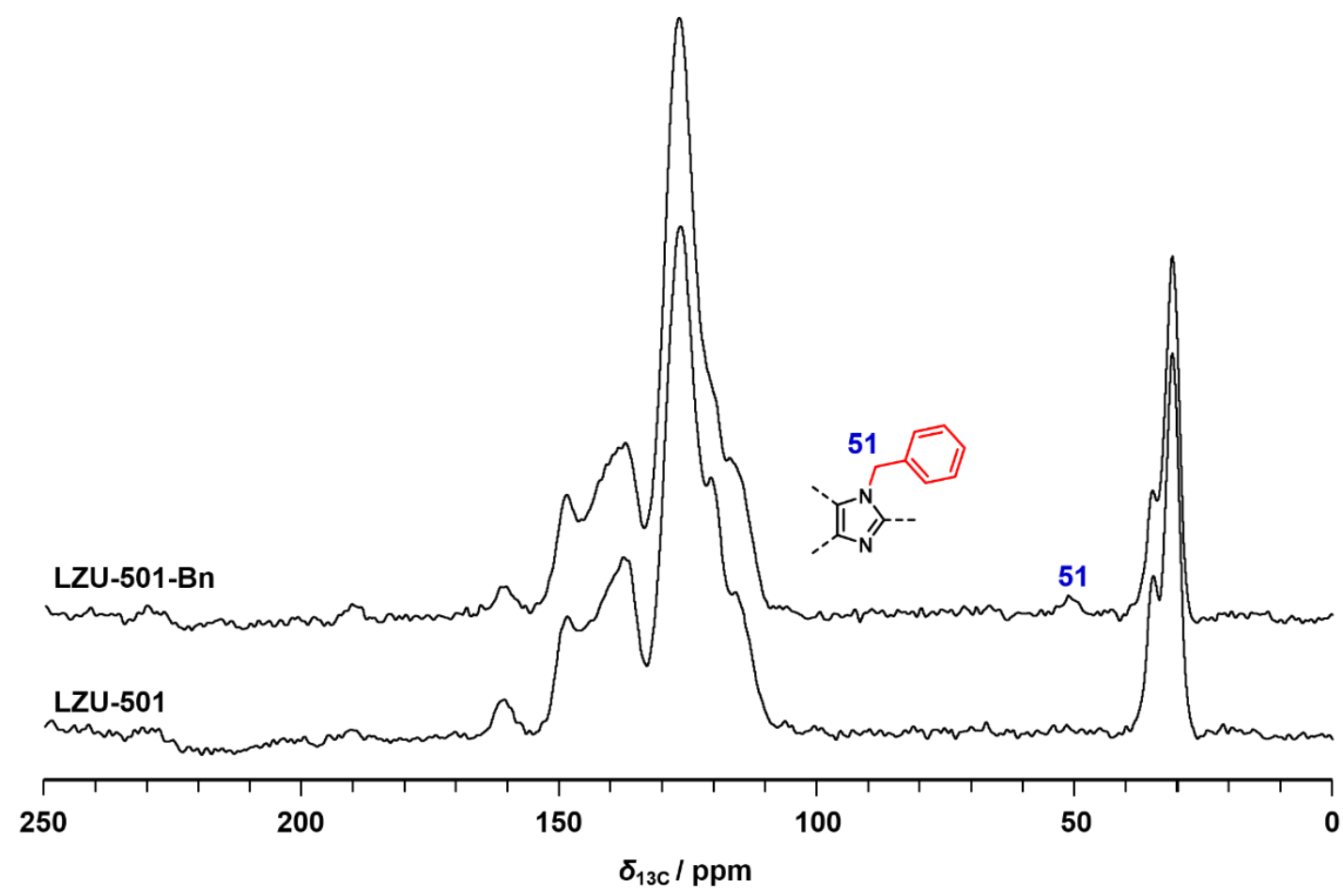

Figure S73. ${ }^{13} \mathrm{C}$ CP-TOSS MAS NMR spectra of LZU-501 and LZU-501-Bn. The new peak appearing at $51 \mathrm{ppm}$ indicates the successful formation of the $N$-benzyl imidazole. 


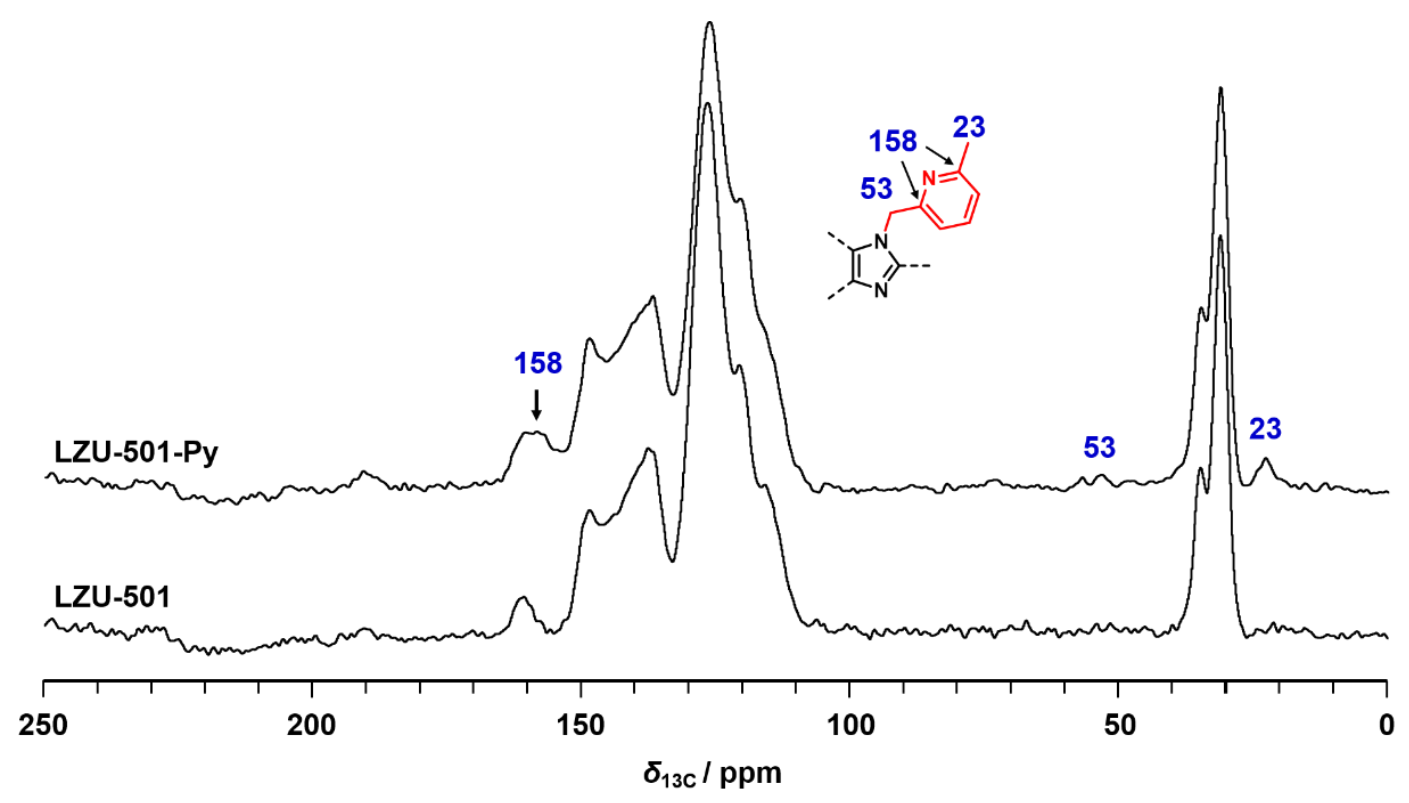

Figure S74. ${ }^{13} \mathrm{C}$ CP-TOSS MAS NMR spectra of LZU-501 and LZU-501-Py. The new peaks appearing at 158,53 , and 23 ppm indicate the successful formation of the $N$-pyridine imidazole.

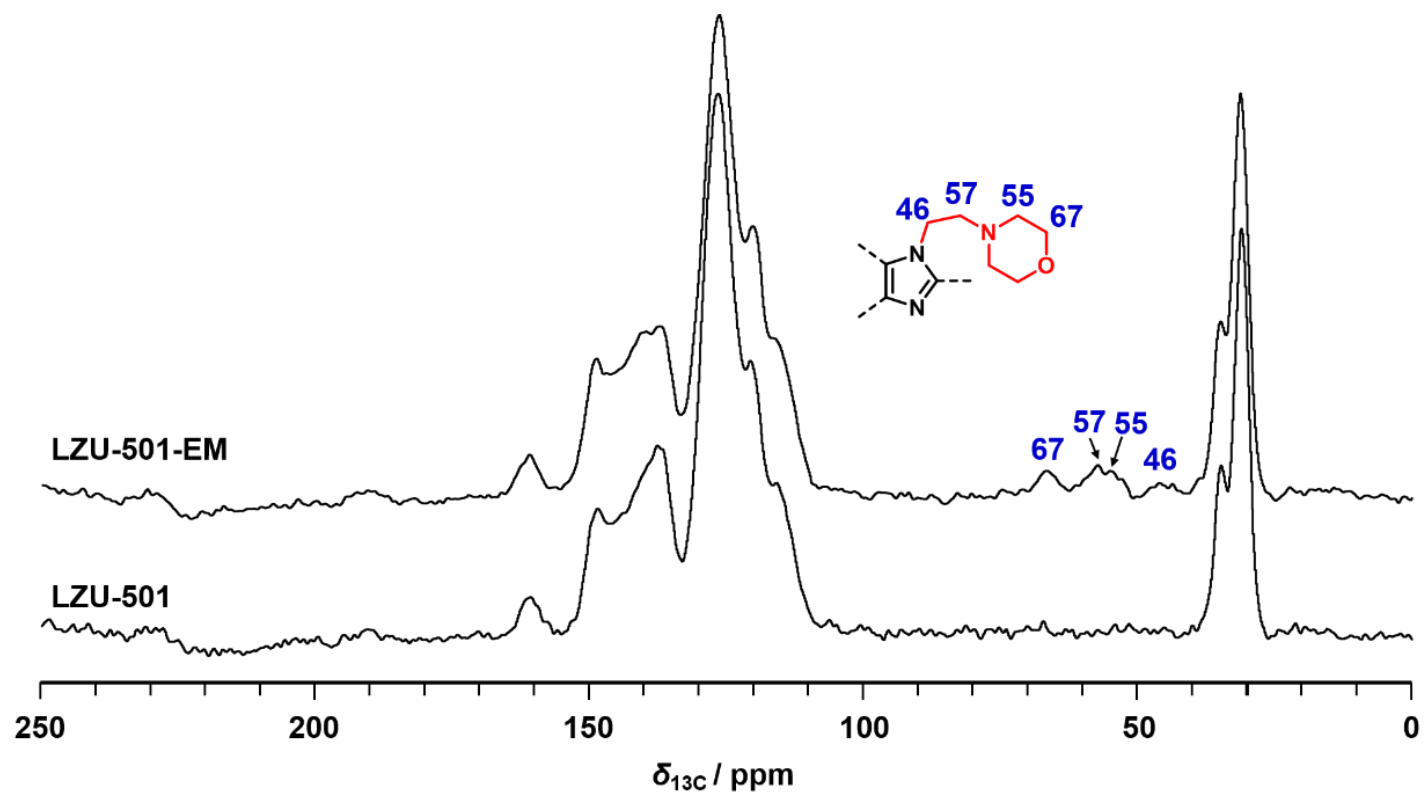

Figure S75. ${ }^{13} \mathrm{C}$ CP-TOSS MAS NMR spectra of LZU-501 and LZU-501-EM. The new peaks appearing at $67,57,55$, and $46 \mathrm{ppm}$ indicate the successful formation of the $N$-ethylmorpholine imidazole. 


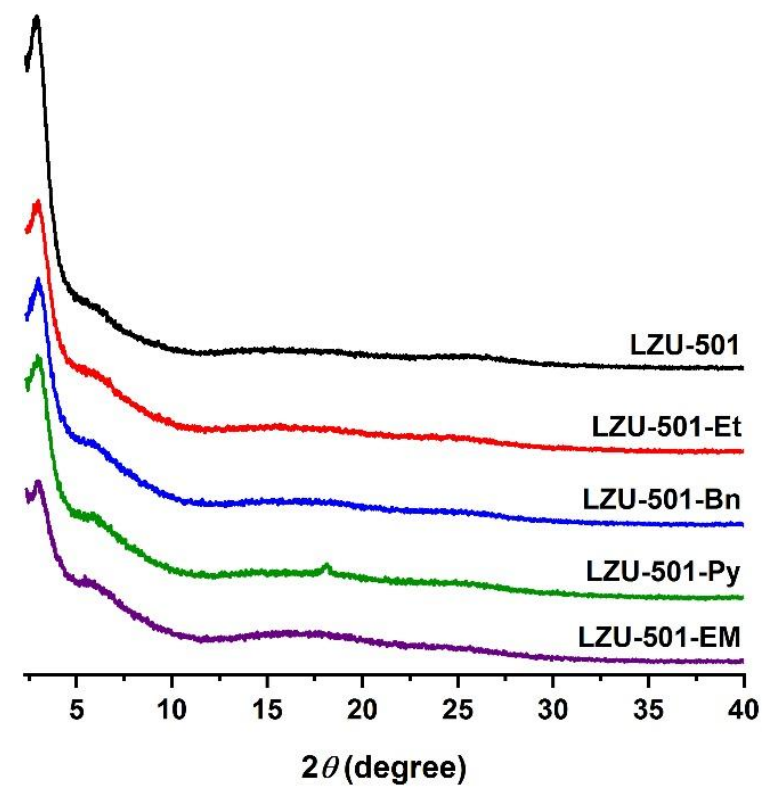

Figure S76. PXRD patterns of LZU-501 and LZU-501-FGs. The almost unchanged PXRD patterns indicate that the structure of LZU-501 was maintained after postmodification. 


\section{K. References}

1. Acke, D. R. J.; Orru, R. V. A.; Stevens, C. V. Continuous synthesis of tri- and tetrasubstituted imidazoles via a multicomponent reaction under microreactor conditions. QSAR Comb. Sci. 2006, 25, 474.

2. Thomas, O. D.; Soo, K. J.; Peckham, T. J.; Kulkarni, M. P.; Holdcroft, S. A stable hydroxide-conducting polymer. J. Am. Chem. Soc. 2012, 134, 10753.

3. Kuhn, P.; Antonietti, M.; Thomas, A. Porous, covalent triazine-based frameworks prepared by ionothermal synthesis. Angew. Chem. Int. Ed. 2008, 47, 3450.

4. Shao, P.; Li, J.; Chen, F.; Ma, L.; Li, Q.; Zhang, M.; Zhou, J.; Yin, A.; Feng, X.; Wang, B. Flexible films of covalent organic frameworks with ultralow dielectric constants under high humidity. Angew. Chem. Int. Ed. 2018, 57, 16501.

5. Materials Studio v.7.0 (Accelrys Software, San Diego, 2013). 